\title{
TOWARD THE CONSTRUCTION OF A KINETIC MODEL OF METHIONINE AND THREONINE BIOSYNTHESIS TO INCREASE SEED NUTRITIONAL VALUE: CHARACTERIZATION OF THREONINE SYNTHASE
}

\author{
By \\ Dominique Morneau, B.Sc.H \\ A thesis submitted to the Faculty of Graduate and Post-Doctoral Affairs in partial \\ fulfillment of the the requirements for the degree of \\ Doctor of Philosophy \\ in \\ Biology \\ Department of Biology \\ Ottawa-Carleton Institute of Biology \\ Carleton University \\ Ottawa, Ontario \\ March 2014 \\ (C) 2014 \\ Dominique Morneau
}




\begin{abstract}
Improving the nutritional quality of crop species, like Cicer arietinum and Lens culinaris, is of particular interest to agricultural biotechnology. These crops are deficient, from a human dietary perspective, in the essential amino acid L-methionine (L-Met). In plants, the biosynthesis of L-Met is initiated by the formation of L-cystathionine from $O$ phospho-L-homoserine (OPHS) catalyzed by cystathionine $\gamma$-synthase (CGS). OPHS occupies the branch-point between L-Met and L-threonine (L-Thr) biosynthesis, catalyzed by threonine synthase (TS), making these two enzymes targets for metabolic engineering studies to increase L-Met production. The construction of a kinetic model recreating the branch-point can facilitate the metabolic engineering of important crop species by providing a tool for anticipating disturbances in metabolic flux caused by manipulations to the branch-point. The focus of the research described in this thesis is to provide a starting point for the creation of a kinetic model of the OPHS branch-point in the target species. The characterization of plant TS requires a continuous spectrophotometric assay, which was developed using a non-allosteric variant of threonine deaminase from Escherichia coli $\left(\mathrm{eTD}_{\mathrm{L} 447 \mathrm{~F}}\right)$ and hydroxyisocaproate dehydrogenase $(\mathrm{HO}-\mathrm{HxoDH})$ from Lactobacillus delbrueckii. The assay was verified for suitability for use under the various $\mathrm{pH}$ optima of TS across phyla. The functional coding sequences of TS from $C$. arietinum (CaTS) and L. culinaris (LcTS) share approximately 80\% amino acid sequence identity with TS from Glycine max, and the residues of the allosteric site are conserved with those of TS from other plant species. The PLP-binding motif, which is conserved across plant and microbial species, is present in the active site of both enzymes. The kinetic parameters of CaTS, LcTS, and AtTS2 were measured with $100 \mu \mathrm{M}$ of the
\end{abstract}


allosteric activator $S$-adenosyl-L-methionine (SAM), with the parameters of AtTS1 measured as a control. SAM increases the $k_{c a t} / K_{m}{ }^{\text {OPHS }}$ of AtTS2, LcTS, CaTS, and AtTS1 by 10-, 20-, 25-, and 80-fold, respectively. Due to the varying flux control patterns of TS from A. thaliana, C. arietinum, and L. culinaris, the construction of a species-specific kinetic model of the branch-point is needed for future aimed at increasing L-Met biosynthesis to nutritionally significant levels. 


\section{PREFACE}

This thesis follows the integrated thesis format and so the main chapters represent work that has already been published in a peer-reviewed journal (Chapters 2 and 3 ) at the time of submission of this thesis, or will soon be submitted for publication (Chapter 4).

\section{Status of manuscripts corresponding to research Chapters at the time of thesis submission}

\section{Chapter 2:}

D.K. Morneau, E. Abouassaf, J.E. Skanes, and S.M. Aitken. Development of a continuous assay and steady-state characterization of Escherichia coli threonine synthase, Analytical Biochemistry. 423 (2012) 78-85.

\section{Chapter 3:}

D.K. Morneau, A.F. Jaworski, and S.M. Aitken. Identification of Cystathionine $\gamma-$ Synthase and Threonine Synthase from Cicer arietinum and Lens culinaris, Biochemistry and Cell Biology. 91 (2013) 95-101.

\section{Chapter 4:}

D.K. Morneau and S.M. Aitken. Measuring the steady-state kinetic parameters of Threonine Synthase from A. thaliana, C. arietinum, and L. culinaris. To be submitted to the journal Biochimica et Biophysica Acta. 


\section{Statement of contributions}

My contributions to the research described in this thesis include:

1. development of research questions and experimental design, in partnership with Dr. S.M. Aitken,

2. collection and analysis of data,

3. the co-supervision, in collaboration with Dr. S.M. Aitken, of three undergraduate students: Seghen Woldai, who participated in the creation of the silent mutation in AtTS2 removing the internal $N d e I$ site and the complementation described in Chapter 3; and Alexander Edwards and Jason Koppart, who assisted in the purification of eTD $\mathrm{L}_{447 \mathrm{~F}}, \mathrm{HO}-\mathrm{HxoDH}$, and eTS described in Chapters 2 and 4.

I formally acknowledge the contributions of the co-authors of the manuscripts that comprise the research chapters of this thesis. My supervisor, Dr. S.M. Aitken, contributed her expertise by guiding me in the formulation of the research questions and experimental design, and with the interpretation of data and the preparation of manuscripts for each of the three research chapters of my thesis. Edgar Abouassaf (Ph.D. candidate, Aitken lab, Dept. of Biology) and Jennifer E. Skanes (M.Sc. 2011) are coauthors of the published article corresponding to Chapter 2. Edgar constructed the 6Histidine tagged constructs of E. coli threonine deaminase and L. delbrueckii Ho-HxoDH and completed the affinity purification and preliminary steady-state kinetic characterization of the two enzymes. Jennifer Skanes constructed the 6-Histidine tagged construct of E. coli threonine synthase. The contributions of undergraduate students is described above. Allison F. Jaworski (Ph.D. candidate, Aitken lab, Dept. of Biology) is a co-author of the published article corresponding to Chapter 3. Allison amplified the 
coding sequences of CGS from C. arietinum, L. culinaris, and A. thaliana, completed the complementation studies for plant CGS, aided in the infiltration of GFP constructs into $N$. tabacum, and played a significant role in the writing of the manuscript.

I have obtained copyright permission from each publisher to reproduce published manuscripts and from each of my co-authors to use collaborative works in this thesis. 


\section{ACKNOWLEDGEMENTS}

I would like to extend my deepest and sincerest gratitude to Dr. Susan Aitken, first for giving me the incredible opportunity to learn from her, and for providing a rich and challenging environment throughout the last six years. You encouraged me to work harder every day, and in doing so, helped me find a confidence I did not know I had. This experience, and the person I have grown into because of it, would not have been the same without your influence and your support, so thank you. I would also like to thank my thesis committee members, Drs. Owen Rowland and John Vierula. Both Owen and John have provided valuable advice, feedback, and ideas throughout the progression of my thesis. John always had a smile when I met him in the hallways of Nesbitt, and was always interested in my progress. Owen provided me with new ideas frequently, and gave me great opportunities through his professional contacts.

The boisterous environment of the Aitken lab has been an amazing place to complete my research. Duale Ahmed, Victoria Samaki, Emily Hopwood, Nikita Rayne, Justin Kicks, Jennifer Skanes, Colleen Woodhouse, Pratik Lodha, and Sorin Gustin were wonderful colleagues, and made each day a joy. Your advice on presentations, posters, research, and manuscripts was invaluable, and helped me grow both as a graduate student and as a scientist. Duale, thank you for being my companion on early mornings and weekends, for listening to me and giving me wise-beyond-your-years life advice, for laughing with/at me, and for your friendship. Undergraduate students of the Aitken lab, both past and present (Navya Kalidindi, Heidi Los, Ali Masoud, Lubna El-Sarji, Seghen Woldai, Rogeh Habashi, Winsfield Ling, Alexander Edwards, Jason Koppart, Amanda Foster, Nick Humphreys, Adrienne Manders, Sherwin Habibi, and Katrina Farrell) were 
always willing to provide me with assistance in my work and helped create a wonderfully dynamic learning experience. I would also like to extend a huge thank you to Denise Chabot and Keith Hubbard from Agriculture and Agri-Food Canada, who manned the confocal microscope which enabled me to complete my localization studies. And finally, a big thanks to the administrative staff who keep the Department of Biology running. Lisa Chiarelli, for helping with my paperwork and endless questions about submission and scholarship application deadlines, and Laura Thomas and Michelle O'Farrell, for always being available for a mid-afternoon chat break.

Over the last six years, I have befriended some wonderful people, in the Department of Biology, the Institute of Health, and outside of Carleton. Thank you to Emilie Milroy, Jordan Miller, and Chris White for your friendship while I was completing my graduate diploma in the Institute of Health, and also to Siri Chunduri and Chandni Sondagar for being my CPHA cheering squad. And of course my sincerest gratitude to my lovely friends Eileen Conboy and Kim Bisson (and recently Eleanor Bisson) for their gracious, calming influence on my life.

I have had the unimaginable fortune of having the five very best friends that anyone could ever ask for in Valerie Hamelin, Chris Bisson, Sarah Edwards, Allison Jaworski, and Edgar Abouassaf. Over the years, each of you has contributed to this thesis in ways you may not be aware of. Valerie and Chris, you have been like family to me for 16-19 years, and I am so grateful to always have you to turn to when life gets overwhelming. Sarah, your friendship throughout our undergrad and grad degrees has been amazing. I love you and miss you so much more than I can say. Ally, you are a warrior-poet. If you had not been a part of this experience I would have left and gone to 
live under a bridge ages ago. Your friendship means the world to me. Eddy, we had a rough start, but I'm glad we stuck with it. You've been a wonderful friend to me, thank you. I have had the most amazing time laughing, crying, and sharing with each of you, and your unwavering support throughout this process has been unbelievable. I don't think I could have made it here without each and every one of you.

And finally, none of this would have been possible without the unconditional love and support of my family. I love you guys with all of my heart. Ann, you are the best sister anyone could have (I mean that). You've been my friend, roommate, advocate, and therapist over the years, thank you for your love and for always having my back. Mom and dad, everything that I am and will ever be, I owe to your love, your confidence in me, and the sacrifices you have made in your dedication to seeing me succeed. I will never find the words to express to you how grateful I am for you in my life and the amazing opportunites that being your child has awarded me. Si vous n'étiez pas mes parents, je vous aurais voulu. 


\section{DEDICATION}

For my parents, Michel and Nicole Morneau. I owe you everything. 


\section{TABLE OF CONTENTS}
ABSTRACT ............................................................................................................ ii

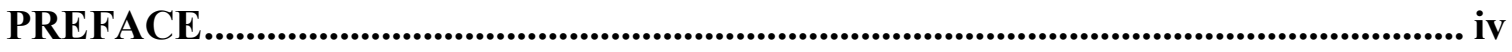
ACKNOWLEDGEMENTS .................................................................................... vii
DEDICATION..........................................................................................................
TABLE OF CONTENTS ......................................................................................... xi

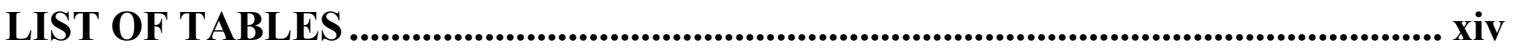

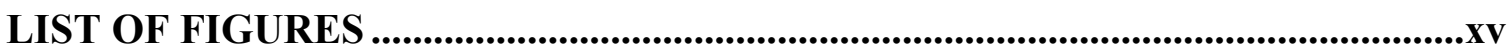
ABBREVIATIONS ........................................................................................................ xvii

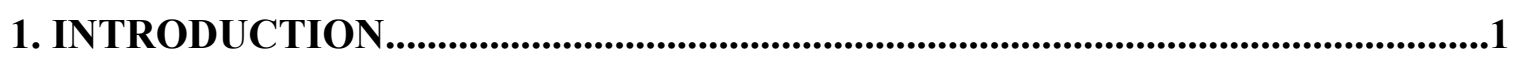

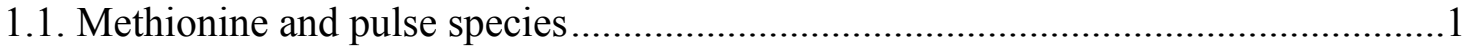

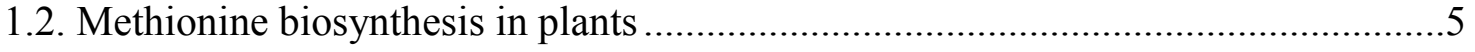

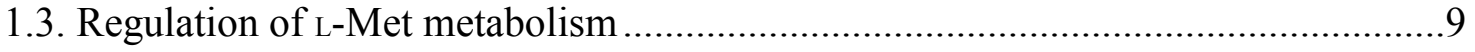

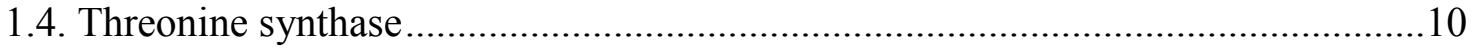

1.4.1. Allosteric regulation of TS....................................................................12

1.5. Threonine synthase as a target for increasing L-Met biosynthesis ..........................17

1.6. Rational metabolic engineering through kinetic modelling ....................................19

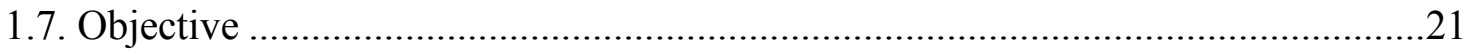

2. Development of a continuous assay and steady-state characterization of Escherichia coli threonine synthase ...............................................................................23

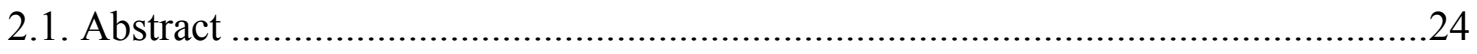

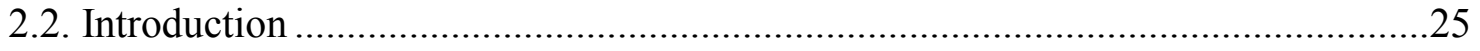

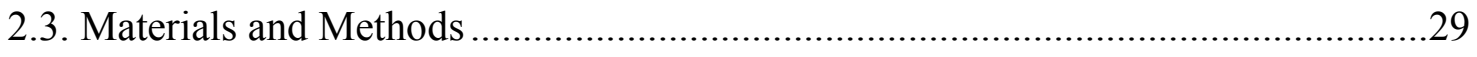

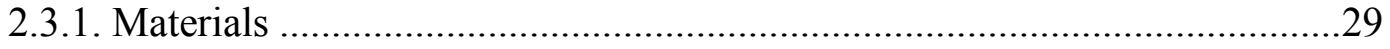

2.3.2. Construction of expression constructs and purification of eHSK, eTS, eTD, and HO-HxoDH ............................................................................. 30

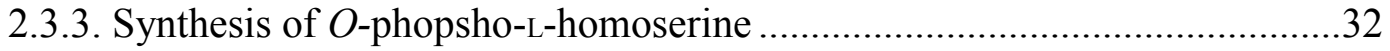

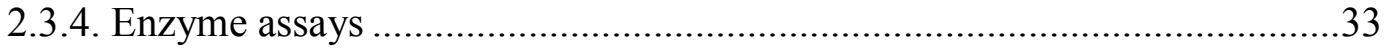

2.3.5. Evaluation of the $\mathrm{pH}$ dependence of $\mathrm{HO}-\mathrm{HxoDH}, \mathrm{eTD}_{\mathrm{L} 447 \mathrm{~F}}$, and eTS........35

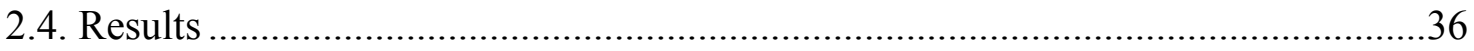

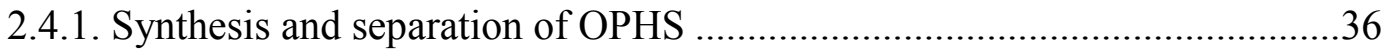




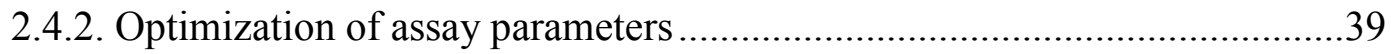

2.4.3. The $\mathrm{pH}$ dependence of eTS, eTD $\mathrm{L}_{\mathrm{L} 47 \mathrm{~F}}$, and HO-HxoDH .............................46

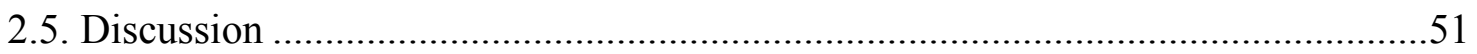

3. Identification of Cystathionine $\gamma$-Synthase and Threonine Synthase from Cicer arietinum and Lens culinaris ................................................................................60

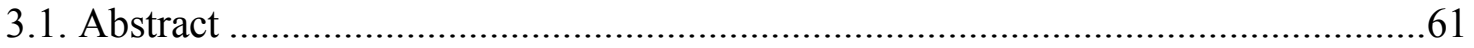

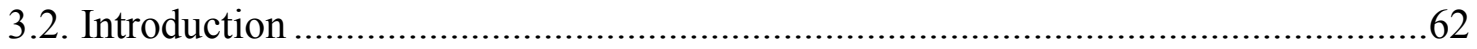

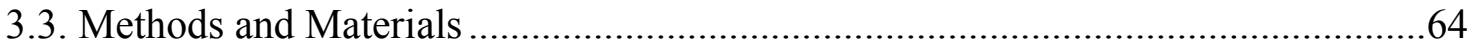

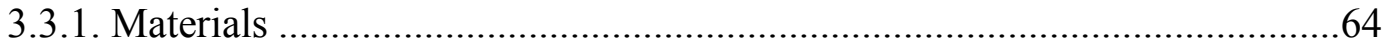

3.3.2. Amplification of CGS and TS coding sequences ......................................64

3.3.3. Complementation of L-Met and L-Thr auxotrophic E. coli strains .............65

3.3.4. Binary plasmid construction and intracellular localization .........................67

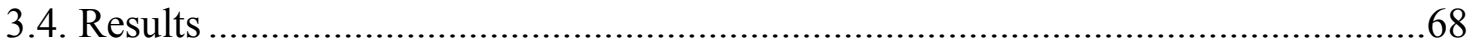

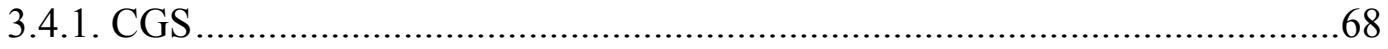

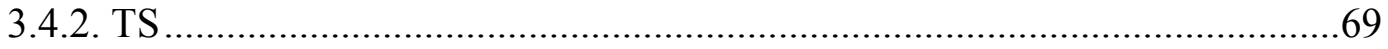

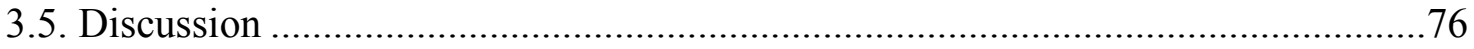

4. Measuring the steady-state kinetic parameters of Threonine Synthase from $A$. thaliana, $C$. arietinum, and $L$. culinaris .....................................................................81

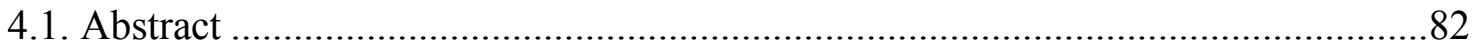

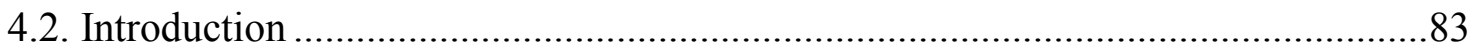

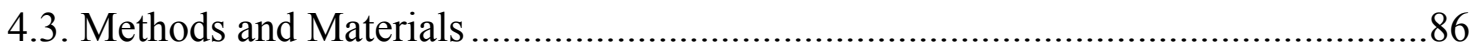

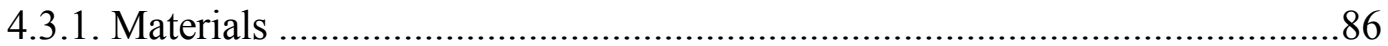

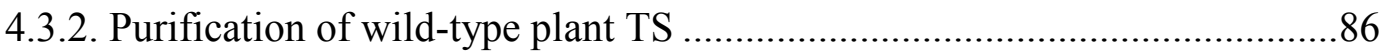

4.3.3. Construction of expression construct and purification of affinity tagged

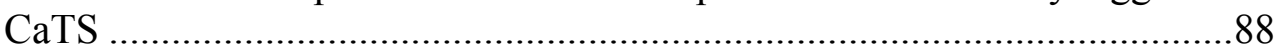

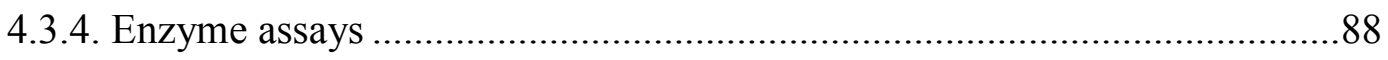

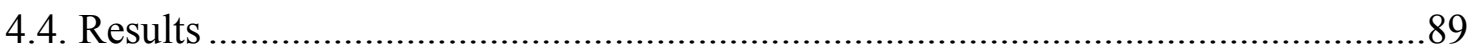

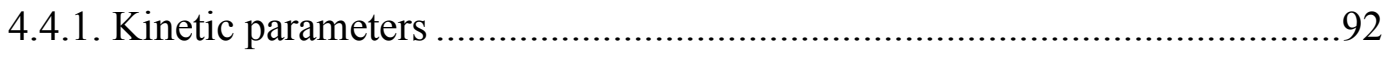

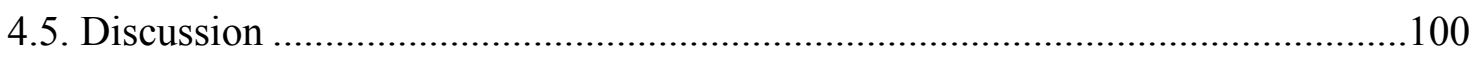

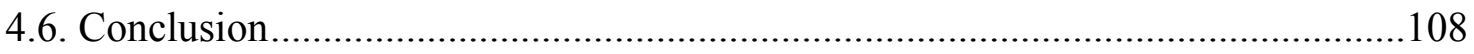

5. GENERAL CONCLUSIONS .....................................................................................110

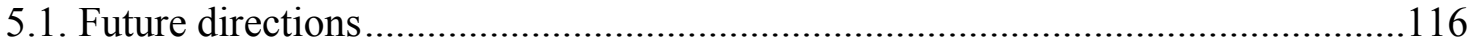




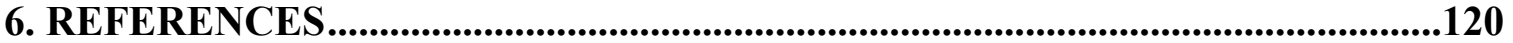




\section{LIST OF TABLES}

Table 2.1. Primers employed for the eHSK, eTS, eTD, eTD ${ }_{L 447 F}$, and HO-HxoDH expression constructs

Table 2.2. Kinetic parameters of E. coli threonine synthase (eTS), homoserine kinase (eHSK), threonine deaminase (eTD) and the site-directed variant $\mathrm{eTD}_{\mathrm{L} 447 \mathrm{~F}}$, and L. delbrueckii hydroxyisocaproate dehydrogenase (HO-

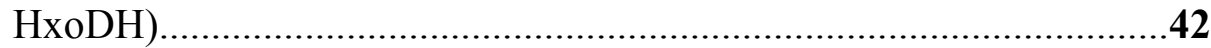

Table 3.1. Primers used to amplify full-length and mature CGS and TS..............66

Table 3.2. Complementation of L-Met and L-Thr auxotrophic E. coli strains by full-length and mature CGS and TS, respectively, from A. thaliana, $C$. arietinum, L. culinaris, and E. coli.

Table 4.1. Kinetic parameters of wild-type TS from A. thaliana, C. arietinum and L. culinaris and C-terminally 6-Histidine tagged TS from C. arietinum (CaTS-His), in the presence and absence of $100 \mu \mathrm{M}$ SAM 


\section{LIST OF FIGURES}

Figure 1.1. The transsulfuration pathway of plants and microorganisms and the reverse transsulfuration pathway of mammals.........................................3

Figure 1.2. The biosynthesis of L-Met and L-Thr from L-Asp in plants.....................6

Figure 1.3. Crystal structure of A. thaliana TS1 in complex with PLP and

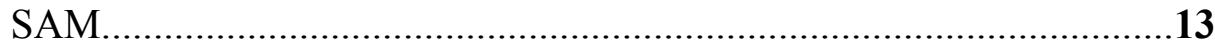

Figure 1.4. Cartoon and surface representations of allosteric and active sites of AtTS1 upon SAM-binding.

Figure 2.1. The continuous, coupled-coupled enzyme assay developed for TS.......27

Figure 2.2. SDS-PAGE of the purified recombinant enzymes...................................37

Figure 2.3. Verification of OPHS production by eHSK by thin-layer chromatography.

Figure 2.4. Dependence of the rate of NADH oxidation on eTS, eTD ${ }_{\mathrm{L} 447 \mathrm{~F}}$, and HO$\mathrm{HxoDH}$ concentration in the coupled $\mathrm{eTD}_{\mathrm{L} 447 \mathrm{~F}} / \mathrm{HO}-\mathrm{HxoDH}$ assay .44

Figure 2.5. The $\mathrm{pH}$ dependencies of $k_{\text {cat }} / K_{m}$ of $L$. delbrueckii $\mathrm{HO}-\mathrm{HxoDH}$ and $E$. coli $\mathrm{TD}_{\mathrm{L} 447 \mathrm{~F}}$. 47

Figure 2.6. The $\mathrm{pH}$ dependence of $k_{\text {cat }} / K_{m}{ }^{O P H S}$ of eTS .........................................49

Figure 2.7. The proposed mechanism of the $\beta, \gamma$-replacement reaction catalyzed by threonine synthase.

52

Figure 3.1. Figure 3.1. Amino acid sequence alignment of AtTS1, AtTS2, CaTS, LcTS, and GmTS

Figure 3.2. Expression of fluorescent fusion proteins in epidermal cells of Nicotiana tabacum. 75

Figure 4.1. $\quad$ SDS-PAGE analysis of purified plant TS.............................................91

Figure 4.2. Michaelis-Menten plot of the reaction catalyzed by AtTS1 in the presence and absence of $100 \mu \mathrm{M}$ SAM.

Figure 4.3. Michaelis-Menten plot of the reaction catalyzed by CaTS, LcTS, and AtTS2 in the presence and absence of $100 \mu \mathrm{M}$ SAM. 
Figure 4.4. Michaelis-Menten plot of the reaction catalyzed by CaTS and CaTS-His in the presence or absence of $100 \mu \mathrm{M}$ SAM....................................99

Figure 4.5. Expression patterns of AtTS1 and AtTS2 in various tissues...............106 


\section{ABBREVIATIONS}

$\alpha-\mathbf{K B} \quad \alpha$-ketobutyrate

ADP Adenosine diphosphate

AK Aspartate kinase

ASDH Aspartate semialdehyde dehydrogenase

A. thaliana Arabidopsis thaliana

AtCGS Arabidopsis thaliana cystathionine $\gamma$-synthase

ATP Adenosine triphosphate

AtTS1 Arabidopsis thaliana threonine synthase homologue 1

AtTS2 Arabidopsis thaliana threonine synthase homologue 2

A. tumefaciens Agrobacterium tumefaciens

C. arietinum Cicer arietinum

CaCGS Cicer arietinum cystathionine $\gamma$-synthase

CaMV Cauliflower mosaic virus

CaTS Cicer arietinum threonine synthase

CaTS-His Cicer arietinum threonine synthase with C-terminal 6-His tag

CBL Cystathionine $\beta$-lyase

CBS Cystathionine $\beta$-synthase

CGL Cystathionine $\gamma$-lyase

CGS Cystathionine $\gamma$-synthase

CIAP Calf intestinal alkaline phosphatase

CLSM Confocal laser scanning microscopy

DEAE Diethylethanolamine 


\begin{tabular}{|c|c|}
\hline DHDPS & Dihydrodipicolinate synthase \\
\hline DNA & Deoxyribonucleic acid \\
\hline DTT & Dithiothreitol \\
\hline E. coli & Escherichia coli \\
\hline EDTA & Ethylenediaminetetraacetic acid \\
\hline eCGS & Escherichia coli cystathionine $\gamma$-synthase \\
\hline eHSK & Escherichia coli homoserine kinase \\
\hline eTD & Escherichia coli threonine deaminase \\
\hline $\mathbf{e T D}_{\mathrm{L} 447 \mathrm{~F}}$ & Escherichia coli threonine deaminase with Phe substitution at Leu447 \\
\hline eTS & Escherichia coli threonine synthase \\
\hline FaCGS & Fragaria ananassa cystathionine $\gamma$-synthase \\
\hline GFP & Green fluorescent protein \\
\hline G. $\max$ & Glycine $\max$ \\
\hline GmCGS & Glycine max cystathionine $\gamma$-synthase \\
\hline GmTS & Glycine max threonine synthase \\
\hline HEPES & (4-(2-hydroxyethyl)-1-piperazineethanesulfonic acid \\
\hline HPLC & High performance liquid chromatography \\
\hline HSDH & Homoserine dehydrogenase \\
\hline HSK & Homoserine kinase \\
\hline HO-HxoDH & D-2-Hydroxyisocaproate dehydrogenase \\
\hline IPTG & Isopropyl- $\beta$ - $D$-thiogalactopyranoside \\
\hline L-Asp & L-Aspartate \\
\hline L-Cys & L-Cysteine \\
\hline
\end{tabular}




$\begin{array}{ll}\text { LDH } & \text { L-Lactate dehydrogenase } \\ \text { L. culinaris } & \text { Lens culinaris } \\ \text { LcCGS } & \text { Lens culinaris cystathionine } \gamma \text {-synthase } \\ \text { LcTS } & \text { Lens culinaris threonine synthase } \\ \text { L-HSer } & \text { L-homoserine } \\ \text { L-Ile } & \text { L-isoleucine } \\ \text { L-Lys } & \text { L-lysine } \\ \text { L-Met } & \text { L-Methionine } \\ \text { L-Pro } & \text { L-Proline } \\ \text { L-Thr } & \text { L-Threonine } \\ \text { L-Val } & \text { L-Valine } \\ \text { LcTS } & \text { Lens culinaris threonine synthase } \\ \text { MBP } & \text { MOPS/Bicine/L-proline }\end{array}$

M. sativa

Medicago sativa

M. truncatula Medicago truncatula

MtTS Medicago truncatula threonine synthase

MOPS 3-(N-morpholino)propanesulfonic acid

MS L-Methionine synthase

mto Methonine over-accumulating

$\mathrm{NaCl} \quad$ Sodium chloride

NAD $^{+} \quad$ Nicotinamide adenine dinucleotide, oxidized form

NADH Nicotinamide adenine dinucleotide, reduced form

Ni-NTA Nickel-nitrilo triacetic acid 


\begin{tabular}{ll} 
N. tabacum & Nicotiana tabacum \\
NtCGS & Nicotiana tabacum cystathionine $\gamma$-synthase \\
OPHS & O-phospho-L-homoserine \\
ORF & Open reading frame \\
PCR & Polymerase chain reaction \\
PEM & Protein energy malnutrition \\
PEP & Phospho(enol)pyruvate \\
PK & Pyruvate kinase \\
PLP & Pyridoxal 5'-phosphate \\
P. sativum & Pisum sativum \\
RNA & Ribonucleic acid \\
SAM & S-adenosyl-L-methionine \\
SAMS & S-adensosyl-L-methionine synthase \\
SDS-PAGE & Sodium dodecyl suflate polyacrylamide gel electrophoresis \\
S. tuberosum & Solanum tuberosum \\
StTS & Solanum tuberosum threonine synthase \\
TLC & Thin-layer chromatography \\
TS & Threonine synthase \\
TD & Threonine deaminase \\
UV & Ultraviolet \\
yTS angularis & Vigna angularis \\
\hline
\end{tabular}




\section{INTRODUCTION}

\subsection{Methionine and Pulse Species}

Customizing crops to improve their nutritional quality for human and animal consumption is a primary goal of plant genetic and metabolic engineering. Humans and non-ruminant animals cannot produce de novo half of the 20 proteinogenic amino acids, relying on their food source to supply them. These are referred to as essential amino acids, and deficiency of one or more can lead to protein energy malnutrition (PEM), lowered disease resistance, decreased blood proteins, and retarded mental and physical development in children under the age of 4 (Hoorweg and Stanfield, 1976). PEM is estimated to affect one third of the children in developing countries, and accounts for up to $8 \%$ of all childhood deaths (de Onis, 1993; World Health Organization, 2006). While animal products generally contain a balance of amino acids aligned with human dietary requirements, plant proteins are often deficient in at least one of the essential amino acids (Hesse et al., 2001). Methionine and lysine, for example, are two essential amino acids that are often limiting, from the perspective of human nutritional requirements, in legumes and cereals, respectively (Tabe and Higgins, 1998; Elango et al. 2009).

Grain legumes are crop plants of the Fabaceae family that develop pods and are cultivated for their protein-rich seeds. Pulse species are a subset of the grain legumes that are harvested for their dry seeds, and include Cicer arietinum (chickpea) and Lens culinaris (lentil). Pulses make up 10\% of the world's supply of dietary protein and are an important source of Canadian agricultural revenue (Muntz et al. 1998). In 2009-2010, Canadian pulse exports exceeded 2 million tonnes, bringing in over $\$ 2$ billion in revenue (Agriculture and Agri-Food Canada, 2011). These crops are also a dietary staple in areas 
where vegetarian diets are predominant, with the majority of Canadian exports going to south-east Asian countries, such as India, Pakistan, and Bangladesh (Muntz et al. 1998; Agriculture and Agri-Food Canada, 2011).

In humans and non-ruminant animals, methionine is the precursor for the production of the amino acid cysteine, and so meeting the dietary requirements for these two sulfur-containing amino acids is dependent on the intake of sufficient amounts of methionine (Figure 1.1) (Mato et al. 2008; Elango et al. 2009). Humans and monogastric animals require a combined intake of methionine and cysteine of 3-5\% of total dietary protein. In contrast, methionine and cysteine comprise $0.8-1.5 \%$ and $0.6-1 \%$, of total protein, respectively, in the pulse species Pisum sativum, and the two sulfur-containing amino acids make up $1.3 \%$ of total protein in chickpeas (Tabe and Higgins, 1998; Elango et al. 2009). Increasing methionine content in the seeds of grain legumes has the potential to both increase the nutritional quality of these staple foods, as well as boost Canadian agricultural exports.

Increasing the level of methionine in legume seed proteins has previously been undertaken through the engineering of seed proteins with additional methionine residues, or through the expression of heterologous methionine-rich proteins. The former has generally been unsuccessful due to the inserted residues interfering with proper folding and accumulation of seed proteins, as exemplified by the degradation of mutated $\beta$ phaseolin from Phaseolus vulgaris containing a nine-methionine insertion in its variable region (Hoffman et al. 1988). The availability of the three-dimensional structure of 
Figure 1.1. The transsulfuration pathway of plants and microorganisms and the reverse transsulfuration pathway of mammals. Abbreviations: CGS, cystathionine $\gamma$-synthase; CBL, cystathionine $\beta$-lyase; CGL, cystathionine $\gamma$-lyase; CBS, cystathionine $\beta$-synthase Figure adapted from Steegborn et al. (1999) and Farsi et al. (2009). 
Plants and

Mammals

Microorganisms

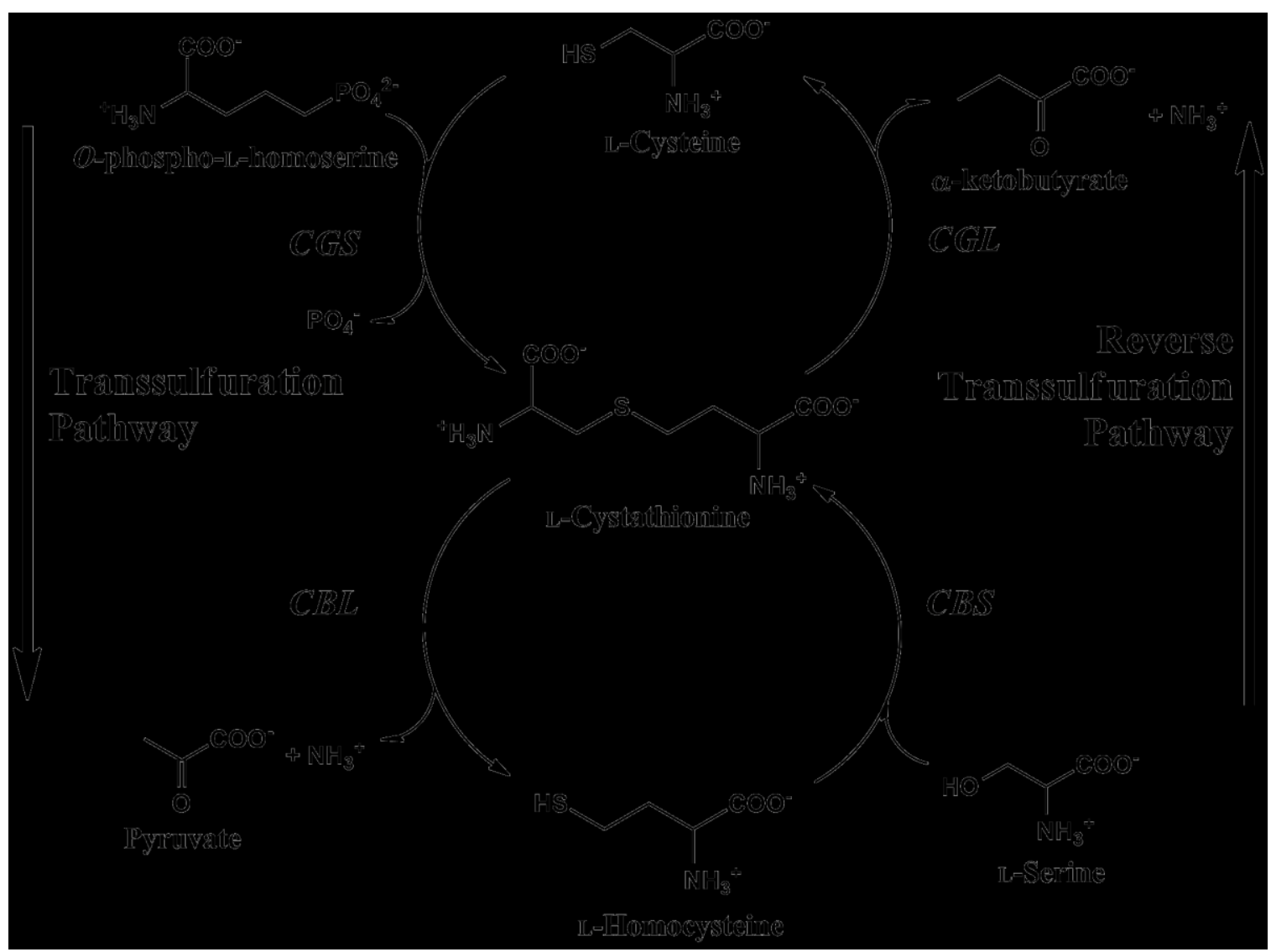


$\beta$-phaseolin later revealed that the insertion of nine residues at this site may have destabilized the formation of the quaternary structure of the seed protein (Sun et al. 2004). The expression of heterologous methionine-rich proteins has also been unsuccessful due to transferred allergenicity or the inability of transgenic plants to meet the increased demand for sulfur-containing amino acids. For example, the expression of some foreign methionine-rich proteins, such as $2 \mathrm{~s}$ albumin from Brazil nut, has been shown to transfer allergenicity to transgenic Glycine max (Nordlee et al. 1996). Furthermore, in chickpea, the seed-specific expression of methionine-rich sunflower seed albumin increased methionine content in transgenic chickpea seeds, with an accompanying decrease in cysteine-containing proteins, resulting in no net gain in the seed sulfur amino acid content (Chiaiese et al. 2004). These results indicate that the rational engineering of endogenous seed storage proteins to increase the number of methionine residues may be preferable, to avoid the introduction of allergens, but must be complemented with enhanced methionine production to meet the increased demand for sulfur-containing amino acids (Hesse et al. 2004).

\subsection{Methionine biosynthesis in plants}

L-Methionine (L-Met) is a member of the L-aspartate (L-Asp)-derived family of amino acids. In plants, the carbon backbone of L-Met is supplied by the L-Asp-derivative O-phospho-L-homoserine (OPHS), which occupies the branch-point between the synthesis of L-Met and L-threonine (L-Thr) (Figure 1.2) (Jander and Joshi, 2010). In plants, the first step in L-Met biosynthesis is the condensation of OPHS with L-cysteine (L-Cys) by cystathionine $\gamma$-synthase (CGS), producing L-cystathionine; this enzyme 
Figure 1.2. The biosynthesis of L-Met and L-Thr from L-Asp in plants. Abbreviations: AK, aspartate kinase; ASDH, aspartate semialdehyde dehydrogenase; HSDH, homoserine dehydrogenase; HK, homoserine kinase; CGS, cystathionine $\gamma$-synthase; TS, threonine synthase; SAMS, $S$-adenosyl-L-methionine synthase. Figure adapted from Morneau et al. (2013). 

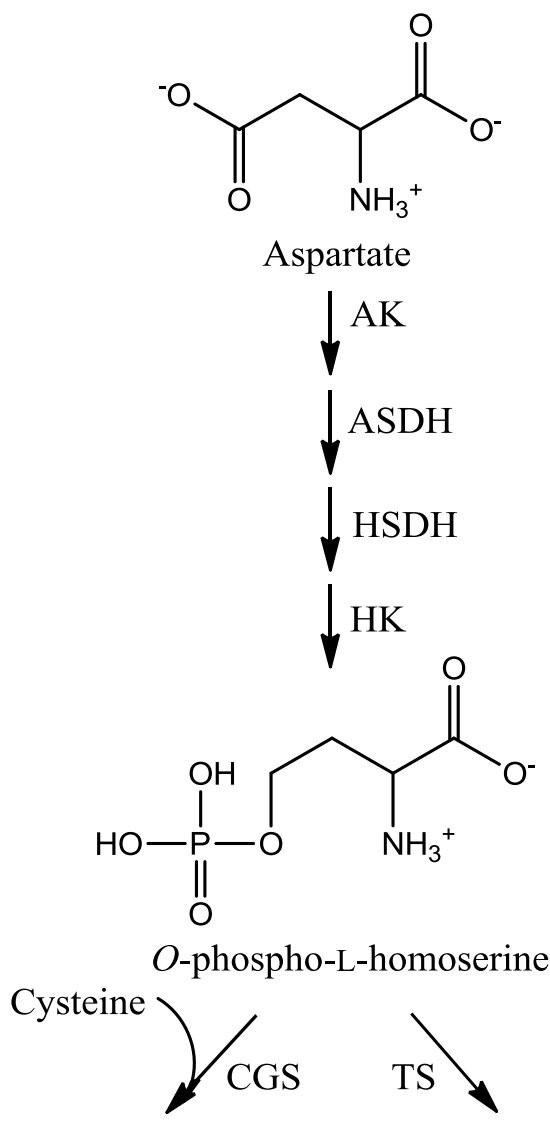<smiles>[NH3+]C(CCSCC([NH3+])C(=O)[O-])C(=O)[O-]</smiles>

Cystathionine<smiles>CSCCC([NH3+])C(=O)[O-]</smiles><smiles>CC1OC(C[S+](C)CCC([NH3+])C(=O)O)C(O)C1O</smiles>

$S$-adenosylmethionine

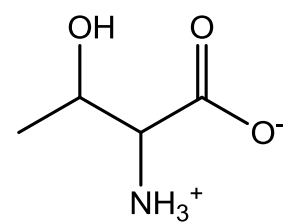

Threonine 
competes with threonine synthase (TS), which catalyzes the production of L-Thr from OPHS (Hesse et al. 2004). The metabolic flux of this pathway, or the flow of the substrate to L-Met or L-Thr biosynthesis, is determined by the activity of CGS and TS.

The synthesis of L-Met continues via the cleavage of L-cystathionine by cystathionine $\beta$-lyase (CBL), forming L-homocysteine. The reactions catalyzed by CGS and CBL make up the transsulfuration pathway of plants, which transfers the sulfur moiety from the $\beta$-carbon of L-Cys to the $\gamma$-carbon of L-homocysteine (Ravanel, 1997). Studies on transgenic Solanum tuberosum expressing antisense CBL constructs under the control of the CaMV-35S promoter revealed that CBL is necessary for L-Met synthesis and normal plant development, but that it is not involved in the regulation of OPHS partitioning between the competing L-Met and L-Thr pathways (Maimann et al. 2000; Maimann et al. 2001; Azavedo et al. 2006). The final step in L-Met synthesis is the methylation of L-homocysteine by methionine synthase (MS) (Eichel et al. 1995; Hesse et al. 2004). This step takes place in the cytosol, while the transsulfuration pathway, along with the biosynthetic pathways of the other L-Asp-derived amino acids, L-lysine (L-Lys), L-Thr, and L-isoleucine (L-Ile), are compartmentalized in the chloroplast (Eichel et al. 1995; Jander and Joshi, 2010).

The enzymes CGS and TS were identified as promising targets for the manipulation of OPHS flux to increase L-Met production following the discovery of the methionine over-accumulating (mto) mutant loci in Arabidopsis thaliana. The mto mutants comprise point mutations in the coding regions of CGS (mtol) or TS (mto2) (Inaba et al. 1994; Bartlem et al. 2000; Ominato et al. 2002). The mtol lines express $C G S$ transcripts that are not susceptible to post-transcriptional regulation, and thus the 
plants accumulate CGS protein, leading to 15 - to 40 -fold increases in free L-Met content in rosette leaves (Inaba et al. 1994; Ominato et al. 2002). The $m t o 2$ line carries a leucine to arginine substitution in the TS active site, reducing the enzyme's capacity to bind OPHS, thereby reducing L-Thr synthesis 15 -fold, and increasing L-Met levels 22 -fold (Bartlem et al. 2000). The disruption of metabolic flux caused by impaired TS activity is associated with negative phenotypic effects including delayed growth, and reductions in fresh weight and root length (Bartlem et al. 2000; Kusano et al. 2010). This indicates that increasing L-Met synthesis in crop species can be achieved through manipulation of metabolic flux at the OPHS branch-point, but that the successful metabolic engineering of L-Met production without phenotypic side-effects requires a detailed understanding of the role of CGS and TS in OPHS partitioning in the target species.

\subsection{Regulation of L-Met biosynthesis}

Methionine is involved in the synthesis of proteins, initiation of translation, and is a precursor for a number of other biologically important compounds including $S$ adenosyl-L-methionine (SAM) (Inaba et al. 1994). SAM is the primary methyl-group donor for most methylation reactions occurring within the cell, and is also the precursor of polyamines and the phytohormone ethylene (Ravanel et al. 1998a; Roje, 2006). Amino acid biosynthetic pathways are commonly regulated by metabolic end-products, as exemplified by the L-Asp metabolic pathway, which is regulated through the feedback inhibition of aspartate kinase (AK) by both L-Thr, L-Lys, and SAM (Jander and Joshi, 2010). The partitioning of OPHS into the L-Met and L-Thr biosynthetic pathways is determined by intracellular SAM concentration. 
In A. thaliana, SAM mediates the post-transcriptional regulation of CGS mRNA by binding to the regulatory region, designated the MTO region, which acts in cis to decrease CGS transcript stability. The $m t o 1$ lines of $A$. thaliana contain point mutations in this region that inhibit regulation by SAM (Chiba et al. 2003). The regulation of CGS by SAM may vary across species. For example, in vitro transcription/translation studies of mRNA encoding $C G S$ from $S$. tuberosum in the presence of varying concentrations of L-Met, with $A$. thaliana $C G S$ as a control, found that $A$. thaliana $C G S$ transcript stability was decreased when exposed to $0.1 \mathrm{mM}$ L-Met, while $S$. tuberosum $C G S$ transcripts were not affected (Kreft et al. 2003). At the time, the regulation of $A$. thaliana $C G S$ was thought to be mediated by L-Met, hence its addition into the in vitro translation mixture; the L-Met was likely converted into SAM by SAM synthase (SAMS) in the wheat germ extract of the reaction mixture. These results indicate that the SAM-mediated regulation of CGS may be species-specific, illustrating the need to study the regulation of L-Met biosynthesis in the target species for future biotechnological endeavours.

The L-Met-derivative SAM also regulates TS activity, via allosteric activation, increasing its catalytic efficiency up to 87 -fold (Laber et al. 1999). The posttranscriptional and allosteric regulation of CGS and TS, respectively, by SAM demonstrates the complexity of metabolic partitioning at the OPHS branch-point.

\subsection{Threonine Synthase}

In plants and bacteria, the last step in L-Thr biosynthesis is the TS-catalyzed $\beta, \gamma$ replacement of OPHS producing L-Thr, and inorganic phosphate (Curien et al. 1996). The newly formed L-Thr is either incorporated into protein, or used as a precursor for the 
amino acids L-Ile and L-glycine (Jander and Joshi, 2010). The TS enzyme has been characterized from several plant species including A. thaliana (Curien et al. 1996; Curien et al. 1998; Laber et al. 1999), Lemna paucicostata (Giovanelli et al. 1984), and S. tuberosum (Casazza et al. 2000; Zeh et al. 2001). Plant TS, like other enzymes involved in amino acid synthesis, is a pyridoxal 5'-phosphate (PLP)-dependent enzyme (Curien et al. 1996; Casazza et al. 2000). PLP-dependent enzymes are categorized by their foldtype structure (Eliot and Kirsch, 2004). There are five evolutionary fold types of PLPdependent enzymes and the homodimeric plant TS is a member of the fold-type II structural family (Curien et al. 1996; Mas-Droux et al. 2006). The enzymes of the foldtype II structural family generally possess at least one regulatory domain and active sites composed of residues from only one monomer despite being functional dimers (Eliot and Kirsch, 2004). Plant TS contains two regulatory SAM-binding sites at the dimer interface (Mas-Droux et al. 2006). In contrast, TS from microorganisms is not regulated by SAM and is a functional monomer (Garrido-Franco et al. 2002).

A. thaliana contains two forms of TS (AtTS1 and AtTS2). The purification of TS from A. thaliana leaves found AtTS1 (At4g29840) eluted in a single peak of activity, at a similar ionic strength to recombinantly expressed AtTS1, leading to the assumption that a single copy of TS is expressed in A. thaliana chloroplasts. However, the A. thaliana genome contains a gene encoding a second homologue of TS (AtTS2; At1g72810). Kinetic characterization of AtTS2 demonstrated that it is also subject to activation by SAM, but has a $k_{\text {cat }}$ value that is 120 -fold lower than that of AtTS1 in the presence of physiological concentrations of SAM $(20 \mu \mathrm{M})$ (Curien et al. 2009). 


\subsubsection{Allosteric Regulation of TS}

The crystal structure of AtTS1, solved with and without the allosteric effector, revealed the mechanism of activation of plant TS by SAM (Thomazeau et al. 2001; MasDroux et al. 2006). In its inactive form, the orientation of the PLP cofactor in the active site of AtTS1 prevents OPHS binding to the substrate site and acts as an inhibitor (MasDroux et al. 2006). AtTS1 binds SAM at the dimer interface; two SAM molecules associated with each monomer, with the functional dimer binding a total of four SAM molecules (Figure 1.3; Mas-Droux et al. 2006). Of these four SAM molecules, the two solvent exposed molecules, defined as SAM2 and SAM4, are mainly stabilized by forming stacking interactions with W101 of monomer A and B, respectively; however, the carboxylate group of SAM2 forms an electrostatic interaction with K141 and N147 of

monomer B, whereas the methionine moiety of SAM4 interacts with only K141 of monomer A (Figure 1.4) (Mas-Droux et al. 2006). The interaction of SAM2 with both K141 and N147 contributes to the stabilization of residues 137-149 of monomer B, which does not occur in monomer A (Mas-Droux et al. 2006). This leads to the active site of monomer A undergoing a large rearrangement upon SAM-binding, consisting of a shift in loops $190-195,260-264$, and $294-299$, resulting in a $150^{\circ}$ rotation of the PLP molecule and leading to an active site conformation similar to that of TS from microorganisms (Figure 1.4) (Mas-Droux et al. 2006). The active site of monomer B remains unchanged, and it has been proposed that subsequent binding of OPHS to the active site of monomer A induces a rearrangement of the active site of monomer B (Mas-Droux et al. 2006). Thus, in the absence of OPHS, the PLP of monomer B remains in an inactive orientation (Figure 1.4) (Mas-Droux et al. 2006). 
Figure 1.3. Crystal structure of $A$. thaliana TS1 in complex with PLP (yellow) and 2 molecules of SAM (green and blue) per monomer. Monomer A is shown in pink, and monomer B is shown in gray. (PDB: 2C2B) (Mas-Droux et al. 2006). 


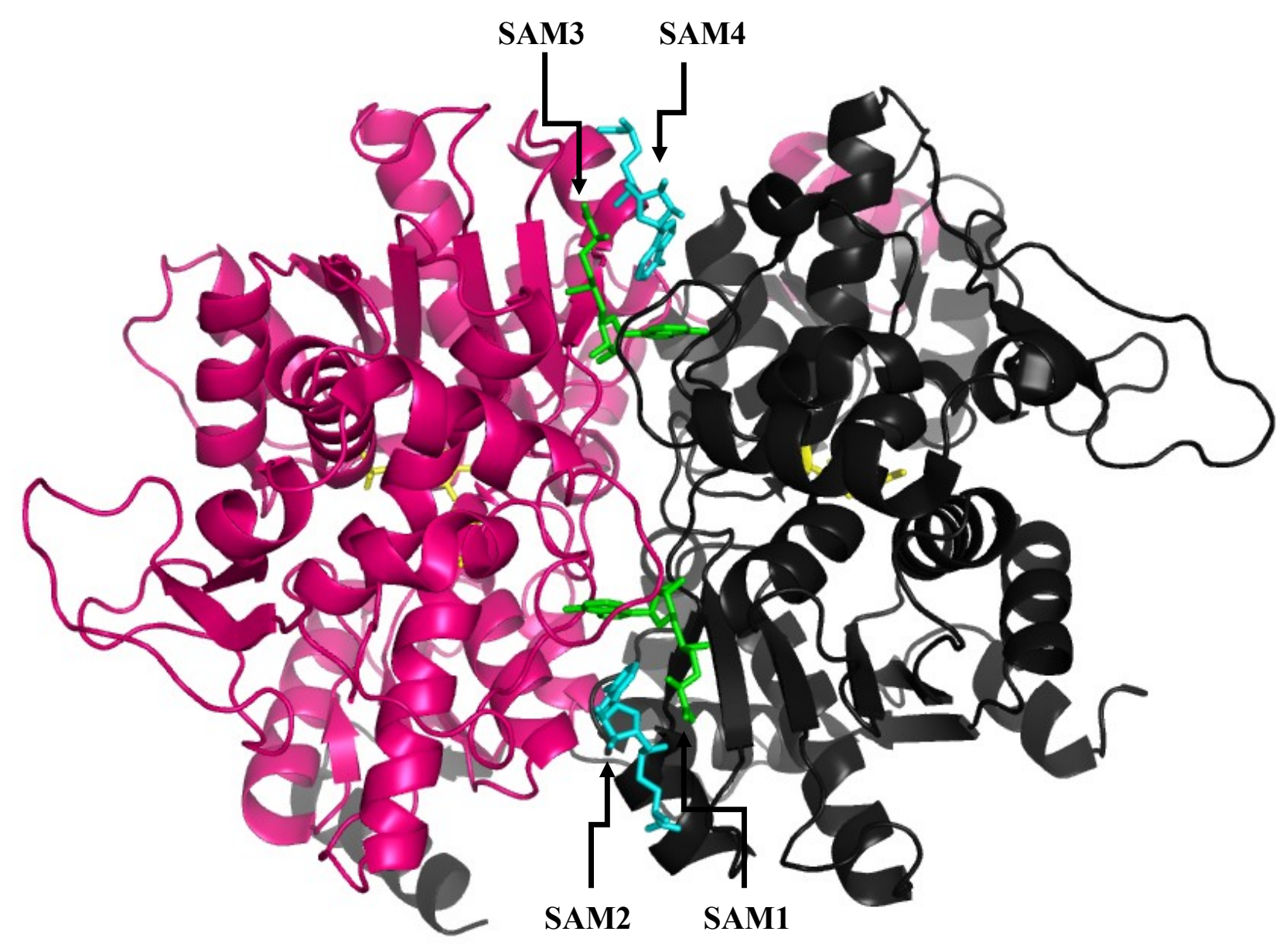


Figure 1.4. Cartoon and surface representations of the allosteric and active sites of $A$. thaliana TS1 (AtTS1) upon SAM binding. Monomers A and B are shown in pink and gray, respectively. SAM1 and SAM3 are in green, SAM2 and SAM4 are shown in blue. (A) Residues involved in the binding of SAM1 and SAM2 (i), and SAM3 and SAM4 (ii) are shown in the colors of their respective monomers. (B) Surface view of the active site and orientation of the PLP cofactor in the inactive form of monomer B (i) and the active form of monomer A (ii) upon SAM-binding. (C) Residues of loops 190-195 (green), 260-264 (pink), and 294-299 (blue) of the active sites of monomer B (i) and monomer A (ii) shown in stick format. (PDB: 2C2B) (Mas-Droux et al. 2006). 
A

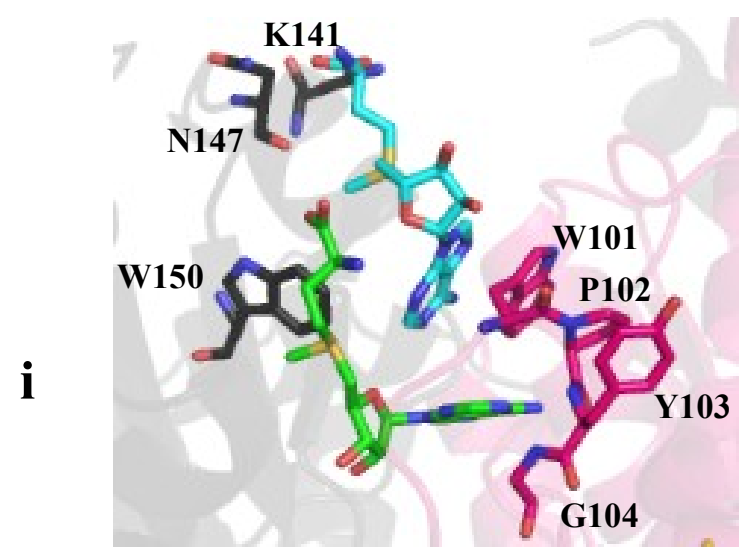

ii
B
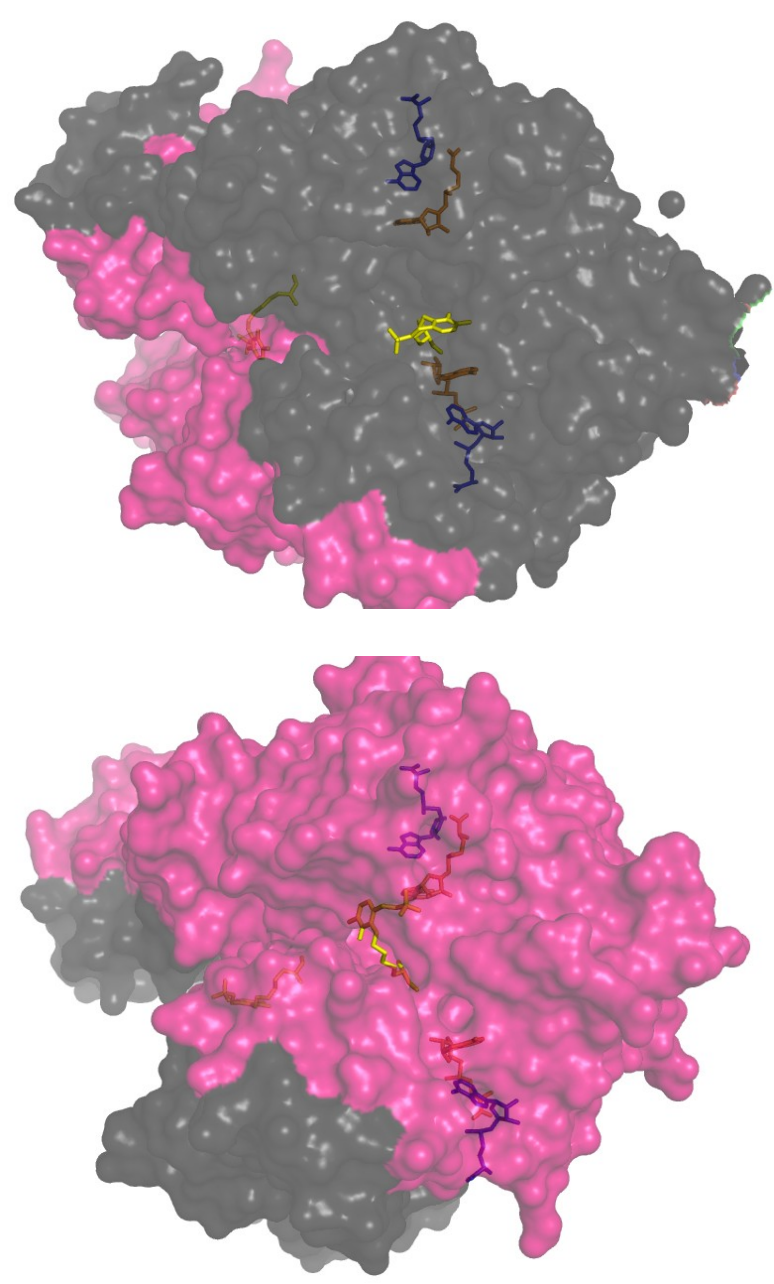

C
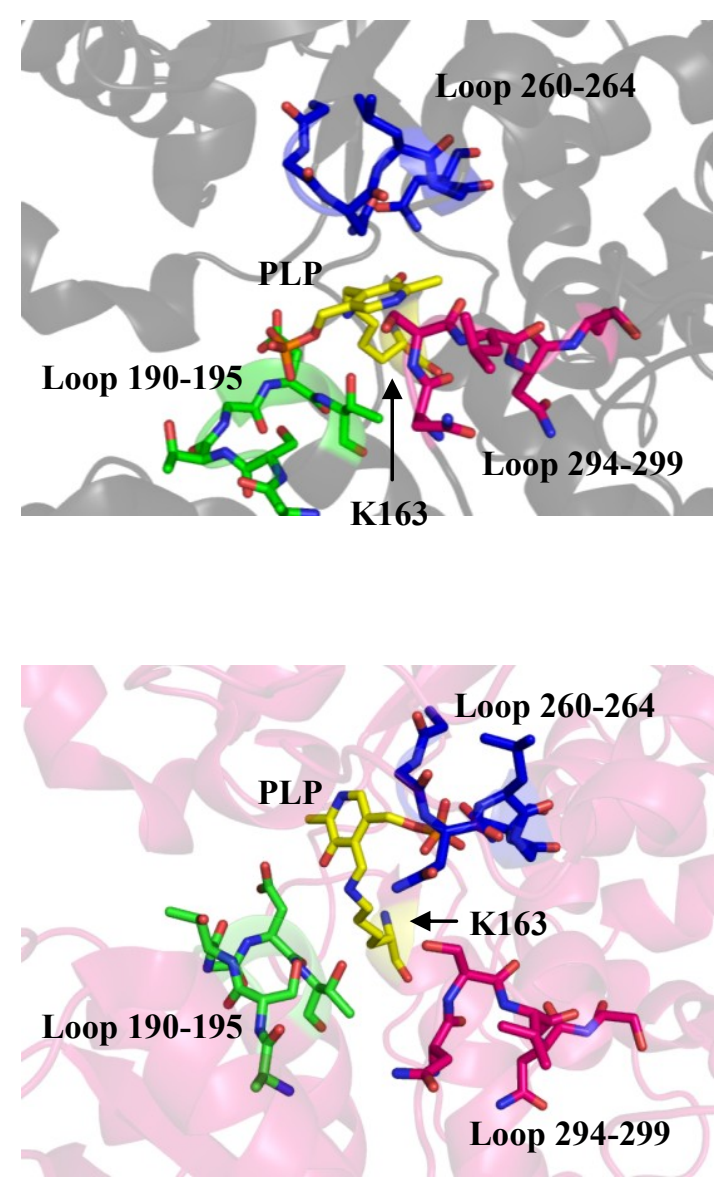
The presence of SAM increases the catalytic efficiency $\left(k_{c a t} / K_{m}\right)$ of TS by affecting both the $K_{m}{ }^{\text {OPHS }}$ and $k_{c a t}$ values, however this interaction is complex (Curien et al.1998; Laber et al. 1999). The $k_{\text {cat }}$ of AtTS1 increases in a sigmoidal fashion at low SAM concentrations $(<10 \mu \mathrm{M})$, suggesting cooperativity between the enzyme and activator (Curien et al. 1998). At SAM concentrations less than $2 \mu \mathrm{M}, K_{m}{ }^{\text {OPHS }}$ increases from $250 \mu \mathrm{M}$ to $500 \mu \mathrm{M}$, then decreases at SAM concentrations $>2 \mu \mathrm{M}$ (Curien et al. 1998). While physiological SAM concentrations in the chloroplast are estimated at $20-40 \mu \mathrm{M}$, peak enzyme activity is reached at SAM concentrations of 100-250 $\mu \mathrm{M}$ (Laber et al.1999; Curien et al. 2003). At $100 \mu \mathrm{M} \mathrm{SAM,} \mathrm{the} k_{\text {cat }}$ and $K_{m}{ }^{\text {OPHS }}$ of AtTS1 are reported at $0.86 \mathrm{~s}^{-1}$ and $30 \mu \mathrm{M}$, respectively, compared to $0.04 \mathrm{~s}^{-}$ ${ }^{1}$ and $120 \mu \mathrm{M}$, respectively, in the absence of SAM (Laber et al. 1999).

\subsection{Threonine synthase as a target for increasing L-Met biosynthesis}

The activation of plant TS by SAM underlies the key role this enzyme plays in the partitioning of OPHS between the L-Met and L-Thr biosynthetic pathways. In vitro assessments of SAM-activated AtTS1 demonstrated a 83-fold lower $K_{m}{ }^{\text {OPHS }}$ than that of CGS from A. thaliana (AtCGS), such that under conditions of sufficient cellular L-Met and SAM, OPHS is channeled primarily to L-Thr synthesis (Ravanel et al. 1998b; Curien et al. 2009). Furthermore, the level of AtTS1 expressed in the chloroplast has been estimated to be 7-fold higher than that of CGS (Curien et al. 2003). As such, the L-Thr biosynthetic pathway accounts for $70-80 \%$ of OPHS flux under physiological conditions, and provides a good candidate for biotechnological manipulation to increase L-Met yield (Curien et al. 2003). In the $m t o 2$ plant lines, the 
arginine substitution in the TS active site impairs the synthesis of L-Thr, causing a 94\% reduction in L-Thr synthesis, and resulting in a range of altered metabolic processes (Bartlem et al. 2000; Kusano et al. 2010). These plants are associated with a 3-fold accumulation of the upstream metabolites of L-Thr, along with a 3-fold increase in overall amino acid biosynthesis and in SAM concentration, which leads to a 3-fold increase in the synthesis of polyamines (Kusano et al. 2010). This illustrates the inter-connected nature of metabolic pathways and demonstrates that careful consideration must be given to the cellular role of TS when seeking to alter its effects on OPHS flux partitioning.

Manipulations of TS expression have had varying effects on cellular L-Met and L-Thr pools and plant phenotype in different species, as exemplified by studies in A. thaliana and S. tuberosum (Zeh et al. 2001; Avraham and Amir, 2005). For example, expression of $A$. thaliana TS in the antisense orientation downstream of the CaMV-35S promoter, thus reducing $T S$ expression, led to a 17- to 47-fold accumulation of L-Met in transgenic A. thaliana. Similar expression of $S$. tuberosum $T S$ in the antisense orientation in transgenic $S$. tuberosum plants led to up to 240 -fold accumulation of L-Met (Zeh et al. 2001). These results highlight the necessity of characterizing TS and mapping metabolic flux in the target species prior to engaging in genetic engineering endeavours in vivo, since the degree to which TS affects OPHS flux distribution may vary across species. 


\subsection{Rational metabolic engineering through kinetic modeling}

The pursuit of increased L-Met production has involved experiments using strong constitutive promoters, such as the CaMV-35S promoter, to increase expression of CGS or decrease expression of TS (Gakiere et al. 2002; Zeh et al. 2001). The resulting 15 - to 240-fold increases in L-Met levels are higher than necessary to meet human dietary requirements, and are often associated with phenotypic effects, such as retarded growth, leaf chlorosis, and reduction in fresh weight (Zeh et al. 2001; Gakiere et al. 2002; Avraham and Amir, 2005). A 3-fold increase in seed L-Met is sufficient to achieve adequate nutritional quality, and is unlikely to cause perturbations to metabolic flux in other pathways, thus avoiding undesirable phenotypic effects. For example, the expression of a feed-back insensitive form of dihydrodipicolinate synthase (DHDPS), the first committed enzyme in the L-Lys metabolic pathway, under the control of the CaMV-35S promoter or a seed-specific promoter, led to a 5-fold and a 3-fold increase in L-Lys accumulation, respectively, in Oryza sativa (Shaver et al. 1996; Lee et al. 2001). The seeds expressing DHDPS under the strong constitutive promoter had poor germination rates and altered seed morphology, a trend that was proportional to DHDPS expression and L-Lys accumulation (Lee et al. 2001). The expression of a bacterial, feed-back insensitive form of DHDPS in Zea mays under the control of a maize seed promoter, successfully generated a high-lysine maize variety, with 2- to 3fold elevations in L-Lys content, that was available commercially (LY038) but has since been withdrawn due to safety concerns raised by opponents of genetically modified foods (Dizigan et al. 2007; Galili and Amir, 2012). These results indicate 
that modest increases in seed amino acid composition are possible, but require more subtle strategies that have been verified in vitro prior to engaging in metabolic engineering projects in vivo. This in vitro verification can be facilitated through the use of a mathematical model of metabolic flux (Rohwer, 2012).

Traditionally, the analysis of metabolism has been reductionist in nature, with the study of the enzymes of a given pathway occurring in isolation (Rohwer, 2012). Metabolic engineering causes changes in flux that affect the activities of other enzymes in the metabolic network, and so the assimilation of disparate kinetic data into a kinetic model can be used to recreate the dynamics of a metabolic pathway (Stitt et al. 2010; Rohwer, 2012). A kinetic model of the OPHS branch-point requires the integration of information about the activity and regulation of the component enzymes, TS and CGS for the OPHS branch-point, as well as the physiological conditions and metabolite concentrations in the relevant subcellular compartment (Rohwer, 2012).

Kinetic models increase our understanding of complex metabolic networks and enable the description of their behaviour and regulation in a quantitative manner (Rohwer and Botha, 2001). As such, these models can be used to predict the effect of manipulations on a given metabolic pathway prior to making these alterations in vivo. For example, the creation of kinetic models of sucrose metabolism have been used to identify the enzymes that regulate the energetically costly process of futile cycling of sucrose (Rohwer and Botha, 2001; Uys et al. 2007). The model was used to inform rational enhancement strategies for the improvement of sucrose accumulation by predicting the in vivo sucrose accumulation occurring when the expression of one of 
the enzymes involved in futile cycling was decreased using RNA interference (Rossouw et al. 2007; Rohwer, 2012). Another model simulating the synthesis of aliphatic glucosinolates, an important secondary metabolite, in A. thaliana was used to understand interconnections in the regulation and expression of two homologues of one of the component enzymes, thus permitting the assessment of the relative flux contributions of each enzyme individually, which would not have been possible experimentally (Knoke et al. 2009).

\subsection{Objective}

Since methionine and cysteine make up $1.3 \%$ of the total protein content in C. arietinum seed proteins, and humans require a combined daily intake of $3-5 \%$ of total dietary protein for both amino acids (Elango et al. 2009), only a slight increase (approximately 3-fold) in seed L-Met is required to meet the daily nutritional needs of humans and non-ruminant animals. Many previous metabolic engineering projects aimed at increasing L-Met biosynthesis have employed strong constitutive promoters to increase the expression of $C G S$ or decrease $T S$ expression through anti-sense repression have yielded significant accumulation of free L-Met (Zeh et al. 2001; Kim et al. 2002). However, the use of a strong promoter like CaMV-35S is frequently associated with disruptions in flux accompanying the 8 - to 240 -fold increases in LMet synthesis, leading to negative effects on plant phenotype, and thus making these strategies undesirable for use in crop species (Zeh et al. 2001; Kim et al. 2002; Nikiforova et al. 2002). To facilitate the engineering of the pulse species of interest with a modest increase in L-Met content, a detailed understanding of the flux at the 
OPHS branch-point between the L-Met and L-Thr biosynthetic pathways is required. The construction of a metabolic model of the OPHS branch-point in important pulse species will provide the knowledge base required for manipulating flux to increase LMet biosynthesis and meet the requirements for human nutrition.

Kinetic studies of TS of C. arietinum and L. culinaris under maximal activity conditions require the isolation of the enzymes and in vitro study using an efficient and reliable kinetic assay. The purpose of the research described in this thesis is to enhance our understanding of the role of TS from $C$. arietinum and L. culinaris through:

1. The development of a suitable continuous, coupled-coupled spectrophotometric assay for measuring TS activity, and a simplified and consistent method for the synthesis and purification of the OPHS substrate (Chapter 2);

2. The isolation of functional TS from the target species (Chapter 3); and

3. The measurement of the steady-state kinetic parameters of TS from $C$. arietinum and L. culinaris which, in combination with those of CGS, will provide the basis for modeling the partitioning of OPHS in these pulse species (Chapter 4). 
Chapter 2: Development of a continuous assay and steady-state characterization of Escherichia coli threonine synthase 


\subsection{Abstract}

Threonine synthase (TS) catalyzes the hydrolysis of $O$-phospho-L-homoserine (OPHS) to produce L-threonine (L-Thr) and inorganic phosphate. Here, we report a simplified purification protocol for the OPHS substrate and a continuous, coupledcoupled, spectrophotometric TS assay. The sequential actions of threonine deaminase (TD) and hydroxyisocaproate dehydrogenase (HO-HxoDH) convert the L-Thr product of TS to $\alpha$-ketobutyrate ( $\alpha-\mathrm{KB})$ and then to 2-hydroxybutyrate, respectively, and are monitored as the decrease in absorbance at $340 \mathrm{~nm}$ resulting from the concomitant oxidation of $\mathrm{NADH}$ to $\mathrm{NAD}^{+}$by $\mathrm{HO}-\mathrm{HxoDH}$. The effect of $\mathrm{pH}$ on the activities of Escherichia coli TD, and Lactobacillus delbrueckii HO-HxoDH was determined in order to establish this continuous assay as suitable for steady-state characterization and to facilitate the optimization of coupling enzyme concentrations under different assay conditions to enable studies of TS across phyla. To validate this assay, TS from E. coli was characterized. The kinetic parameters $\left(k_{c a t}=4 \mathrm{~s}^{-1}, K_{m}{ }^{\mathrm{OPHS}}=0.34 \mathrm{mM}\right)$ and the $\mathrm{pH}$ optimum of 8.7 , determined using the continuous assay, are consistent with the values reported for this enzyme based on the discontinuous malachite green assay. The $k_{\text {cat }} / K_{m}{ }^{\text {OPHS }}$ versus $\mathrm{pH}$ profile of eTS is bell-shaped and the apparent $\mathrm{p} K_{a}$ values for the acidic and basic limbs are 7.1 and 10.4, respectively. 


\subsection{Introduction}

In plants and bacteria, threonine synthase (TS; E.C. 4.2.3.1) catalyzes the pyridoxal 5'-phosphate (PLP)-dependent hydrolysis of $O$-phospho-L-homoserine (OPHS) to produce L-threonine (L-Thr) and inorganic phosphate. The TS enzyme has been studied from a variety of species of microorganisms, including yeast, Bacillus subtilis, Mycobacterium tuberculosis, Crytococcus neoformans, Thermus thermophilus, and Escherichia coli, as well as from multiple plant species, including Arabidopsis thaliana, Pisum sativum, Beta vulgaris and Lemna paucicostata (Cohen and Hirsch, 1954; Watanabe and Shimura, 1955; Wormser and Pardee, 1958; Flavin and Slaughter, 1960; Madison and Thompson, 1976; Szczesiul and Wampler, 1976; Thoen et al. 1978; Giovanelli et al. 1984; Farrington et al. 1993; Laber et al. 1994a; Laber et al. 1994b; Ramos and Calderon, 1994; Curien et al. 1996; Curien et al. 1998; Laber et al. 1999; Chassagnole et al. 2001; Rais et al. 2001; Covarrubias et al. 2008; Kingsbury and McCusker, 2008; Murakawa et al. 2011). As an enzyme limited to plants and bacteria, TS is an attractive target for biotechnological applications, such as the development of anti-microbial and herbicidal compounds, and manipulation of amino acid biosynthesis (Thomazeau et al. 2001; Covarrubias et al. 2008). The OPHS substrate of TS is labile, and must be synthesized as it is not commercially available. The reliability of TS kinetic parameters is dependent on the purity and accurate quantification of the OPHS substrate and the variability in reported protocols for the synthesis and purification of OPHS complicates the comparison of reported kinetic values (Flavin and Slaughter, 1960; Datko et al. 1974; Madison and Thompson, 1976; Szczesiul and Wampler, 1976; Thoen et al. 1978; 
Giovanelli et al.1984; Ramos and Calderon, 1994; Laber et al. 1994a; Laber et al. 1994b; Curien et al. 1996; Curien et al. 1998; Laber et al. 1999; Curien et al. 2003).

The discontinuous TS assays reported typically rely on quantification of the phosphate product, via reaction with malachite green, the use of $\left[{ }^{3} \mathrm{H}\right]$-labeled OPHS, or derivatization and detection of phenylthiocarbmoyl-L-threonine. The labourintensive nature of these methods and the cost and difficulty of synthesizing a radioactive substrate illustrate the need for the development of a continuous TS assay. A continuous method for monitoring flux at the branch-point between the L-Met and L-Thr biosynthetic pathways of $A$. thaliana, reported by Curien et al., employed threonine deaminase (TD; E.C. 4.2.1.16) and lactate dehydrogenase (LDH) as coupling enzymes for TS (Curien et al. 2003). However, this method was not optimized for the steady-state characterization of TS and subsequent studies reporting TS kinetic parameters have continued to employ discontinuous assays (Lee et al. 2005; Covarrubias et al. 2008; Murakawa et al. 2011).

Although LDH can reduce the $\alpha$-ketobutyrate $(\alpha-\mathrm{KB})$ product of TD, its catalytic efficiency for this reaction is an order of magnitude lower than that of the enzyme hydroxyisocaproate dehydrogenase (HO-HxoDH; E.C. 1.1.1.-) from Lactobacillus delbrueckii (Aitken et al. 2003). Therefore, the latter was selected for the design of a continuous, coupled-coupled assay to monitor TS activity (Figure 2.1). In order to validate this assay, via the characterization of $E$. coli TS, the TD enzyme from E. coli (eTD) was selected as a coupling enzyme. However, wild-type eTD is not an optimal coupling enzyme, as it displays cooperative substrate binding (Eisenstein, 1991). Therefore, the L447F site-directed variant of this enzyme, which 
Figure 2.1. The continuous, coupled-coupled enzyme assay developed for TS. The TS-catalyzed $\beta, \gamma$-replacement of OPHS yields L-Thr and inorganic phosphate. The first coupling enzyme, TD, deaminates L-Thr, producing $\mathrm{NH}_{3}$ and $\alpha-\mathrm{KB}$, which is subsequently reduced to 2-hydroxybutyrate by the second coupling enzyme, HO$\mathrm{HxoDH}$, with the concurrent oxidation of $\mathrm{NADH}\left(\varepsilon 340=6200 \mathrm{M}^{-1} \mathrm{~cm}^{-1}\right)$. 


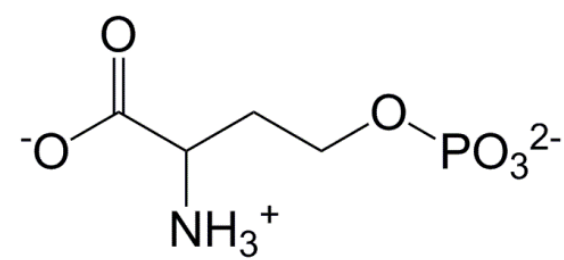

$O$-phospho-L-homoserine
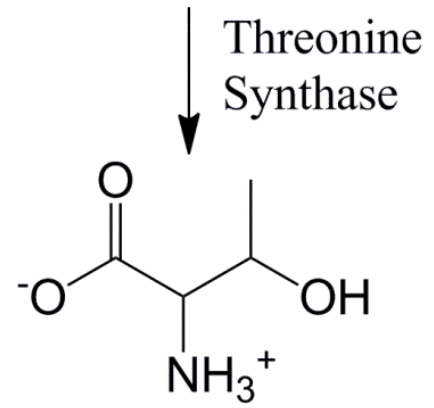

L-Threonine
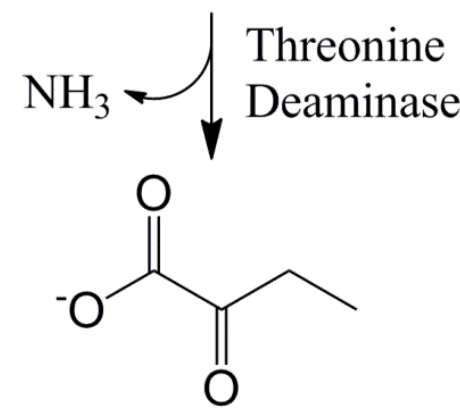

$\alpha$-ketobutyrate

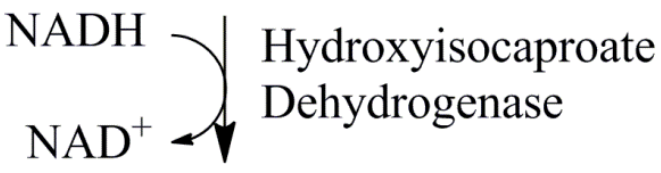<smiles>CCC(O)C(=O)[O-]</smiles>

2-hydroxybutyrate 
displays Michaelis-Menten kinetics, was selected for this system (Eisenstein et al. 1995). In this method the L-Thr product of TS is converted by eTD to $\alpha-\mathrm{KB}$, which is subsequently reduced by $\mathrm{HO}-\mathrm{HxoDH}$ with the concomitant oxidation of NADH to $\mathrm{NAD}^{+}\left(\varepsilon_{340}=6200 \mathrm{M}^{-1} \mathrm{~cm}^{-1}\right)$. The effect of $\mathrm{pH}$ on the catalytic efficiency of TD and HO-HxoDH was determined in order to establish this continuous, coupled-coupled assay as a method for studying TS activity from a variety of species, including plants, bacteria and other microorganisms, which have distinct $\mathrm{pH}$ optima (Sczcesiul and Wampler, 1976; Curien et al. 1998; Covarrubias et al. 2008).

\subsection{Methods}

\subsubsection{Materials}

L-Homoserine (L-HSer), adenosine-5' -triphosphate (ATP), $\alpha$-ketobutyrate ( $\alpha$ $\mathrm{KB}$ ), $\beta$-nicotinamide adenine dinucleotide (NADH), bicine, phospho(enol)pyruvate (PEP), pyruvate kinase (PK), L-lactate dehydrogenase (LDH), calf intestinal alkaline phosphatase (CIAP), ninhydrin, Triton x-100, and ammonium molybdate were obtained from Sigma-Aldrich. 4-(2-hydroxyethyl)-1-piperazineethanesulfonic acid (HEPES), 3-(N-morpholino)propanesulfonic acid (MOPS), L-proline (L-Pro), L-Thr, L-valine (L-Val) dithiothreitol (DTT), and isopropyl $\beta$-D-thiogalactopyranoside (IPTG) were Fisher Scientific products. Nickel-nitrilotriacetic acid (Ni-NTA) resin was purchased from Qiagen. Malachite green and diethylaminoethyl (DEAE) resin were obtained from $\mathrm{BDH}$ and GE Healthcare, respectively. 
2.3.2. Construction of expression constructs and purification of eHSK, eTS, eTD and Ho- $H x o D H$

The coding regions of E. coli homoserine kinase (eHSK; thrB), threonine synthase (eTS; thrC) and eTD $(i l v A)$ were amplified from the genomic DNA of strain DH10B (Table 2.1). The 3' primers for eHSK and eTS were designed to introduce a 6-Histidine (6-His), affinity tag at the C-terminal end of the recombinantly expressed proteins. Farsi et al. (2009) replaced the NcoI site of the pTrc-99a expression vector with a NdeI site, to produce pTrc-99a2, and subsequently introduced the sequence encoding a N-terminal, 6-His tag and linker containing a Factor Xa cleavage site, yielding the pTrc-99aAF expression vector (Farsi et al. 2009). The eHSK, eTS and eTD amplicons were inserted at the $N c o \mathrm{I}$ and $X b a \mathrm{I}, N d e \mathrm{I}$ and $\mathrm{SacI}$, and the $N d e \mathrm{I}$ and XbaI sites of the pTrc99a (GE Healthcare), pTrc-99a2 and pTrc-99aAF plasmids, respectively. The coding region of HO-HxoDH (hdhA; Genbank accession X65222) was amplified from pTrc-99a and inserted between the NdeI and $X b a \mathrm{I}$ restriction sites of pTrc-99aAF (Aitken et al. 2003). Therefore, the 6-His, affinity tags of the expressed eTD and $\mathrm{HO}-\mathrm{HxoDH}$ proteins are at the N-terminus, while those of eTS and eHSK are C-terminal. Overlap-extension, site-directed mutagenesis was employed to construct the L447F variant of eTD $\left(\mathrm{eTD}_{\mathrm{L} 447 \mathrm{~F}}\right)$. All constructs were sequenced prior to expression and purification of the gene products. The genes encoding eHSK, eTD, eTD ${ }_{\mathrm{L} 447 \mathrm{~F}}$, eTS and HO-HxoDH were expressed in E. coli strain DH10B and purified via Ni-NTA affinity chromatography, as described by Farsi et al. (2009). Following the addition of glycerol, to a final concentration of $30 \%(\mathrm{v} / \mathrm{v})$, the purified enzymes were aliquoted and stored at $-80^{\circ} \mathrm{C}$. Protein concentrations were 
Table 2.1. Primers employed for the eHSK, eTS, eTD, eTD ${ }_{\mathrm{L} 447 \mathrm{~F}}$, and HO-HxoDH expression constructs.

\begin{tabular}{ll}
\hline Primer & Primer \\
\hline eHK Fc-NcoI & 5'-gagtctgccatggttaaagttatgcc \\
eHK-6His Rc-XbaI & 5'-gctctagattaatggtggtgatggtggtggtttccagtactcgtgcgc \\
eTS-Start-NdeI & 5'-gacatatgaaactctacaatctgaaagatca \\
eTS-Stop-SacI & 5'-ggagctcttaatgatggtgatgatgatgctgatgattcatcatcaaattacgca \\
TD 5'c-f-NdeI & 5'-tctcatatggctgactcgcaacccctgtc \\
TD 3'c-r-XbaI & 5'-gcatctagactaacccgccaaaagaaacctgaacgc \\
TD-L447F-F & 5'-tcaccgggcgcgttcctgcgcttcctc \\
TD-L447F-R & 5'-gaggaagcgcaggaacgcgeccggtga \\
HO-HxoDHfc-NdeI & 5'-gactcatatgactaaattgccatgtataatgtc \\
HO-HxoDHrc-XbaI & 5'-gacttctagattacaggttaacgatgcttcttgg \\
\hline
\end{tabular}

${ }^{a}$ Primers employed for site-directed mutagenesis of eTD. 
determined via the Bradford assay (Bio-Rad) using bovine serum albumin as the standard (Bradford, 1976).

\subsubsection{Synthesis of O-phospho-L-homoserine}

The reaction conditions for the phosphorylation of L-HSer were modified from those reported by Laber and colleagues, by reducing the ATP in solution from 5 $\mathrm{mM}$ to $1 \mathrm{mM}$, to facilitate quantification using malachite green hydrochloride (Laber et al. 1994a; Laber et al. 1994b). The 3-mL reaction mixture was comprised of 25 $\mathrm{mM}$ Tris- $\mathrm{HCl}(\mathrm{pH}$ 7.8), $10 \mathrm{mM} \mathrm{MgCl} 2,1 \mathrm{mM} \mathrm{ATP,} 100 \mathrm{mM}$ L-HSer and $100 \mathrm{mM}$ PEP and the reaction was initiated by the addition of $0.2 \mu \mathrm{M}$ PK and $1.2 \mu \mathrm{M}$ eHSK. An identical aliquot of both enzymes was added after 2 hours and the reaction was incubated at $25^{\circ} \mathrm{C}$ for a further 22 hours before being applied to a $20-\mathrm{mL}$ column $(2.5$ $\mathrm{cm} \times 10 \mathrm{~cm}$ ) of DEAE anion exchange resin. The column was subsequently washed with $100 \mathrm{~mL}$ of water and the OPHS was eluted with a $100 \mathrm{~mL}$ linear gradient of 0 $200 \mathrm{mM} \mathrm{NaCl}$ and collected in $3.5-\mathrm{mL}$ fractions, with the OPHS generally eluting between fractions $15-23$. The amino acid content of the fractions was determined by reaction with ninhydrin, following separation by thin layer chromatography using $70 \%$ isopropanol. Fractions containing OPHS were tested for residual pyruvate by reaction with $20 \mu \mathrm{M} \mathrm{HO}-\mathrm{HxoDH}$ and $1.5 \mathrm{mM} \mathrm{NADH}$, as the presence of pyruvate, produced from PEP, will increase background in the eTS coupled assay. Fractions containing OPHS and pyruvate were pooled, reapplied to the DEAE column and separated under the same conditions. All fractions containing OPHS, but not pyruvate, generally fractions $20-25$, were pooled and concentrated by rotary 
evaporation. The concentration of OPHS was determined via the malachite green assay, following treatment with CIAP $(1 \mathrm{mg} / \mathrm{mL})$ for 5-6 hours at room temperature to release the phosphate moiety of OPHS (Lanzetta et al. 1979; van Veldhoven and Mannaerts, 1987). Ammonium molybdate was added, to a final concentration of $0.6 \%$ $(\mathrm{v} / \mathrm{v})$, and samples were incubated at room temperature for 10 minutes. Malachite green was subsequently added to a final concentration of $0.006 \%$ (v/v), and samples were incubated at room temperature for a further 10 minutes. Absorbance was measured at $620 \mathrm{~nm}$, and the concentration of released phosphate was determined by comparison to a standard curve of 0-50 $\mu \mathrm{M}$ inorganic phosphate.

\subsubsection{Enzyme Assays}

All enzyme assays were performed in a total volume of $100 \mu \mathrm{L}$ at $25^{\circ} \mathrm{C}$ and monitored at $340 \mathrm{~nm}$ using a SpectraMax spectrophotometer. Unless otherwise stated, the assay solution was comprised of $50 \mathrm{mM}$ HEPES ( $\mathrm{pH} 8.0$ ) and $1.5 \mathrm{mM}$ NADH. Pyridoxal 5'-phosphate (PLP) was added to a final concentration of $20 \mu \mathrm{M}$ for assays involving the PLP-dependent enzymes eTD and eTS. All reactions were equilibrated with coupling enzyme(s) at $25^{\circ} \mathrm{C}$ and a background rate was recorded prior to initiation of the reaction by the addition of the enzyme being assayed. The reduction of $\alpha-\mathrm{KB}(0.35-60 \mathrm{mM})$ to 2-hydroxybutyrate by $\mathrm{HO}-\mathrm{HxoDH}(0.14 \mu \mathrm{M})$ was detected by the concomitant conversion of NADH to $\operatorname{NAD}^{+}\left(\varepsilon_{340}=6,200 \mathrm{M}^{-1} \mathrm{~s}^{-1}\right)$. The deamination of L-Thr $(0.2-80 \mathrm{mM})$ by eTD and $\operatorname{eTD}_{\mathrm{L} 447 \mathrm{~F}}(0.07 \mu \mathrm{M})$ was similarly monitored, using HO-HxoDH $(5.1 \mu \mathrm{M})$ as the coupling enzyme, both in the presence and absence of $0.5 \mathrm{mM} \mathrm{L-Val}$, an allosteric activator of wild-type eTD (Eisenstein, 
1991). The production of L-Thr from OPHS $(0.05-8 \mathrm{mM})$ by eTS $(0.14 \mu \mathrm{M})$ was also detected as the conversion of NADH to $\mathrm{NAD}^{+}$, using the continuous assay employing $\operatorname{eTD}_{\mathrm{L} 447 \mathrm{~F}}(2.6 \mu \mathrm{M})$ and $\mathrm{HO}-\mathrm{HxoDH}(8.2 \mu \mathrm{M})$ as coupling enzymes (Figure 2.1). Homoserine kinase activity was monitored using the PK/LDH coupled assay (Theze et al. 1974). The eHSK assay mixture contained $25 \mathrm{mM}$ Tris- $\mathrm{HCl}(\mathrm{pH} 7.8), 10 \mathrm{mM}$ $\mathrm{MgCl}_{2}, 4.8 \mathrm{mM}$ PEP, $1.5 \mathrm{mM}$ NADH, $2.5 \mathrm{mM}$ ATP and 0.03-4.8 mM L-HSer, or 0.03-4.8 mM ATP and 1.5 mM L-HSer, $0.96 \mu \mathrm{M}$ PK and 1.2 $\mu \mathrm{M}$ LDH. Reactions were initiated by the addition of $1 \mu \mathrm{M}$ eHSK and the production of OPHS from LHSer was detected via the recycling of ADP to ATP by PK, coupled with the reduction of pyruvate to lactate by $\mathrm{LDH}$, with the concomitant conversion of NADH to $\mathrm{NAD}^{+}$.

The $k_{c a t}$ and $K_{m}$ of HO-HxoDH, eTD $\mathrm{L}_{\mathrm{L} 44 \mathrm{~F}}$, and eTS were determined by fitting the data to the Michaelis-Menten equation, and the $k_{c a t} / K_{m}$ values were obtained independently from equation 2.1.

$$
\frac{v}{[E]}=\frac{k_{c a t} / K_{m}[S]}{1+[S] / K_{m}}
$$

Values for $k_{c a t}$ and $K_{m}^{\mathrm{L}-\mathrm{Thr}}$ of eTD, which exhibits cooperative binding at low L-Thr concentrations, were obtained by fitting the data to equation 2.2 .

$$
\frac{v}{[E]}=\frac{k_{c a t}[S]^{n}}{K_{m}{ }^{n}+[S]^{n}}
$$


The $k_{\text {cat }}$ and $K_{m}{ }^{\text {ATP }}$ values of eHSK were obtained by fitting the data to the MichaelisMenten equation, while $K_{m}{ }^{\mathrm{L}-\mathrm{HSer}}$ was determined from equation 2.3, which incorporates the $K_{i}^{\mathrm{L}-\mathrm{HSer}}$ term for substrate inhibition of eHSK by L-HSer.

$$
\frac{v}{[E]}=\frac{k_{c a t}[S]}{K_{m}+[S]\left(1+[S] / K_{i}^{L-H s e r}\right)}
$$

\subsubsection{Evaluation of the $\mathrm{pH}$ dependence of $\mathrm{HO}-\mathrm{HxoDH}$, eTD $\mathrm{L}_{447 F}$, and eTS}

The $\mathrm{pH}$ dependence of the reactions catalyzed by HO-HxoDH, eTD $\mathrm{L}_{447 \mathrm{~F}}$ and eTS was determined in the three-component MBP buffer (50 mM MOPS, $\mathrm{p} K_{a}=7.2$; $50 \mathrm{mM}$ bicine, $\mathrm{p} K_{a}=8.3 ; 50 \mathrm{mM}$ L-Pro, $\left.\mathrm{p} K_{a}=10.7\right)$ (Perrachi et al. 1996). The activity of $\mathrm{HO}-\mathrm{HxoDH}(0.83-26.6 \mu \mathrm{M})$ was measured between $\mathrm{pH}$ 6.2-10.6 in MBP assay buffer containing $0.22-55 \mathrm{mM} \alpha-\mathrm{KB}$ and $1.5 \mathrm{mM}$ NADH. The $\mathrm{pH}$ dependence of $\mathrm{eTD}_{\mathrm{L} 447 \mathrm{~F}}$ was determined between $\mathrm{pH} 7.2-10.6$ in a reaction mixture comprising 0.6-90 mM L-Thr, 1.5 mM NADH, $20 \mu \mathrm{M}$ PLP, 15-20 $\mu \mathrm{M}$ HO-HxoDH, and 0.07 $\mu \mathrm{M}$ eTD $\mathrm{L} 447 \mathrm{~F}_{\text {. The }}$ The effect of $\mathrm{pH}$ on the catalytic efficiency of eTS was determined between $\mathrm{pH} 6.8-10.5$ in a reaction mixture comprising $0.1-8 \mathrm{mM}$ OPHS, $1.5 \mathrm{mM}$

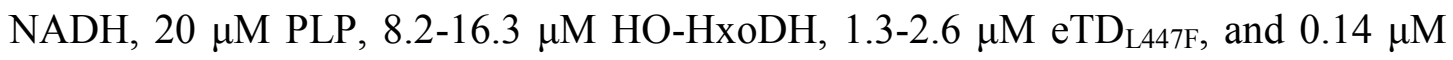
eTS. The concentration of the HO-HxoDH and eTD $\mathrm{T}_{\mathrm{L} 47 \mathrm{~F}}$ coupling enzymes were optimized and the measured activity was shown to be linearly dependent on eTS concentration across the $\mathrm{pH}$ range investigated. The $k_{\text {cat }} / K_{m}$ versus $\mathrm{pH}$ data for eTD $_{\text {L447F }}$ and eTS were fitted to the bell-shaped curve described by equation 2.4 , and the $\mathrm{pH}$ dependence of the $k_{\text {cat }} / K_{m}$ of $\mathrm{HO}-\mathrm{HxoDH}$ was fitted to the curve described by equation 2.5 (Aitken et al. 2003). 


$$
\begin{gathered}
\frac{k_{c a t}}{K_{m}}=\frac{\left(k_{c a t} / K_{m}\right)_{\max }}{1+10^{p K_{a 1}-p H}+10^{p H-p K_{a 2}}} \\
\frac{k_{c a t}}{K_{m}}=\frac{\left(k_{c a t} / K_{m}\right)_{\max }}{1+10^{p H-p K_{a 2}}}
\end{gathered}
$$

\subsection{Results}

All enzymes were recombinantly expressed in fusion with a 6-His tag, to enable purification via Ni-NTA affinity chromatography, and their purity was verified

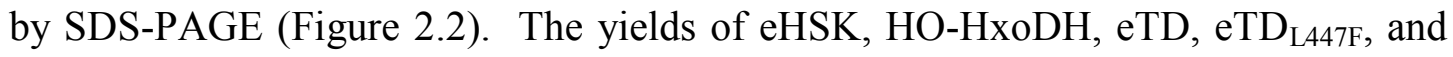
eTS were 19, 24, 33, 16 and 23 mg per 1L of E. coli culture, respectively.

\subsubsection{Synthesis and separation of OPHS:}

The $K_{m}{ }^{\text {ATP }}(0.19 \mathrm{mM}), K_{m}{ }^{\mathrm{L}-\mathrm{HSer}}(0.8 \mathrm{mM})$ and $K_{i}^{\mathrm{L}-\mathrm{HSer}}(3.5 \mathrm{mM})$ values determined for eHSK are within 2.5-fold of those previously reported, demonstrating that the C-terminal, 6-His affinity tag has negligible effect on the enzyme (Theze et al. 1974; Shames and Wedler 1984). The use of the malachite green assay for quantification of OPHS requires treatment with CIAP to release the phosphate moiety. Separation of OPHS from residual pyruvate, produced from PEP by PK, is not required for the malachite green or $\left[{ }^{1} \mathrm{H}\right]-\mathrm{OPHS}$ endpoint assays, but is essential for the continuous TD/HO-HxoDH assay as pyruvate is converted to lactate by HO$\mathrm{HxoDH}$, thereby resulting in increased background and the possibility of overestimating TS activity. Therefore, the OPHS synthesis method reported by Laber 
Figure 2.2. SDS-PAGE of the purified recombinant enzymes. Lane $1-E$. coli HSK $(\mathrm{MW}=30 \mathrm{kDa})($ Burr et al. 1976); Lane $2-$ E. coli TS (MW $47 \mathrm{kDa})$ (Parsot et al. 1983); Lane $3-$ E. coli $\mathrm{TD}(\mathrm{MW}=56 \mathrm{kDa})$ (Eisenstein, 1991); Lane $4-$ E. coli $\mathrm{TD}_{\mathrm{L} 447 \mathrm{~F}}(\mathrm{MW}=56 \mathrm{kDa})$ (Eisenstein, 1991); Lane 5 - L. delbrueckii HO-HxoDH $(\mathrm{MW}=36 \mathrm{kDa})($ Bernard et al. 1994); Lane 6 - Benchmark protein ladder (Invitrogen). Molecular markers are indicated at $50 \mathrm{kDa}$ and $20 \mathrm{kDa}$. 


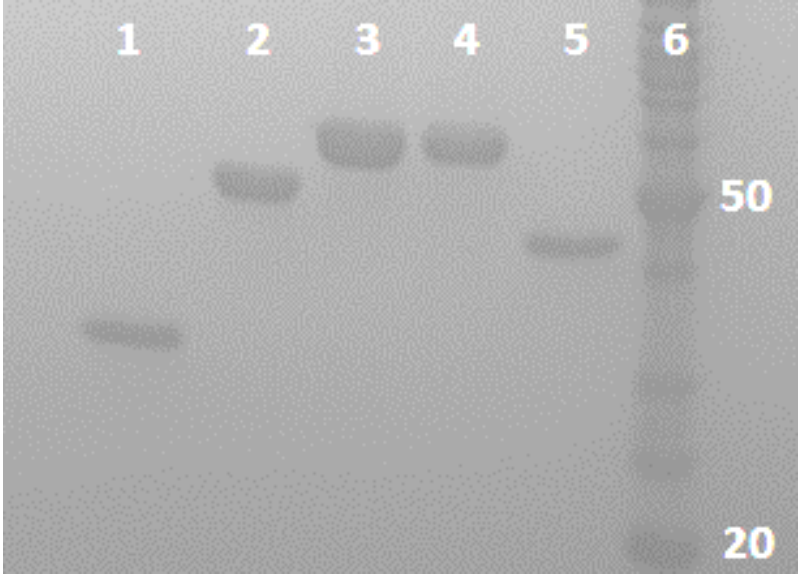


and colleagues was modified to reduce the ATP concentration from $5 \mathrm{mM}$ to $1 \mathrm{mM}$ to minimize the effect of the $\alpha$ and $\beta$ phosphates of ADP, also released by CIAP treatment, on the accuracy of OPHS quantification, and the OPHS purification procedure was optimized to ensure the separation of OPHS from pyruvate (Laber et al. 1994a; Laber et al. 1994b). The presence of OPHS following separation, via anion exchange chromatography, was confirmed by TLC analysis, and by reaction with eTS, and fractions were tested with $\mathrm{HO}-\mathrm{HxoDH}$ to ensure pyruvate was not present (Figure 2.3). Rotary evaporation was employed to concentrate the purified OPHS to $\sim 25-30 \mathrm{mM}$, for use in eTS enzyme assays.

\subsubsection{Optimization of Assay Parameters}

The steady-state kinetic parameters of eTD, eTD $\mathrm{L}_{447 \mathrm{~F}}$, and $\mathrm{HO}-\mathrm{HxoDH}$ were determined under eTS assay conditions (Table 2.2) and the effect of $0.5 \mathrm{mM} \mathrm{L}-\mathrm{Val}$ on eTD activity was investigated $\left(\mathrm{eTD}_{\mathrm{Val}}\right)$. The $K_{m}{ }^{\mathrm{L}-\mathrm{Thr}}$ values of eTD $(10.6 \mathrm{mM})$ and eTD ${ }_{\text {Val }}(11.7 \mathrm{mM})$ are within 2-fold of the reported $K_{m}{ }^{\mathrm{L}-\mathrm{Thr}}$ values of $8 \mathrm{mM}$ and 5.7 $\mathrm{mM}$, respectively (Eisenstein, 1991). The $K_{m}{ }^{\mathrm{L}-\mathrm{Thr}}$ value of eTD $\mathrm{T}_{\mathrm{L} 447 \mathrm{~F}}(5.7 \mathrm{mM})$, which displays Michaelis-Menten behavior and is not allosterically activated by L-Val, is identical to the reported value for this site-directed variant (Eisenstein et al. 1995). The $k_{\text {cat }} / K_{m}{ }^{\alpha-\mathrm{KB}}$ for the reduction of $\alpha-\mathrm{KB}$ to 2 -hydroxybutyrate by the N-terminally, 6-His tagged HO-HxoDH at $\mathrm{pH} 8.0$ is $1.2 \times 10^{4} \mathrm{M}^{-1} \mathrm{~s}^{-1}$, which is in agreement with the reported values of $2.6 \times 10^{4} \mathrm{M}^{-1} \mathrm{~s}^{-1}$, for the wild-type enzyme (Bernard et al. 1994), and $1.6 \times 10^{4} \mathrm{M}^{-1} \mathrm{~s}^{-1}$ (Aitken et al. 2003), for the C-terminally 6-His tagged enzyme, both assayed at $\mathrm{pH} 7.5$. 
Figure 2.3. Verification of OPHS production by eHSK by thin-layer chromatography. Lane $1-10 \mathrm{mM}$ L-homoserine standard $\left(\mathrm{R}_{\mathrm{f}}=0.62\right)$; Lane $2-$ OPHS, product of eHSK reaction, $\left(\mathrm{R}_{\mathrm{f}}=0.36\right)$; Lane 3 - OPHS sample treated with CIAP for 6 hrs, to produce L-HSer and inorganic phosphate, $\left(\mathrm{R}_{\mathrm{f}}=0.62\right)$; Lane $4-10$ $\mathrm{mM} \mathrm{L-Thr} \mathrm{standard}\left(\mathrm{R}_{\mathrm{f}}=0.62\right)$; Lane 5 - OPHS sample following reaction with eTS, to produce $\mathrm{L}-\mathrm{Thr},\left(\mathrm{R}_{\mathrm{f}}=0.62\right)$. Chromatography was performed using $70 \%$ isopropanol. 


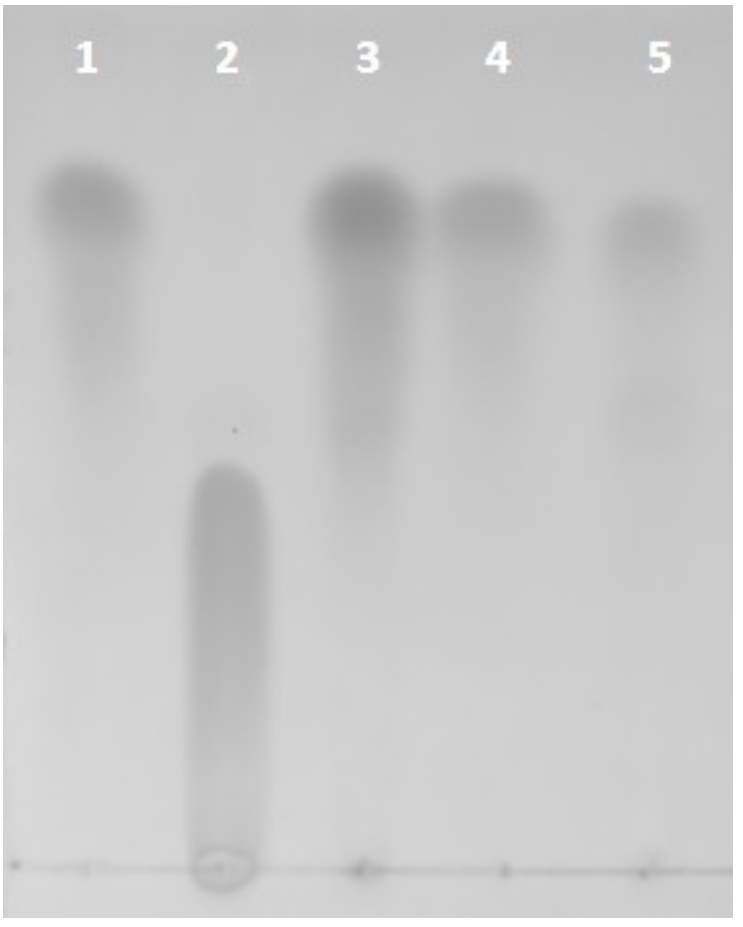


Table 2.2. Kinetic parameters of $E$. coli threonine synthase (eTS), homoserine kinase (eHSK), threonine deaminase (eTD) and the site-directed variant eTD $\mathrm{L}_{447 \mathrm{~F}}$, and $L$. delbrueckii hydroxyisocaproate dehydrogenase (HO-HxoDH). ${ }^{a}$

\begin{tabular}{llll}
\hline Enzyme & $K_{\mathrm{M}}(\mathrm{mM})$ & $k_{\text {cat }}\left(\mathrm{s}^{-1}\right)$ & $k_{\text {cat }} / K_{\mathrm{M}}\left(\mathrm{M}^{-1} \mathrm{~s}^{-1}\right)$ \\
\hline eHSK & $0.19 \pm 0.01(\mathrm{ATP})$ & $4.3 \pm 0.06$ & $(2.3 \pm 0.13) \times 10^{4}$ (ATP) \\
& $0.8 \pm 0.1(\mathrm{~L}-\mathrm{HSer})$ & $8.8 \pm 0.6$ & $(1.1 \pm 0.05) \times 10^{4}$ (L-HSer) \\
HO-HxoDH & $3.6 \pm 0.2(\alpha-\mathrm{kb})$ & $42.4 \pm 0.7$ & $(1.2 \pm 0.7) \times 10^{4}(\alpha-\mathrm{kb})$ \\
eTD & $10.6 \pm 0.4(\mathrm{~L}-\mathrm{Thr})$ & $51.6 \pm 1.4$ & $4.9 \times 10^{3}(\mathrm{~L}-\mathrm{Thr})$ \\
eTD $_{\text {Val }}$ & $11.7 \pm 0.7(\mathrm{~L}-\mathrm{Thr})$ & $66.1 \pm 1.3$ & $(5.6 \pm 0.2) \times 10^{3}$ (L-Thr) \\
eTD & $5.7 \pm 0.4(\mathrm{~L}-\mathrm{Th}$ ) & $42.1 \pm 0.8$ & $(7.3 \pm 0.4) \times 10^{3}$ (L-Thr $)$ \\
eTS & $0.34 \pm 0.04(\mathrm{OPHS})$ & $4.0 \pm 0.1$ & $(1.2 \pm 0.1) \times 10^{4}$ (OPHS) \\
\hline
\end{tabular}

${ }^{a}$ The 6-His, affinity tag of eHSK and eTS are C-terminal, while those of HO-HxoDH, eTD and eTD $\mathrm{L}_{447 \mathrm{~F}}$ are N-terminal. The assay solution for HO-HxoDH, eTS, eTD and $\mathrm{eTD}_{\mathrm{L} 447 \mathrm{~F}}$ was comprised of $50 \mathrm{mM}$ HEPES (pH 8.0) and $1.5 \mathrm{mM} \mathrm{NADH}$ and $20 \mu \mathrm{M}$ PLP, for eTD and eTS enzymes. The substrate and enzyme concentrations for HO$\mathrm{HxoDH}$ and eTD assays were $0.35-60 \mathrm{mM} \alpha-\mathrm{KB}$ and $0.14 \mu \mathrm{M} \mathrm{HO}-\mathrm{HxoDH}$, and 0.2$80 \mathrm{mM}$ L-Thr and $0.07 \mu \mathrm{M}$ eTD or eTD $\mathrm{L}_{447 \mathrm{~F}}$, with $5.1 \mu \mathrm{M}$ HO-HxoDH coupling enzyme, respectively. The substrate and enzyme concentrations for the eTS assay were 0.05-8 mM OPHS and 0.14 $\mu \mathrm{M}$ eTS with $2.6 \mu \mathrm{M}_{\mathrm{eTD}} \mathrm{L}_{447 \mathrm{~F}}$ and $8.2 \mu \mathrm{M}$ HO$\mathrm{HxoDH}$. Homoserine kinase $(1 \mu \mathrm{M})$ activity was monitored in $25 \mathrm{mM}$ Tris- $\mathrm{HCl}(\mathrm{pH}$ 7.8), $10 \mathrm{mM} \mathrm{MgCl}_{2}$, 4.8 mM PEP, 1.5 mM NADH, 2.5 mM ATP and 0.03-4.8 mM LHSer, or 0.03-4.8 mM ATP and 1.5 mM L-HSer, 0.96 $\mu \mathrm{M}$ PK and 1.2 $\mu \mathrm{M} \mathrm{LDH.}$

${ }^{b}$ Kinetic parameters determined in the presence of $0.5 \mathrm{mM}$ of the allosteric activator LVal. 
The concentration of HO-HxoDH required in the continuous $\mathrm{eTD}_{\mathrm{L} 447 \mathrm{~F}}$ assay, assuming a short lag period $(\tau=4 \mathrm{~s}$ ), was calculated to be $13 \mu \mathrm{M}$ (equation 2.6) (Aitken et al. 2003).

$$
[H O-H x o D H]=\frac{K_{m}^{\alpha-K B}}{k_{c a t}{ }^{H O-H x o D H} \tau}
$$

This value was employed to determine that an $\mathrm{eTD}_{\mathrm{L} 447 \mathrm{~F}}$ concentration of $11.3 \mu \mathrm{M}$ is required for the eTS assay to give an overall lag of $12 \mathrm{~s}$, using eq. 2.7 (Aitken et al. 2003).

$$
\left[e T D_{L 447 F}\right]=\frac{K_{m}^{T h r} / k_{c a t}{ }^{\text {eTD }}}{\tau-\left(K_{m}^{\alpha-K B} / k_{c a t}^{H O-H x o D H}\right)[H O-H x o D H]}
$$

The calculated $\mathrm{HO}-\mathrm{HxoDH}$ and $\mathrm{eTD}_{\mathrm{L} 447 \mathrm{~F}}$ concentrations were subsequently optimized experimentally to 8.2 and $2.6 \mu \mathrm{M}$, respectively, by independently varying the concentration of each enzyme, and the reaction was demonstrated to be linear at eTS concentrations between 0.03-1.6 $\mu \mathrm{M}$ (Figure 2.4). The steady-state kinetic parameters of eTS $\left(k_{\text {cat }}=4 \mathrm{~s}^{-1}\right.$ and $\left.K_{m}{ }^{\text {OPHS }}=0.34 \mathrm{mM}\right)$ were subsequently determined using the $\mathrm{eTD}_{\mathrm{L} 447 \mathrm{~F}} / \mathrm{HO}-\mathrm{HxoDH}$ assay (Table 2.2). The eTS-catalyzed deamination of OPHS was also investigated to determine whether this would be a factor in monitoring the $\beta, \gamma$-replacement activity of this enzyme. However, no conversion of NADH to $\mathrm{NAD}^{+}$was detected when $7.5 \mu \mathrm{M}$ eTS was incubated with $20 \mathrm{mM}$ OPHS, thereby demonstrating that $\alpha$-ketobutyrate is not produced, under assay conditions, by eTS. 
Figure 2.4. Dependence of the rate of NADH oxidation on eTS, (inset A) eTD $\mathrm{L}_{447 \mathrm{~F}}$, and (inset B) $\mathrm{HO}-\mathrm{HxoDH}$ concentration in the coupled $\mathrm{eT}_{\mathrm{L} 447 \mathrm{~F}} / \mathrm{HO}-\mathrm{HxoDH}$ assay. Reactions were carried out in a volume of $100 \mu \mathrm{L}$ at $25^{\circ} \mathrm{C}$. Reaction conditions: 50 $\mathrm{mM}$ HEPES (pH 8.0), $1.5 \mathrm{mM} \mathrm{NADH}, 20 \mu \mathrm{M}$ PLP and $5 \mathrm{mM}$ OPHS, with (main

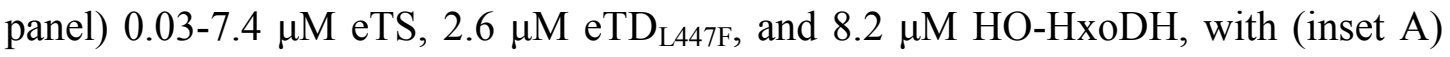
$1.4 \mu \mathrm{M}$ eTS, 0.04-5.25 $\mu \mathrm{M}$ eTD $\mathrm{L}_{447 \mathrm{~F}}$, and $8.2 \mu \mathrm{M}$ HO-HxoDH, or with (inset B) 1.4 $\mu \mathrm{M}$ eTS, $2.6 \mu \mathrm{M}$ eTD $_{\mathrm{L} 447 \mathrm{~F}}$, and 0.12-16.3 $\mu \mathrm{M}$ HO-HxoDH. 


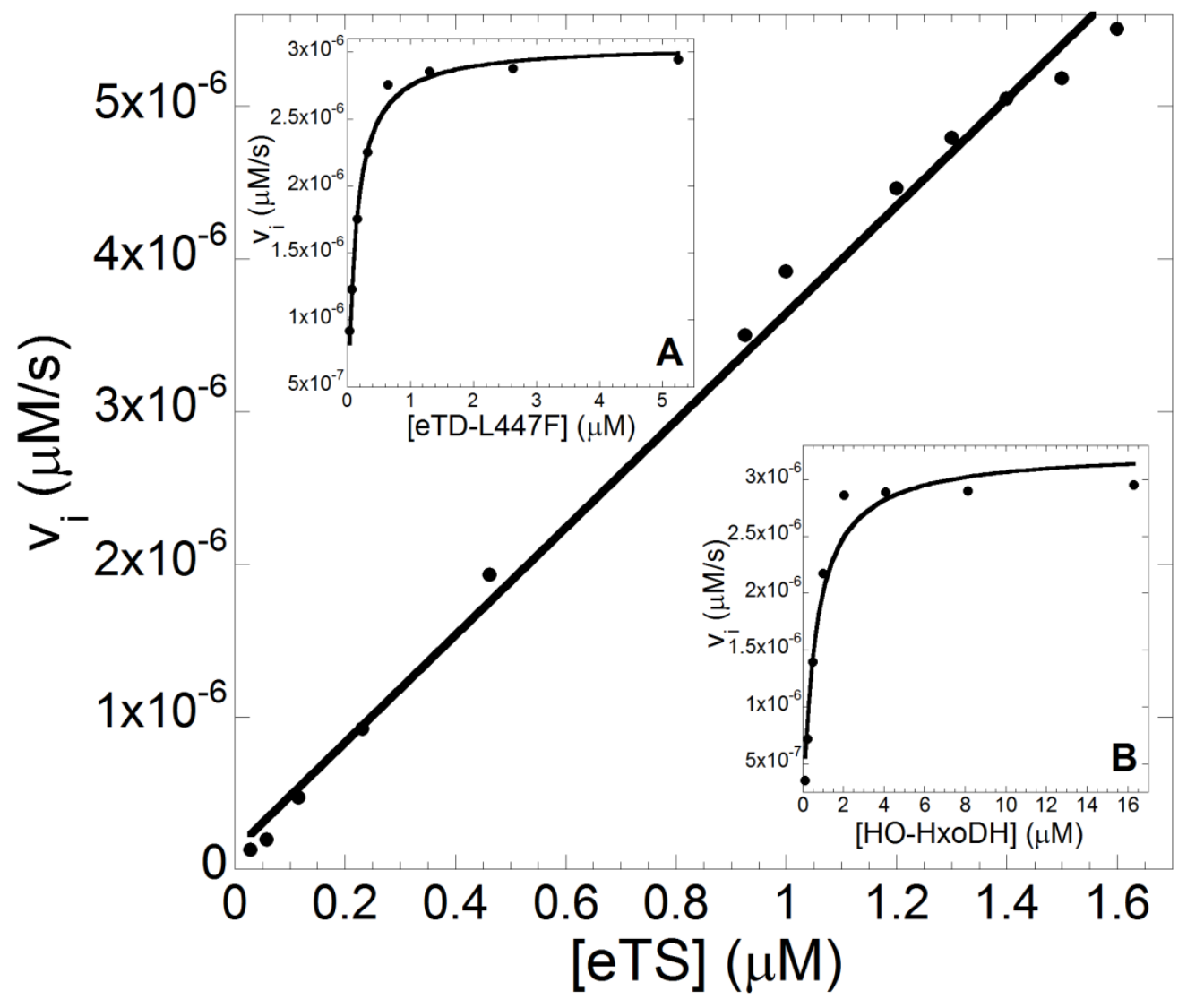




\subsubsection{The $p H$ Dependence of eTS, eTD $D_{L 447 F}$, and HO-HxoDH Activity}

The effect of $\mathrm{pH}$ on the catalytic activity of $\mathrm{HO}-\mathrm{HxoDH}$ and $\mathrm{eTD}_{\mathrm{L} 447 \mathrm{~F}}$ was investigated to assess the suitability of the coupled assay for the steady-state characterization of TS from diverse species, which may have distinct $\mathrm{pH}$ optima, and for investigation of the effect of $\mathrm{pH}$ on the kinetic parameters of eTS (Figure 2.5). The $k_{\text {cat }} / K_{m}$ versus $\mathrm{pH}$ profiles of $\mathrm{eTD}_{\mathrm{L} 447 \mathrm{~F}}\left(\mathrm{p} K_{\mathrm{a} 1}=8.6\right.$ and $\left.\mathrm{p} K_{\mathrm{a} 2}=9.1\right)$ and $\mathrm{HO}-$ HxoDH $\left(\mathrm{p} K_{\mathrm{a}}=7.2\right)$ demonstrate that the $\mathrm{pH}$ optimum of $\mathrm{eTD}_{\mathrm{L} 447 \mathrm{~F}}(\mathrm{pH} 8.8)$ is similar to that of eTS (pH 8.7), while that of HO-HxoDH is $\leq 6.5$. The latter illustrates the importance of optimizing the concentration of coupling enzymes at each $\mathrm{pH}$ in order to reliably determine the effect of $\mathrm{pH}$ on eTS activity. Therefore, the kinetic parameters of the coupling enzymes were employed to calculate their optimal concentration at each $\mathrm{pH}$, using equations 2.6 and 2.7 , and this was subsequently verified experimentally. The $k_{c a t} / K_{m}$ versus $\mathrm{pH}$ data for eTS was fit to eq. 2.4 , and $\mathrm{pH}$ optimum, $\mathrm{p} K_{\mathrm{a} 1}$ and $\mathrm{p} K_{\mathrm{a} 2}$ values of 8.7, 7.1 and 10.4 were determined (Figure 2.6). 
Figure 2.5. The $\mathrm{pH}$ dependencies of $k_{\text {cat }} / K_{m}$ of $L$. delbrueckii HO-HxoDH and E. coli $\mathrm{TD}_{\mathrm{L} 447 \mathrm{~F}}\left(\mathrm{eTD}_{\mathrm{L} 447 \mathrm{~F}}\right)$. Reaction conditions: Bicine-MOPS-Proline buffer $(50 \mathrm{mM}$ bicine, $50 \mathrm{mM}$ MOPS, $50 \mathrm{mM}$ L-Pro), $1.5 \mathrm{mM}$ NADH. For HO-HxoDH (closed circles), $0.22-55 \mathrm{mM} \alpha$-ketobutyrate, and $0.83-26.6 \mu \mathrm{M}$ enzyme were added to the reaction mixture. For eTD $\mathrm{L}_{447 \mathrm{~F}}$ (open circles), $20 \mu \mathrm{M}$ PLP, 0.6-90 mM L-Thr, 15-20 $\mu \mathrm{M}$ HO-HxoDH, and $0.07 \mu \mathrm{M}$ eTD $\mathrm{L} 447 \mathrm{~F}$ were added to the reaction mixture. 


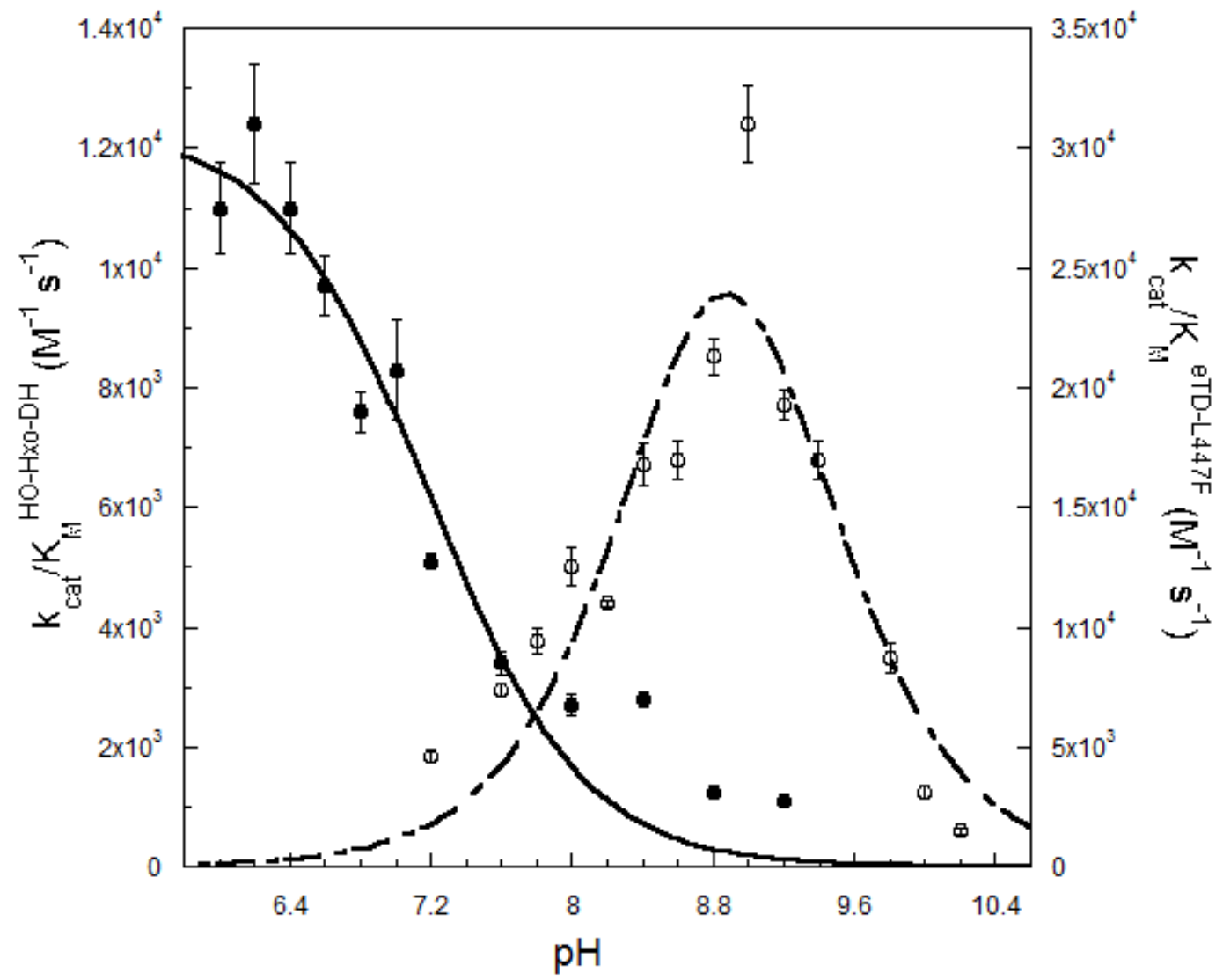


Figure 2.6. The $\mathrm{pH}$ dependence of $k_{c a t} / K_{m}{ }^{O P H S}$ of eTS. Reaction conditions: BicineMOPS-Proline buffer (50 mM bicine, 50 mM MOPS, 50 mM L-Pro), 1.5 mM NADH, $20 \mu \mathrm{M}$ PLP, 0.1-8 mM OPHS, 8.2-16.3 $\mu \mathrm{M}$ HO-HxoDH, 1.3-2.6 $\mu \mathrm{M}$ eTD $\mathrm{L}_{\mathrm{L} 44 \mathrm{~F}}$ and $1.4 \mu \mathrm{M}$ eTS. 


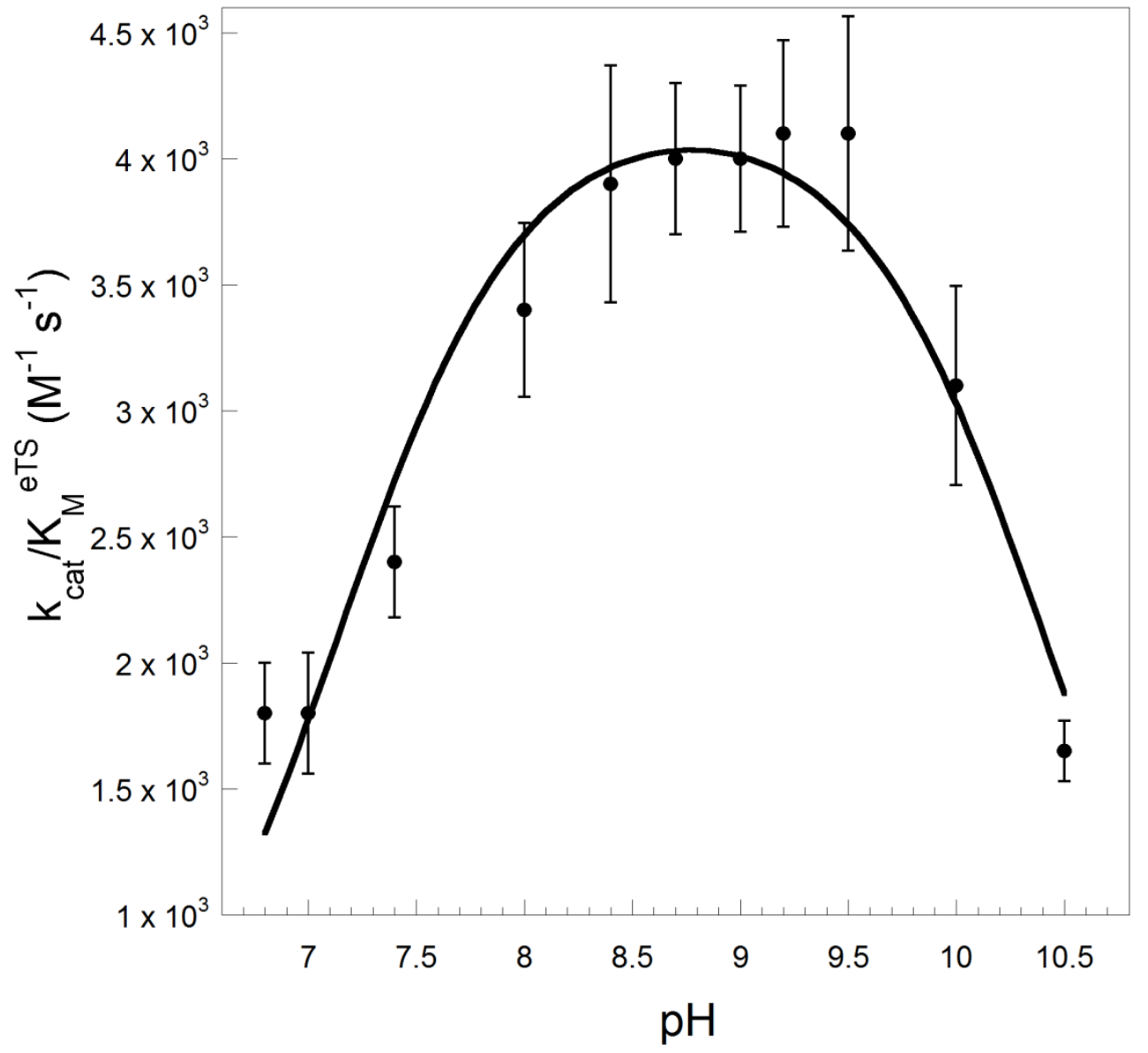




\subsection{Discussion}

The restriction of TS to plants and microorganisms, which synthesize L-Thr de novo, provides a suitable target for many biotechnological applications, including the development of antibiotics and herbicides and metabolic engineering to produce crop varieties with increased nutritional value (Thomazeau et al. 2001; Covarrubias et al. 2008). In plants, OPHS occupies the branch point between the L-Thr and L-Met biosynthetic pathways (Ravanel et al. 1998b). Manipulation of the metabolic flux of either pathway, suggested as a strategy to increase the L-Met content of crop species deficient in this essential amino acid, requires an in-depth knowledge of the kinetic and regulatory properties of the enzymes involved (Curien et al. 2003). Therefore, an efficient, reliable, and robust continuous assay for the measurement of TS activity is necessary to enhance our understanding of this enzyme, and to provide a starting point for biotechnological applications.

A continuous, spectrophotometric TS assay was developed in this study with the goal of providing a rapid and rigorous method to investigate TS kinetic parameters. The proposed mechanism of the $\beta, \gamma$-replacement reaction catalyzed by TS has been described by Laber and coworkers (Figure 2.7) (Laber et al. 1994a). An enzymatic method for the synthesis of the OPHS substrate was optimized for compatibility with this assay. Chemical and enzymatic methods for the synthesis of OPHS have been reported (Watanabe and Shimura, 1955; Wormser and Pardee, 1958; Flavin and Slaughter, 1960; Schildkraut and Greer, 1973; Skarstedt and Greer, 1973; Datko et al. 1974; Schnyder and Rottenberg, 1975; Madison and Thompson, 
Figure 2.7. The proposed mechanism of the $\beta, \gamma$-replacement reaction catalyzed by threonine synthase (Laber et al. 1994a). 1, PLP in Schiff base linkage with the active site lysine of AtTS1 (internal aldimine); 2, transaldimination of PLP with OPHS forming the external aldimine; 3, quinonoid intermediate of OPHS and PLP; 4, $\gamma$-elimination of phosphate group; 5, PLP-quinonoid intermediate gains a proton at $\mathrm{C} \gamma$; and $\mathbf{6}$, formation of L-threonine through the addition of a hydroxyl group at $\mathrm{C} \beta$, and release through reverse transaldimination reaction. 

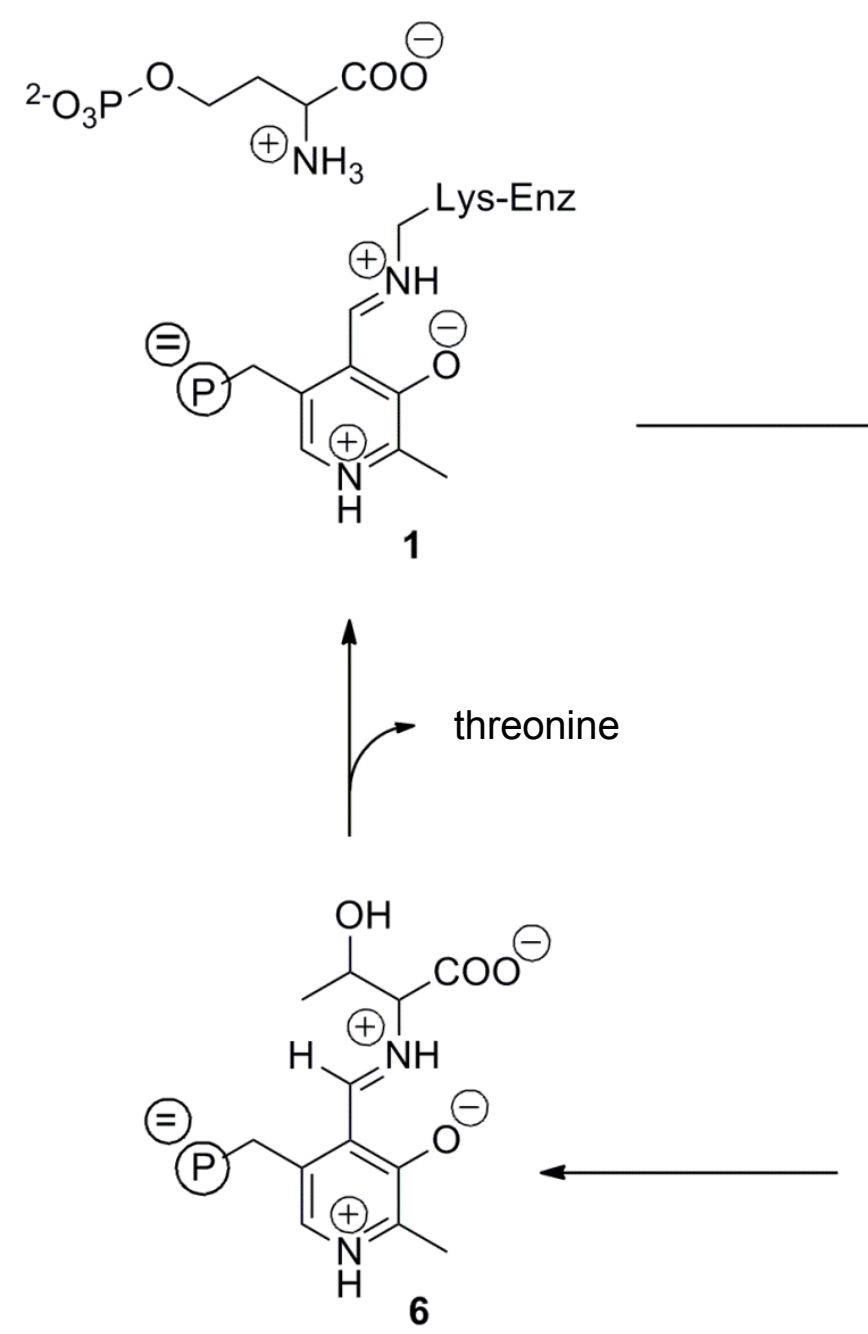
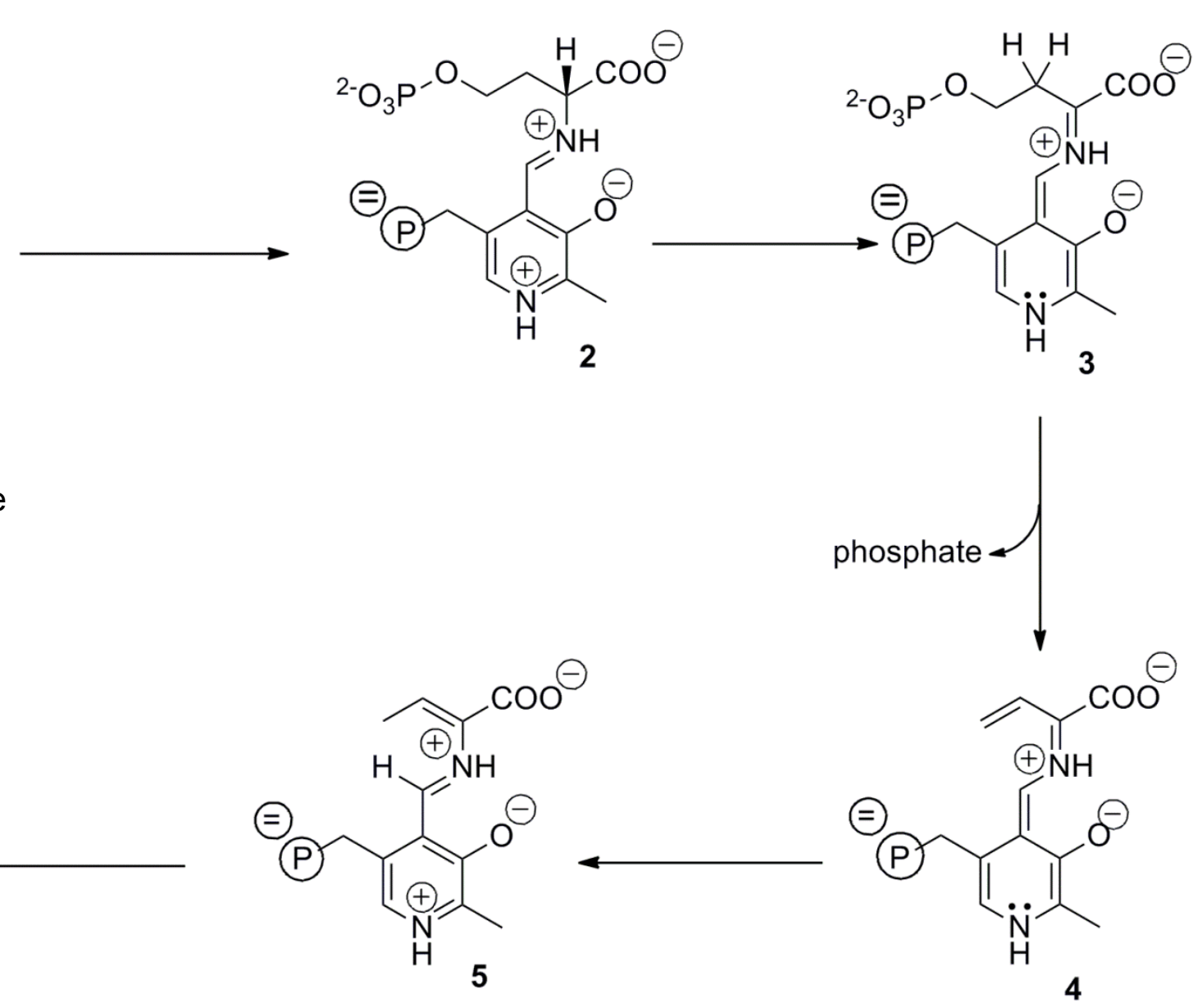
1976; Szczesiul and Wampler, 1976; Thoen et al. 1978; Giovanelli et al. 1984; Farrington et al. 1993; Laber et al. 1994a; Laber et al. 1994b; Ramos and Calderon, 1994; Ravanel et al. 1995; Chassagnole et al. 2001; Rais et al. 2001; Covarrubias et al. 2008). The commercial availability of the L-HSer and ATP substrates, combined with the simplicity of the single-step synthesis catalyzed by HSK, provides a method that is accessible to researchers investigating the properties of TS from a biological perspective. Enzymatic synthesis also has the advantage of allowing small amounts of substrate, sufficient for immediate experimental requirements, to be produced quickly, thereby reducing the need for assessment of substrate stability and purity following storage. However, the reported methods for the enzymatic synthesis, and subsequent purification, of OPHS vary and the necessity to accurately quantify the OPHS produced, as well as the type of TS assay to be employed, must be considered when selecting the appropriate synthetic method. The two primary variables in reported methods are the use of crude cell extracts versus purified HSK, and the addition of PEP and PK to recycle the ATP substrate of HSK (Watanabe and Shimura, 1955; Wormser and Pardee, 1958; Flavin and Slaughter, 1960; Schildkraut and Greer, 1973; Skarstedt and Greer, 1973; Datko et al. 1974; Madison and Thompson, 1976; Szczesiul and Wampler, 1976; Thoen et al. 1978; Giovanelli et al. 1984; Farrington et al. 1993; Laber et al. 1994a; Laber et al. 1994b; Ramos and Calderon, 1994; Ravanel et al. 1995; Chassagnole et al. 2001; Rais et al. 2001). Modern recombinant methods now enable the use of affinity tags, thereby obviating the need for complex purifications and increasing the accessibility of enzymes for the synthesis of a variety of compounds, including substrates. The addition of a carboxy- 
terminal, 6-His, affinity tag to eHSK was shown to have negligible effect on the kinetic parameters of the enzyme, demonstrating that it is suitable for use in the preparation of the OPHS substrate of TS. Although synthesis of OPHS from equimolar amounts of L-HSer and ATP is the simplest enzymatic method, requiring only HSK, the difficulty of separating the ADP and OPHS products can result in overestimation of the concentration of the latter when using the malachite green assay, commonly employed for this purpose, which measures free phosphate and requires that the sample be treated with CIAP to release the phosphate moiety. To circumvent this problem PEP and PK were added to the HSK reaction mixture, as described by Laber and colleagues, to recycle the ADP product to ATP, and the ATP concentration was further reduced from 5 to $1 \mathrm{mM}$ (Laber et al. 1994a; Laber et al. 1994b). The OPHS product was subsequently purified by ion exchange chromatography, to separate it from the pyruvate product of PK and concentrated to 25-30 $\mathrm{mM}$ for use in eTS assays.

Previous investigations of plant and bacterial TS have relied on four end-point assays: (1) detection of the phosphate product via a colorimetric method, such as malachite green (Watanabe and Shimura, 1955; Wormser and Pardee, 1958; Szczesiul and Wampler, 1976; Farrington et al. 1993; Laber et al. 1994a; Laber et al. 1994b; Laber et al. 1999; Chassagnole et al. 2001; Rais et al. 2001; Covarrubias et al. 2008); (2) separation and quantification of the L-Thr product via HPLC (Ramos and Calderon, 1994; Curien et al. 1998; Murakawa et al. 2011); (3) use of a radioactive tracer with subsequent separation of the OPHS substrate and L-Thr product by TLC and quantification of the latter by scintillation counting (Madison and Thompson, 
1976; Thoen et al. 1978) and (4) measurement of the L-Thr product via periodate oxidation (Flavin and Slaughter, 1960; Schildkraut and Greer, 1973). The eTD $\mathrm{L} 447 \mathrm{~F}_{\mathrm{HO}} / \mathrm{HO}-\mathrm{HxoDH}$ continuous assay described here will facilitate the study of TS by reducing sample handling and eliminating the need for separation of substrates and products or for the use of radioactive tracers in routine applications. A continuous assay also enhances data quality by allowing the collection of larger data sets and ensuring that measurements of initial velocity are not underestimated, thereby resulting in a reduced $k_{c a t}$ value, by mis-selection of sampling time points in endpoint assays. A further advantage is that L-Thr is processed by the coupling enzymes, thereby mimicking steady-state cellular conditions and preventing the overestimation of $K_{m}{ }^{\text {OPHS }}$, as the OPHS substrate and L-Thr product of TS bind to the same enzyme form.

The continuous TS assay described in the current study employs two coupling enzymes, eTD $\mathrm{L}_{\mathrm{L} 44 \mathrm{~F}}$ and $\mathrm{HO}-\mathrm{HxoDH}$, and monitors the production of L-Thr via a decrease in absorbance at $340 \mathrm{~nm}$ as $\alpha-\mathrm{KB}$, the product of $\mathrm{L}-\mathrm{Thr}$ deamination by eTD ${ }_{\mathrm{L} 447 \mathrm{~F}}$, is reduced by HO-HxoDH with the concomitant oxidation of NADH. A continuous method for studying the flux of OPHS, the branch-point metabolite between the L-Thr and L-Met biosynthetic pathways of $A$. thaliana, has been described, in which TS was coupled with TD and LDH (Curien et al. 2003). However, the TD/LDH system employed to simulate and monitor metabolic flux was not optimized for the determination of TS kinetic parameters and although these enzymes provided a useful method to mimic metabolic flux, they are not optimal for the development of a continuous TS assay. The enzyme HO-HxoDH is a more 
appropriate selection than LDH for this purpose because the catalytic efficiency of the latter for $\alpha-\mathrm{KB}\left(k_{\text {cat }} / K_{m}{ }^{\alpha-\mathrm{KB}}=1.8 \times 10^{3} \mathrm{M}^{-1} \mathrm{~s}^{-1}\right)$ is an order of magnitude lower than that of HO-HxoDH (Table 2.2) (Aitken et al. 2003). Additionally, the wild-type eTD enzyme is not suitable because it displays a sigmoidal response to substrate at L-Thr concentrations in the micromolar to low-millimolar range, a factor that limits its usefulness as a coupling enzyme, as maximal responsiveness to the product of the target enzyme, L-Thr in the case of TS, is required for an effective continuous assay. In contrast, the L447F site-directed variant of this enzyme exhibits Michaelis-Menten

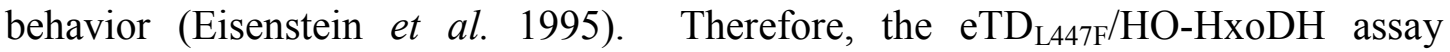
described in this paper is well suited to the measurement of TS activity. The close agreement between the kinetic parameters of both coupling enzymes (Table 2.2) and the reported values demonstrate that the addition of a 6-His, affinity tag, to facilitate purification of the coupling enzymes, is well tolerated and does not affect their use for the continuous TS assay. In order to validate this assay, the kinetic parameters of eTS obtained (Table 2.2) were compared to those previously reported. The $K_{m}{ }^{\text {OPHS }}$ of $0.34 \mathrm{mM}$ and the $k_{\text {cat }}$ of $4 \mathrm{~s}^{-1}$ determined are within 2-fold of the reported values of $0.5 \mathrm{mM}$ and $7.3 \mathrm{~s}^{-1}$, respectively, and the $k_{\text {cat }} / K_{m}{ }^{\text {OPHS }}$ of $1.2 \times 10^{4} \mathrm{M}^{-1} \mathrm{~s}^{-1}$ is almost within experimental error of the value of $1.5 \times 10^{4} \mathrm{M}^{-1} \mathrm{~s}^{-1}$, obtained using the standard malachite green assay (Laber et al. 1994a). This comparison demonstrates the effectiveness of the eTD $\mathrm{L}_{\mathrm{L} 47 \mathrm{~F}} / \mathrm{HO}-\mathrm{HxoDH}$ assay and that the addition of the $\mathrm{C}$ terminal 6-His tag does not alter the kinetic parameters of eTS. The slight reduction in the $K_{m}{ }^{\text {OPHS }}$ value of eTS reported here may result from the relief of product inhibition by the $\mathrm{eTD}_{\mathrm{L} 447 \mathrm{~F}} / \mathrm{HO}-\mathrm{HxoDH}$ coupled assay. 
The $\mathrm{eTD}_{\mathrm{L} 447 \mathrm{~F}} / \mathrm{HO}-\mathrm{HxoDH}$ assay was optimized at $\mathrm{pH} 8$ to enable comparison to reported kinetic parameters for eTS, as this enzyme has been found to display maximal activity between pH 8-8.5 (Sczcesiul and Wampler, 1976; Laber et al. 1994a; Laber et al. 1994b). The effect of $\mathrm{pH}$ on the kinetic parameters of eTD $\mathrm{L}_{\mathrm{L} 47 \mathrm{~F}}$ and HO-HxoDH was also determined in order to estimate the concentration of each enzyme required under a range of TS assay conditions. The concentrations of the coupling enzymes determined using equations 2.6 and 2.7 were within 5 -fold of the experimentally determined values, thereby facilitating the optimization of TS assay conditions (Figure 2.4). The $\mathrm{pH}$ profiles of the coupling enzymes determined in this study will facilitate the optimization of this assay to study TS from other species, which may have distinct $\mathrm{pH}$ optima. The effect of $\mathrm{pH}$ on the activity of HO-HxoDH has not been previously reported. However, the $\mathrm{pH}$ optimum of $\leq 6.5$ determined for HO-HxoDH is consistent with the observation that many enzymes from L. delbrueckii display optimal activity in the $\mathrm{pH}$ range of 5.5-6.8 (Laloi et al. 1991; Bockelmann et al. 1995; Bourniquel et al. 2002).

The continuous, coupled-coupled eTS assay and optimized method for synthesis of the OPHS substrate described in this study provide tools for the investigation of TS, a significant target for biotechnological applications. The kinetic parameters determined using this continuous assay are in agreement with those previously reported using the malachite green end-point assay (Laber et al. 1994a), demonstrating the effectiveness of the continuous assay. Furthermore, the effect of $\mathrm{pH}$ on each of the enzymes was observed in order to establish this assay as suitable for studying TS from a variety of plant and microbial species. The use of this assay 
in measuring plant TS activity will provide the in-depth knowledge of kinetic and regulatory properties of the enzyme necessary for manipulation of the threonine and methionine biosynthetic pathways. 
Chapter 3: Identification of Cystathionine $\gamma$-Synthase and Threonine Synthase from Cicer arietinum and Lens culinaris 


\subsection{Abstract}

In plants, cystathionine $\gamma$-synthase (CGS) and threonine synthase (TS) compete for the branch-point metabolite $O$-phospho-L-homoserine (OPHS). These enzymes are potential targets for metabolic engineering studies, aiming to alter the flux through the competing methionine and threonine biosynthetic pathways, with the goal of increasing methionine production. Although CGS and TS have been characterized in the model organisms Escherichia coli and Arabidopsis thaliana, little information is available on these enzymes in other, particularly plant, species. The functional CGS and TS coding sequences from the grain legumes Cicer arietinum (chickpea) and Lens culinaris (lentil) identified in this study share approximately $80 \%$ amino acid sequence identity with the corresponding sequences from Glycine max. At least seven active-site residues of grain legume CGS and TS are conserved in the model bacterial enzymes, including the catalytic base. Putative processing sites that remove the targeting sequence and result in functional TS were identified in the target species. 


\subsection{Introduction}

Grain legumes, such as chickpea (Cicer arietinum) and lentil (Lens culinaris), provide approximately $10 \%$ of the world's supply of dietary protein (Alliance grain traders 2011). However, chickpea and lentil are deficient in the essential amino acid methionine, according to the requirements for human nutrition, containing $1.3 \%$ and $0.8 \%$ methionine, respectively, rather than the $3-5 \%$ recommended for daily intake (Galili and Hofgen 2002; Mandal and Mandal 2000; Tabe and Higgins 1998). Since these crops are major contributors to vegetarian diets, and with current trends in population growth, improving the nutritional quality of grain legumes is an area of active research in crop biotechnology.

Plants and bacteria synthesize methionine de novo. In plants, the amino acid backbone, the sulfur atom and the $\varepsilon$-methyl group of methionine (L-Met) are derived from aspartate (L-Asp), via $O$-phospho-L-homoserine (OPHS), the thiol group of cysteine, via the transsulfuration pathway, and the $\beta$-carbon of serine, via methionine synthase, respectively (Ravanel et al. 1998b). The branch-point between the L-Met and threonine (L-Thr) biosynthetic pathways is occupied by OPHS in plants. The first committed step of L-Met biosynthesis is catalyzed by cystathionine $\gamma$-synthase (CGS), which condenses OPHS and cysteine (L-Cys) to form cystathionine, via a $\gamma$ replacement mechanism, displacing the phosphate group of OPHS by the thiol of LCys. Threonine synthase (TS) catalyzes the $\beta, \gamma$-rearrangement of OPHS, with the release of phosphate, to produce L-Thr. $S$-adenosyl-L-methionine (SAM), a direct metabolite of L-Met, regulates the flux of OPHS between the L-Met and L-Thr biosynthetic pathways by diminishing the translation of the CGS transcript and 
allosterically activating TS (Hacham et al. 2002; Chiba et al. 2003; Curien et al. 1998; Mas-Droux et al. 2006).

Altering the flux at the OPHS branch-point is an attractive strategy to increase the level of L-Met in grain legumes. However, the available research indicates the results of altering the expression, activity and/or regulation of CGS and TS can vary from species to species, making it essential to study these enzymes in the targeted species. For example, expression of A. thaliana CGS (AtCGS) under the CaMV-35S promoter in A. thaliana led to an 8- to 15 -fold increase in L-Met accumulation, but expression of Solanum tuberosum (potato) CGS, under the control of the same promoter, did not alter L-Met accumulation in potato (Gakiere et al. 2002; Kreft et al. 2003). Similarly, although the anti-sense expression of $A$. thaliana TS (AtTS) under the CaMV-35S promoter in A. thaliana resulted in 17- to 47-fold increase in L-Met, the transgenic plants produced infertile seeds, while the same strategy resulted in 2- to 240 -fold increase in L-Met in potato that was correlated with a reduction in the aboveground biomass (Avraham and Amir 2005; Zeh et al. 2001).

This study reports the isolation and sequence characteristics of functional chickpea and lentil CGS and TS. Subsequent studies on these enzymes will complement the available research on the flux through the OPHS branch-point by expanding the number of plant species for which CGS and TS have been characterized. 


\subsection{Methods and Materials}

\subsubsection{Materials}

Isopropyl- $\beta$-D-thiogalactopyranoside (IPTG), rifampicin, kanamycin, and gentamicin were purchased from BioShop; ampicillin, L-Met, and L-Thr from Fisher Scientific; and spectinomycin from Sigma-Aldrich. All enzymes were obtained from New England Biolabs, oligonucleotide primers were synthesized by Integrated DNA Technologies and coding sequences were sequenced by BioBasic. The $\Delta$ thrC724(del)::kan E. coli strain JW0003-2 was obtained from The Coli Genetic Stock Center.

\subsubsection{Amplification of CGS and TS coding sequences.}

Total RNA was extracted from A. thaliana, chickpea and lentil young leaf tissue using the RNeasy mini kit (Qiagen), with the DNaseI treatment, and cDNA was synthesized from $1 \mu \mathrm{g}$ of RNA using an oligo(dT $\left.\mathrm{d}_{18}\right)$ primer and $200 \mathrm{U}$ M-MuLV reverse transcriptase (NEB). Degenerate oligonucleotide primers were employed to amplify portions of the coding regions of $C G S$ and $T S$ from the chickpea and lentil cDNA. Degenerate primers for $C G S$ and $T S$ amplification were designed within conserved regions, based on multiple sequence alignments of the coding sequences of Glycine max (GmCGS; Accession number AF141602), A. thaliana (AtCGS; Acc. no. AF039206), and Fragaria ananassa (FaCGS; Acc. no. FVAJ1451) for CGS, and $G$. $\max (G m T S ;$ Acc. no. DQ275353), Medicago truncatula (MtTS; Acc. no. AY560919), S. tuberosum (StTS; Acc. no. AF082894), and A. thaliana (AtTS1; Acc. no. AB027151) for TS. The sequences of the resulting amplicons were used to design 
species-specific primers to amplify the 5 ' end of the coding sequence via the GenomeWalker Universal kit (Clontech), and the 3'-end of the coding sequence via an oligo-dT 18 adapter primer (GTC GGA TCC ACC TCC AGA TCG TTT TTT TTT TTT TTT TTT). Genomic DNA for genome walking was isolated from chickpea and lentil leaf tissue using the DNeasy mini kit (Qiagen), and was digested with EcoRV, HpaI, DraI, and ScaI (NEB).

Sequences encoding the full length and mature (lacking the plastid targeting sequence) transcripts of $A$. thaliana, chickpea and lentil $C G S$ and $T S$ were amplified from cDNA and inserted into the pTrc-99a2 expression vector (Farsi et al. 2009) using the primers in Table 3.1. A silent mutation was introduced into AtTS2 to remove the internal NdeI site, facilitating insertion into pTrc-99a2.

\subsubsection{Complementation of L-Met and L-Thr auxotrophic E. coli strains}

The functional identity of the putative $C G S$ and $T S$ coding sequences was confirmed by complementation of L-Met and L-Thr auxotrophic E. coli strains lacking the met $B$ and $t h r C$ coding sequences, respectively. The plant sequences were placed under the control of the IPTG-inducible trc promoter in the pTrc-99a2 vector. Fulllength and mature CGS and TS coding sequences from A. thaliana, chickpea and lentil were transformed into $\triangle m e t B$ (metB::aadA, ER1821) and $\Delta t h r C$ (thrC724(del)::kan, JW0003-2) strains of E. coli, respectively (Farsi et al. 2009; Baba et al. 2006). Cultures $(10 \mathrm{~mL})$ grown at $37^{\circ} \mathrm{C}$ for $16 \mathrm{~h}$ were harvested, washed three times with $1 \mathrm{~mL}$ of sterile $0.85 \% \mathrm{NaCl}$, and plated on $\mathrm{M} 9$ minimal media $(20 \%$ dextrose, M9 salts, $1 \mathrm{mM} \mathrm{MgCl} 2$ ) containing 1.5\% agar (w/v), $100 \mu \mathrm{g} / \mathrm{ml}$ of 
Table 3.1. Primers used to amplify full-length and mature CGS and $\mathrm{TS}^{a}$

\begin{tabular}{|c|c|}
\hline Primer name & Primer sequence $\left(5{ }^{\prime}-3{ }^{\prime}\right)$ \\
\hline CaCGSF & ATGGCCGTTTCAAGTTTCCACCGC \\
\hline CamatCGSF & ATGCAACTCAGCACCAAAGCTCGTCGT \\
\hline$C a C G S \mathrm{R}$ & CTATATGGCTTCGAGAGCTTGCAGG \\
\hline$L c C G S \mathrm{~F}$ & ATGGCCGTTTCAAGCCTCCACCGTG \\
\hline$L c \mathrm{mat} C G S \mathrm{~F}$ & ATGCAGCGTCAGCTAAGCACTAAAGCTCG \\
\hline LcCGSR & CTATATGACTTCCAGTGCCTGCACG \\
\hline CaTSF & ATGGCGGTGTCTTCTCTGT \\
\hline CamatTSF & ATGGACAACATCAAAGATAAAGC \\
\hline CaTSR & CTACTTTGGGGTCTTACTC \\
\hline LcTSF & ATGTCTTCTTCAACAACAAC \\
\hline$L c \mathrm{mat} T S \mathrm{~F}$ & ATGGAAAACATCCGCGACGAAG \\
\hline LcTSR & CTAATGATACTTGGGTGCCT \\
\hline AtmatTSIF & ATGGATAACATTCGAGATGAGGC \\
\hline AtTSIR & CTAAAAGTTTTCAAA \\
\hline AtmatTS2F & ATGATTCGAGACGAAGCTC \\
\hline AtTS2R & TTATTTATCATTGCTCTTC \\
\hline AtTS2-H339H-F $b$ & CAAAGGGTTTCACATGTGTAAAGAG \\
\hline AtTS2-H339H-R ${ }^{b}$ & СТCTTTACACATGTGAAACCCTTTG \\
\hline
\end{tabular}

${ }^{a}$ Primers used to amplify the full-length and mature (mat) $C G S$ and $T S$ coding sequences from $A$.thaliana $(A t), C$ arietinum $(C a)$ and $L$. culinaris $(L c)$.

${ }^{b}$ Primers used in the site-directed mutagenesis of AtTS2 to remove the internal NdeI site. 
ampicillin, $50 \mu \mathrm{g} / \mathrm{ml}$ of kanamycin and $1 \mathrm{mg} / \mathrm{mL}$ uracil (thrC724(del)::kan strain) or $50 \mu \mathrm{g} / \mathrm{ml}$ spectinomycin and $1 \mathrm{mg} / \mathrm{mL}$ thiamine (metB::aadA strain), in the presence of $1 \mathrm{mM}$ IPTG, $75 \mu \mathrm{g} / \mathrm{mL}$ L-Met, or $75 \mu \mathrm{g} / \mathrm{mL}$ L-Thr (thrC724(del)::kan only). Cells were incubated at $30^{\circ} \mathrm{C}$ for $48 \mathrm{hrs}$.

\subsubsection{Binary plasmid construction and intracellular localization}

The plastid targeting sequences of TS from A. thaliana, chickpea and lentil were transferred from the $\mathrm{pTrC}-99 \mathrm{a} 2$ expression constructs to the $\mathrm{pVKH} 18$ vector, immediately 5' of the coding sequence of green fluorescent protein (GFP), expressed under the control of the CaMV-35S promoter (Sparkes et al. 2006). Constructs were transformed into Agrobacterium tumefaciens (C58C GV3101 pMP90 RK) by electroporation ( $2.5 \mathrm{kV}, 25 \mu \mathrm{F}$, and $400 \Omega$ for 9 secs) and, following incubation at $28^{\circ} \mathrm{C}$ for $3 \mathrm{hrs}$, were plated on LB media containing $1.5 \%$ agar, $50 \mu \mathrm{g} / \mathrm{mL}$ kanamycin, $100 \mu \mathrm{g} / \mathrm{mL}$ rifampicin, and $40 \mu \mathrm{g} / \mathrm{mL}$ gentamicin. Transient expression of GFP, and the transit peptide-GFP fusion constructs, in Nicotiana tabacum epidermal cells was completed as described by Sparkes et al. (2006). Three days after infiltration, $N$. tabacum leaf samples were excised and GFP expression was imaged using confocal laser scanning microscopy (CLSM) with a Zeiss LSM 510 Meta using a Plan Apochromat 63x objective (Carl Zeiss MicroImaging, Inc.). Samples were excited with a $488 \mathrm{~nm}$ argon laser and emission was recorded at $505 \mathrm{~nm}$ for GFP and $650 \mathrm{~nm}$ for chlorophyll autofluorescence. 


\subsection{Results}

One strategy to alleviate the dietary deficiency of L-Met in grain legumes is to alter the flux through the OPHS branch-point, between the competing L-Met and LThr biosynthetic pathways, by manipulating the expression of the competing enzymes, CGS and TS. Available research demonstrates that the result of modifying the expression of these key enzymes of primary metabolism is species dependent, thereby suggesting that additional knowledge of CGS and TS from a range of plant species is required to understand the regulation of flux at the OPHS branch-point, particularly in the target grain legumes. This study describes the isolation of functional CGS and TS coding sequences from the grain legumes chickpea and lentil, as a necessary step to provide the starting point for research in these important crop species.

\subsection{1. $C G S$}

The CaCGS and LcCGS transcripts have open reading frames (ORF) of approximately $1600 \mathrm{bp}$ and encode proteins of approximately $58 \mathrm{kDa}$ that share $85 \%$ and $81 \%$ amino acid sequence identity, respectively, with GmCGS (Acc. no. AF141602). Both CGS amino acid sequences contain the pyridoxal 5'-phosphate (PLP) binding motif, including the active-site lysine residue (CaCGS-K350 and LcCGS-K351). Characteristic of the plant CGS enzymes studied to date, both CaCGS and LcCGS possess an N-terminal extension that is not present in bacterial CGS. This segment includes a plastid targeting peptide and the regulatory MTO region (Chiba et al. 1999; Ominato et al, 2002; Ravanel et al, 1998b). The MTO 
region consists of 11 residues (R77-V89 in AtCGS) and is common to CGS from plant species. The MTO regions of CaCGS (R66-V78) and LcCGS (R68-V80) share $100 \%$ identity with that of AtCGS and GmCGS.

The ability of CaCGS and LcCGS to complement the methionine auxotrophy of the ER1821 1 metB E. coli strain, deficient in E. coli CGS (eCGS), was investigated. The $\Delta m e t B$ strain containing the empty pTrc-99a2 vector produced colonies only on media supplemented with L-Met (Table 3.2). The wild-type eCGS coding sequence, under the control of the trc promoter of pTrc-99a2, complemented the ER1821 $\Delta m e t B$ cells only in the absence of IPTG (Table 3.2), an observation also reported by Farsi et al. (2009). In contrast, complementation of the $\Delta m e t B$ strain was observed for both the full-length and mature forms of CaCGS, LcCGS, and AtCGS only in the presence of IPTG (Table 3.2).

\subsection{2. $T S$}

The AtTS2, CaTS and LcTS transcripts contain ORFs of 1551, 1569 and 1614 bp, encoding 57,57 and $59-\mathrm{kDa}$ proteins, respectively. The resulting protein sequences share $75 \%, 82 \%$ and $77 \%$ amino acid sequence identity, respectively, with GmTS (Acc. no. DQ275353) (Figure 3.1). Analysis of the amino acid sequences reveals the signature PLP-binding motif, including the characteristic active-site lysine residue AtTS2-K194, CaTS-K200 and LcTS-K212. The SAM-binding region identified in AtTS1 is also present in the N-terminal region of the TS enzymes examined in this study (AtTS2: V127-G185, CaTS: V133-G192, and LcTS: V145- 
Table 3.2. Complementation of L-Met and L-Thr auxotrophic E. coli strains by fulllength and mature CGS and TS, respectively, from A. thaliana, C. arietinum, $L$. culinaris, and E. coli. ${ }^{a}$

\begin{tabular}{|c|c|c|c|c|c|}
\hline & \multirow{2}{*}{\multicolumn{3}{|c|}{$\frac{\text { With IPTG }}{\text { M9 }}$}} & \multicolumn{2}{|c|}{ No IPTG } \\
\hline & & & & M9 + Met & M9 \\
\hline AtCGS & \multicolumn{3}{|c|}{$\bullet$} & $\bullet$ & 0 \\
\hline matAtCGS & \multicolumn{3}{|c|}{$\bullet$} & $\bullet$ & 0 \\
\hline CaCGS & \multicolumn{3}{|c|}{$\bullet$} & $\bullet$ & $\circ$ \\
\hline matCaCGS & \multicolumn{3}{|c|}{$\bullet$} & $\bullet$ & 0 \\
\hline LcCGS & \multicolumn{3}{|c|}{$\bullet$} & $\bullet$ & ○ \\
\hline matLcCGS & \multicolumn{3}{|c|}{$\bullet$} & $\bullet$ & ○ \\
\hline eCGS & \multicolumn{3}{|c|}{ o } & $\bullet$ & $\bullet$ \\
\hline$\Delta m e t B$ cells & \multicolumn{3}{|c|}{ ○ } & $\bullet$ & 0 \\
\hline pTrc-99a2 & \multicolumn{3}{|c|}{ o } & $\bullet$ & 0 \\
\hline vector & M9 + Thr & \multicolumn{2}{|l|}{ (-Thr) } & M9 + Thr & M9 \\
\hline \multirow{2}{*}{$\begin{array}{l}\text { AtTS1 } \\
\text { matAtTS1 }\end{array}$} & $\bullet$ & $\bullet$ & $\bullet$ & $\bullet$ & 0 \\
\hline & $\bullet$ & • & $\bullet$ & - & 0 \\
\hline AtTS2 & $\bullet$ & $\bullet$ & O & $\bullet$ & O \\
\hline matAtTS2 & - & $\bullet$ & - & • & o \\
\hline CaTS & $\bullet$ & $\bullet$ & $\bullet$ & $\bullet$ & 0 \\
\hline matCaTS & $\bullet$ & $\bullet$ & $\bullet$ & $\bullet$ & $\circ$ \\
\hline LcTS & $\bullet$ & $\bullet$ & $\bullet$ & $\bullet$ & ○ \\
\hline matLcTS & $\bullet$ & $\bullet$ & $\bullet$ & $\bullet$ & $\circ$ \\
\hline eTS & O & ○ & O & $\bullet$ & $\bullet$ \\
\hline$\Delta t h r C$ cells & $\bullet$ & O & O & $\bullet$ & 0 \\
\hline $\begin{array}{l}\mathrm{pTrc}-99 \mathrm{a} 2 \\
\text { vector }\end{array}$ & $\bullet$ & ○ & O & $\bullet$ & $\circ$ \\
\hline $\begin{array}{l}{ }^{a} \text { Closed }(\bullet) \\
\text { respectively. } \\
48 \text { hrs on } \\
\text { spectinomyci } \\
\mu \mathrm{g} / \mathrm{mL} \mathrm{L-Me} \\
\mathrm{M} 9 \mathrm{minimal} \\
\mu \mathrm{g} / \mathrm{mL} \text { uracil } \\
\text { Met. }\end{array}$ & $\begin{array}{l}\text { nd opened } \\
\text { netB::aadA, } \\
\text { minimal } \\
100 \mu \mathrm{g} / \mathrm{mL} \\
\text { hrC724(del } \\
\text { edia contai } \\
\text { nd supplem }\end{array}$ & $\begin{array}{l}\text { cles (o) in } \\
1821 \text { (Farsi } \\
\text { dia contain } \\
\text { iamine, and } \\
\text { in, JW0003 } \\
100 \mu \mathrm{g} / \mathrm{m} \\
\text { d with } 1 \mathrm{~m}\end{array}$ & $\begin{array}{l}\text { stro } \\
2009 \\
00 \mu \\
\text { lemen } \\
\text { s wer } \\
\text { jicilli } \\
\text { G. } 75\end{array}$ & $\begin{array}{l}\text { wth and } \\
\text { vere grown } \\
\text { ampicillin, } \\
\text { h } 1 \mathrm{mM} \\
\text { at } 30^{\circ} \mathrm{C} \text { fo } \\
\mathrm{g} / \mathrm{mL} \text { kana } \\
\mathrm{L}-\mathrm{Thr} \text { or } 7\end{array}$ & $\begin{array}{l}\text { wth, } \\
\text { f for } \\
\mathrm{g} / \mathrm{mL} \\
\mathrm{m} 75 \\
\text { rs on } \\
100 \\
\mathrm{~L} \text { L- }\end{array}$ \\
\hline
\end{tabular}


Figure 3.1. Amino acid sequence alignment of AtTS1 (AB027151), AtTS2 (NM_105939), CaTS, LcTS, and GmTS (DQ275353.1). The residues responsible for interactions with SAM and PLP are shown in white font in the black and gray boxes, respectively. Leu204, responsible for the mto2-1 methionine overaccumulating mutant, is underlined. Markings below the amino acid sequences denote fully conserved $(*)$, strongly conserved (:), and weakly conserved (.) residues. 


\begin{abstract}
AtTS2 -MAS-----------------FSLPHS-ATYFPSHSETSLKPHSAASFTVRCTSASPA 39 -MSSSTTTLFQSSPFSLNTKTKPYSLPKSKPTNFTLKSQSQSQPQ-PLTHNNNTPTPSPA 58 -MASSCLFN-----------ASVSSLNPKQDPIRRHRSTSLLRHRPVVISCTADGNNIK 47 MAVSSLFHP-------------SFSTLVFNSKPTHLTSNRNNNRSLFIAASSLDPTPI 45 -MLSSLLNP--------------SFTT----TLPIHSILI PNNRRASTVVSCTS--SHL 38

AtTS2 LCTS

AtTS1

CaTs

GmTS

VPP-QTPQKPRRSPDENIRDEARR-RPHQLQNLSARYVPFNAPPSSTESYSLDEIVYRSQ 97 TPP-PSSSKHRRPADENIRDEARR-INVSQHLFSAKYVPFNADPSSTESYSLDEIVYRSQ 116 API-ETAVKPPHRTEDNIRDEARRNRSNAVNPFSAKYVPFNAAPGSTESYSLDEIVYRSR 106 TAANNNNHSP PPSAADNIKDKARR-HVSTTNNFTAKYVPFNATFDSPESYSLDEIVYRSK 104 TTNNHSHVSSPP----NIKDEARR-RPAAENDFTAKYVPFNAGFDSPETYSLDEIVYRSR 93

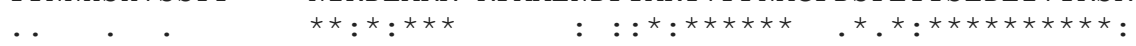

AtTS2

LCTS

AtTS1

CaTs

GmTS

SGALLDVQHDFAALKRYDGEFWRNLFDSRVGKTNWPYGSGVWSKKEWVLPEIDDDDIVSA 157 SGGLLDVQHDLDALKKFDGAYWRNLFDSRVGKTTWPYGSGVWSKKEWVLPEIDDDDIVSA 176 SGGLLDVEHDMEALKRFDGAYWRDLFDSRVGKSTWPYGSGVWSKKEWVLPEIDDDDIVSA 166 SGGLLDVHHDMEALAKFDGAYWRNLFDSRVGKTTWPYGSGVWSKKEWVLPEIHPDDIVSA 164 SGGLLDVQHDMEALGRFDGAYWRALFDSRVGKTTWPYGSGVWSKKEWVLPEIDPDDIVSA 153

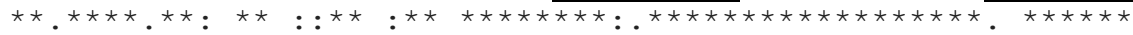

AtTS2

LCTS

AtTS1

CaTS

GmTS

AtTS2

LCTS

AtTS1

CaTS

GmTS

AtTS2

LCTS

AtTS1

CaTs

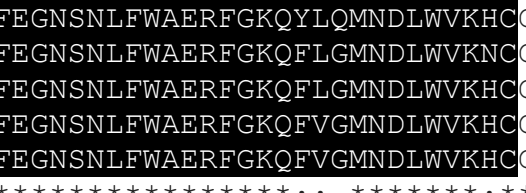

GISHTGSEKDLGMSVLVSQVNRLRKMNKPVIG 217 GTSHTGSFKDLGMTVLVSQVNRLRKMNRPVVG 236 GISHTGSFKDL̈GMTVLVSQVNRLRKMKRPVVG 226 GISHTGSFKDLEMTVLVSQVNRLRKNERPLVG 224 GISHTGSFKDLEGMTVLVSQVNRLRKMNRPVVG 213

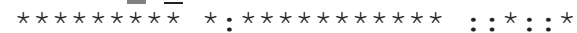

GmTS

AtTS2

VGCASTGDTSAALSAYCASAGIPS IVFLPADKISMAQLVQP IANGAFVLSIDTDFDGCMH 277 VGCASTGDTSAALSAYCASAGI PS IVFLPANRIS IAQLVQP IANGAFVLS IDTDFDGCMQ 296 VGCASTGDISAALSAYCASAGIPS IVFLPANKI SMAQLVQP IANGAFVLSIDTDFDGCMK 286 VGCASTGDTSAALSAYCASAGIPS IVFLPANKISTAQLIQPVSNGALVLSLDTDFDGCMK 284 VGCASTGDISAALSAYCASAGIPSIVFLPANKISTAQLIQPVSNGSLVLS INTDFDGCMK 273

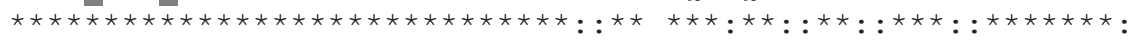

LIREVTAELPIYLANSLNSLRLEGQKTAAIEILQQFNWQVPDWVIVPGGNLGNIYAFYKG 337 LIREVTAELPIYLANSLNSLRLEGQKTAAIEILQQFDWQVPDWVIVPGGNLGNIYAFYKG 356 LIREITAELPIYLANSLNSLRLEGQKTAAIEILQQFDWQVPDWVIVPGGNLGNIYAFYKG 346 LIREITSELPIYLANSLNSLRIEGQKTAAIEI LQQFDWQVPDWVI I PGGNLGNIYAFYKG 344 LIREITAELPIYLANSLNSLRLEGQKTAAIEILQQFNWEVPDWVIVPGGNLGNIYAFYKG 333

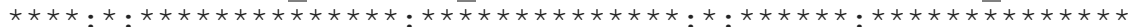

GmTS

FHMCKELGLVDRIPRLVCAQAANANPLYLHYKSGFKEDFNPLKANTTFASAIQIGDPVSI 397 FQMCKELGLVDRI PRLVCAQAANANPLYLYFKSGWKE-FKAVRAQTTFASAIQIGDPVS I 415 FKMCQELGLVDRI PRMVCAQAANANPLYLHYKSGWKD-FKPMTASTTFASAIQIGDPVSI 405 FKMCKDLGLVDKIPRLVCAQAANANPLYLHYKNGFKD-FQAIKAETTFASAIQIGDPVSI 403 FKMCKELGLVERI PRLVCAQAANANPLYLHYKNGFKD-FNAVKAETTFASAIQIGDPVSI 392

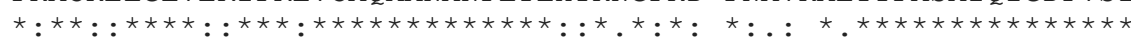

DRAVYALKKSNGIVEEATEEELMDATALADSTGMFICPHTGVALTALMKLRKSGVIGAND 457 DRAVHALKNCNGIVEEATEEELMDAMAQADSTGMFTCPHTGVALTALFKLRNSGVIKPTD 475 DRAVYALKKCNGIVEEATEEELMDAMAQADSTGMFICPHTGVALTALFKLRNQGVIAPTD 465 DRAVLALKNCNGIVEEATEEELMDAMSLADSTGMFTCPHTGVALTALIKLRNSGVIGSSD 463 DRAVHALRNTEGIVEEATEEELMDAMVQADSTGMFICPHTGVALAALIKLRNRGVIGAGE 452

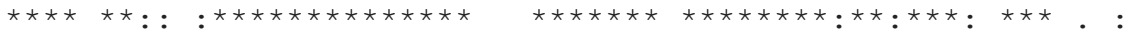

RTVVVSTAHGLKFTQSKIDYHSKNIKEMACRLANPPVKVKAKFGSVMDVLKEYLKSNDK- 516 RTVVVSTAHGLKFTQSKIDYHSKNIKDLACQFANPPMQVKADFGSVMDVLSKYLQSKAPK 535 RTVVVSTAHGLKFTQSKIDYHSNAIPDMACRFSNPPVDVKADFGAVMDVLKSYLGSNTLT 525 RVVVVSTAHGLKFAQSKIDYHSGTIPGMG-RYANPPVSVKADFGSVMDVLKDFLLSKTPK 522 RVVVVSTAHGLKFAQSKIDYHSGLIPGMG-RYANPLVSVKADFGSVMDVLKDFLHNKSPD 511

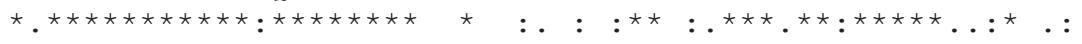


G204). In AtTS1, W101 and W150 are responsible for forming a stacking interaction with the adenine ring and stabilizing the L-Met moiety of SAM, respectively (MasDroux et al. 2006). These two tryptophan residues are conserved in AtTS2 (W132 and W181), CaTS (W139 and W188) and LcTS (W104 and W153).

The junction of the plastid targeting sequence and the mature form of the enzyme is conserved in CGS, but not TS. Therefore, to investigate the plastid-transit capability of the N-terminal region and identify functional truncated TS enzymes, lacking the transit peptide, the putative TS plastid targeting sequences were fused inframe to GFP in the pVKH18 vector and transiently expressed by infiltration of transformed A. tumefaciens (C58C GV3101 pMP90 RK) into tobacco epidermal cells (Sparkes et al. 2006). Imaging of the transient expression of GFP by CLSM demonstrated that the N-terminal regions of AtTS2 (M1-N55), CaTS (M1-D61) and LcTS (M1-E73) are sufficient to direct GFP into the chloroplast, as demonstrated by the overlap of the GFP signal in green $\left(\lambda_{\mathrm{em}}=505 \mathrm{~nm}\right)$ and the autofluorescence of the chloroplast in red $\left(\lambda_{\mathrm{em}}=650 \mathrm{~nm}\right)$ in Figure 3.2 .

The threonine-auxotrophic JW0003-2 thrC724(del)::kan strain, deficient in TS activity, was complemented by the full-length and mature coding sequences of AtTS1, AtTS2, CaTS, LcTS and E. coli TS (eTS), but not the pTrc-99a2 plasmid (Table 3.2). Growth of the $\Delta t h r C$ cells was observed for eTS only in the absence of IPTG, a trend consistent with eCGS complementation (Farsi et al. 2009). In contrast, IPTG enabled complementation by the full-length and mature forms of AtTS1, CaTS and LcTS and the mature form of AtTS2. A unique feature of the full-length AtTS2 
Figure 3.2. Expression of fluorescent fusion proteins in epidermal cells of Nicotiana tabacum. (A) empty pVKH18 vector and (B) pVKH18 vector containing RUBISCOGFP fusion construct, respectively, provide controls for the pVKH18 vector containing the GFP-fusions with the signal peptides of (C) AtTS1 (M1-D61), (D) AtTS2 (M1-N55), and (E) CaTS (M1-D61). Photographs were taken in a dark field showing (i) the autofluorescence of chloroplasts (650 nm, red), (ii) GFP (505 nm, green), and (iii) the overlap showing localization of GFP fusion constructs to chloroplasts. CLSM was done with a Zeiss LSM 510 Meta using a Plan Apochromat 63x objective. The scale bars shown in panel (iii) represent $50 \mu \mathrm{m}$. 
(i)

(A)

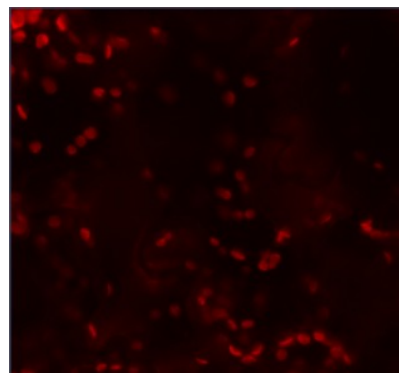

(B)

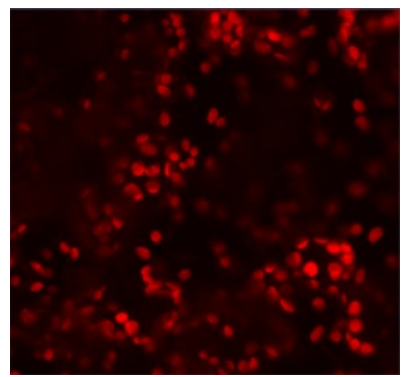

(C)

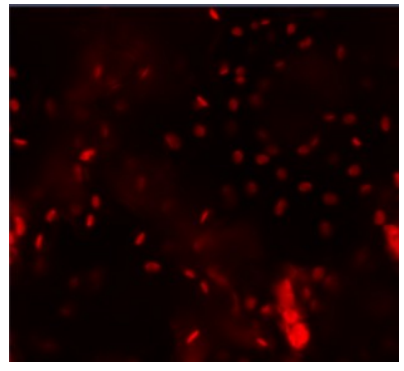

(D)

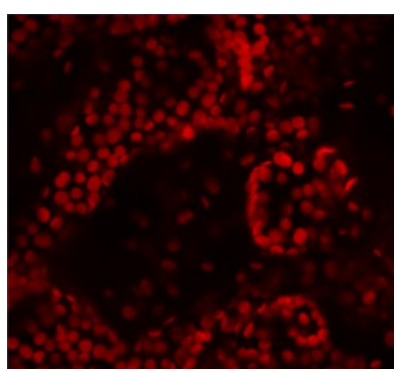

(E)

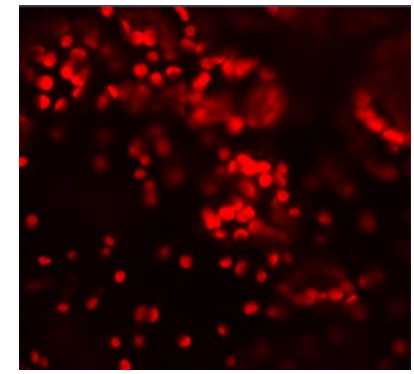

(ii)
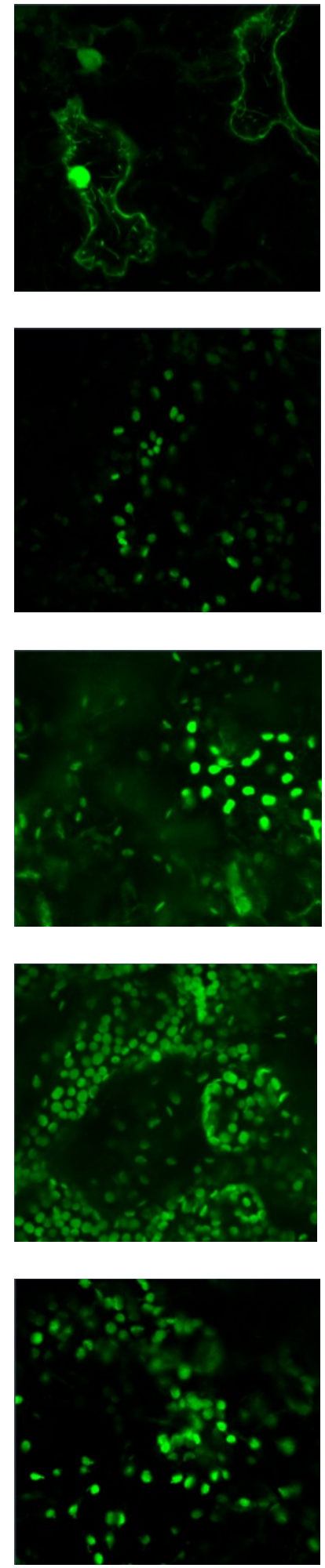

(iii)
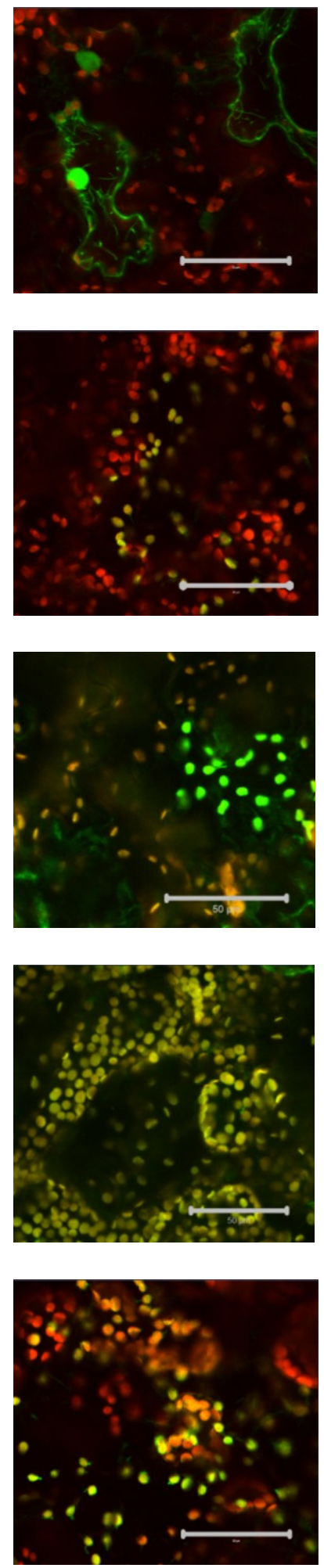
sequence is the requirement for L-Met supplementation in the growth media for complementation of the E. coli $\Delta t h r C$ strain (Table 3.2).

\subsection{Discussion}

A 3-fold increase in accumulation would be sufficient to alleviate the dietary L-Met deficiency of the seeds of grain legumes such as C. arietinum (chickpea) and $L$. culinaris (lentil) (Tabe and Higgins 1998). The enzymes at the OPHS metabolic branch-point, CGS and TS, are targets to improve the nutritional quality of these crop species by increasing the accumulation of L-Met. However, results from previous studies indicate that, as enzymes of primary metabolism, manipulation of CGS and TS expression may produce deleterious phenotypes and/or species-specific changes in L-Met accumulation (Gakiere et al. 2002; Kim et al. 2002; Kreft et al. 2003). For example, transgenic Medicago sativa (alfalfa) expressing AtCGS downstream of the rubisco small subunit promoter accumulated up to 32-fold more L-Met than wild-type plants while expressing the same gene under the CaMV-35S promoter in potato did not alter L-Met accumulation (Kim et al. 2002; Gakiere et al. 2002). Reduction in the expression of TS in A. thaliana and potato resulted in a wide range of increased LMet accumulation, 17- to 47-fold and 2- to 240-fold, respectively, beyond the required 3-fold increase (Avraham and Amir 2005; Zeh et al. 2001). Deleterious phenotypes, including reduced growth and yield, have also been reported, particularly when employing the CaMV-35S promoter, as reported for the transgenic A. thaliana and potato with reduced TS expression (Avraham and Amir 2005; Zeh et al. 2001). Results from previous studies that manipulated the flux of metabolites through the 
OPHS branch-point to increase the accumulation of L-Met illustrate the need to study CGS and TS in target plant species to get an acceptable increase in L-Met content.

The $C G S$ transcripts amplified from C. arietinum (CaCGS) and L. culinaris (LcCGS) encode functional CGS enzymes (Table 3.2) of approximately $58 \mathrm{kDa}$, consistent with the characterized A. thaliana $(60 \mathrm{kDa})$ and G. $\max (58 \mathrm{kDa})$ CGS (Hughes et al. 1999; Ravanel et al. 1998a). Both CaCGS and LcCGS contain the PLP-binding motif LGADLXXHSXTKY (Ravanel et al. 1998a; Hughes et al.1999). Their first exon encodes the conserved chloroplast transit peptide cleavage site (CaCGS-Q58 and LcCGS-Q60) and the MTO region that includes the core RRNCSNIGVAQ sequence that is linked to the post-transcriptional regulation of plant CGS by SAM (Ominato et al. 2002; Ravanel et al. 1998a). The crystal structure of $N$. tabacum CGS in complex with inhibitors identified three active site residues responsible for binding the distal phosphate group of the OPHS substrate (E107, Y111 and K165) (Steegborn et al. 2001). These residues are conserved in plant CGS, including CaCGS (E196, Y200 and K255) and LcCGS (E197, Y201 and K256), but not in bacterial CGS, for which the activated L-homoserine (L-HSer) substrate is $O$ succinyl-L-homoserine (OSHS) not OPHS. The difference in substrates between bacterial and plant CGS may explain the requirement for IPTG in plant CGS complementation studies, as the branch-point between the L-Met and L-Thr biosynthetic pathways is OPHS and L-HSer in plants and bacteria, respectively. The CaCGS and LcCGS sequences share eight conserved active site residues with the structures of NtCGS and E. coli CGS (eCGS: D45, Y46, R48, Y101, R106, K198, S326 and R361), including the catalytic base (eCGS-K198, CaCGS-K350 and 
LcCGS-K351), which tethers the PLP cofactor by Schiff base linkage, and the serine residue (eCGS-S326, CaCGS-S447 and LcCGS-S478) that guides the $\varepsilon$-amino group of the catalytic base (Clausen et al. 1998; Steegborn et al. 2001; Jaworski et al. 2012). The arginine residues in eCGS (R48, R106 and R361) that are responsible for tethering the distal and $\alpha$-carboxylate of OSHS are conserved in the active sites of CaCGS (R199, R256, and R512) and LcCGS (R200, R257, and R512) and are likely involved in positioning the corresponding distal phosphate and $\alpha$-carboxylate groups of the OPHS substrate (Clausen et al. 1998; Jaworski et al. 2012).

Threonine synthase transcripts amplified from C. arietinum (CaTS) and $L$. culinaris (LcTS) encode functional TS enzymes (Table 3.2) of 57 and 59-kDa, respectively, consistent with the 57-kDa AtTS1 (Curien et al. 1998). Both sequences contain the allosteric SAM-binding site found in AtTS1 that is conserved in plant TS including CaTS and LcTS but not in Saccharomyces cerevisiae TS (yTS) or eTS, which are not allosterically regulated by SAM (Mas-Droux et al. 2006). The $k_{c a t} / K_{m}{ }^{\text {OPHS }}$ of AtTS1 is increased approximately 87 -fold by SAM-binding (Laber $e t$ al. 1999). Therefore, the requirement for allosteric activation by SAM of the plant TS enzymes and differences in the cellular pools of SAM between plants and E. coli may explain their requirement of IPTG for complementation of the $\Delta t h r C$ E. coli cells. This distinguishes them from the native eTS enzyme for which the leaky expression of the trc promoter is sufficient. In contrast, the threonine auxotrophic E. coli strain is not complemented by eTS in the presence of IPTG, suggesting that the presence of excess functional TS disrupts primary metabolism. The PLP-binding motif, including the active-site lysine residue responsible for Schiff base linkage (CaTS-K200; LcTS- 
K212) and the residues that form hydrogen bonds with the phosphate group (CaTSS229 and CaTS-T233; LcTS-S242 and LcTS-T246), N1 (CaTS-S299; LcTS-S313) and O3' (CaTS-Q308 and CaTS-N337; LcTS-Q321 and LcTS-N350) of PLP are conserved in fungal, bacterial and plant TS including CaTS and LcTS (Mas-Droux et al. 2006). Plant TS has an N-terminal extension of approximately 50-60 residues compared to yTS and eTS, which contains the transit peptide and mature start site of the enzyme.

There is little conservation among plant TS sequences at the identified cleavage site, T39, of AtTS1 (Curien et al. 1996). The first conserved region in the plant TS, identified through amino acid sequence alignments of all available plant TS sequences begins at AtTS1-D61, AtTS2-N55, CaTS-D61, and LcTS-E73. These residues were used as the truncation sites in this study to confirm the function of both the amino-terminal transit peptide and the truncated enzymes. Complementation of the $\Delta t h r C$ E. coli strain by the truncated coding sequences of AtTS1, AtTS2, CaTS, and LcTS (Table 3.2) demonstrates that these sequences encode functional TS enzymes, suggesting that truncation at this site does not interfere with TS activity. The N-terminal regions of AtTS2 (M1-N55), CaTS (M1-D61) and LcTS (M1-E73) directed GFP into the chloroplasts (Figure 3.1), indicating that this region is sufficient to for plastid targeting of the native enzymes.

AtTS2, identified from analysis of the A. thaliana genome, has not been as extensively studied as AtTS1 and has been excluded from L-Asp-derived amino acid branch-point models because it is 120 -fold less active than AtTS1 at physiological SAM concentrations (Curien et al. 2009). Application of exogenous L-Met, which 
may increase the intracellular concentration of SAM, was a unique requirement of full-length AtTS2 for complementation of the $\triangle t h r C$ E. coli strain (Table 3.2), thereby supporting the reported lower activity of AtTS2 compared to AtTS1. However, the mature AtTS2 is functional (Table 3.2) and is likely localized to the chloroplast (Figure 3.1), where L-Thr and L-Met biosynthesis occurs. Therefore, a role in L-Thr biosynthesis for AtTS2 may exist, suggesting that this enzyme should be considered when modeling the OPHS branch-point.

Research focused on manipulating the flux of metabolites through the OPHS branch-point has shown that the effect of altering the expression or regulation of CGS and TS on L-Met accumulation varies depending on the target plant species. The same strategy, such as expressing AtCGS under the CaMV-35S promoter, employed in two different species may yield distinct results (Gakiere et al. 2002; Kreft et al. 2003). Therefore, characterization of CGS and TS from grain legumes is a necessary prelude to studies aiming to increase the nutritional value of these crops. This study provides a foundation for future research on the activity and regulation of CGS and TS in grain legumes, with the ultimate goal of increasing L-Met content in these important crop plants. 
Chapter 4: The steady-state kinetic parameters of Threonine Synthase from $A$.

thaliana, C. arietinum, and L. culinaris 


\subsection{Abstract}

Threonine synthase (TS) catalyses the $\beta, \gamma$-replacement of $O$-phospho-L-homoserine (OPHS), forming L-threonine (L-Thr) and inorganic phosphate. In plants, OPHS occupies the branch-point between the biosynthetic pathways of L-methionine (L-Met) and L-Thr. In this study, TS from Cicer arietinum (CaTS) and Lens culinaris (LcTS), as well as the two homologues of TS from Arabidopsis thaliana (AtTS1 and AtTS2) was recombinantly expressed in Escherichia coli and purified. The kinetic parameters of TS were measured in the presence and absence of $100 \mu \mathrm{M} S$-adenosylL-methionine (SAM). The activator increases the $k_{\text {cat }} / K_{m}{ }^{\text {OPHS }}$ of CaTS, LcTS, AtTS1, and AtTS2 by 25-, 20-, 80-, and 8.5-fold, respectively. The $k_{\text {cat }} / K_{m}{ }^{\text {OPHS }}$ of AtTS2 in the presence of SAM $\left((1.7 \pm 0.1) \times 10^{3} \mathrm{M}^{-1} \mathrm{~s}^{-1}\right)$ is one order of magnitude lower than that of AtTS1. The analysis of AtTS2 flux control into the mathematical reconstruction of the OPHS branch-point model showed that this enzyme is responsible for $14 \%$ of the flux of OPHS, and that CGS accounts for $6 \%$ of the flux. Therefore AtTS2 should be integrated into the A. thaliana branch-point model. In the presence of SAM, the $k_{c a t} / K_{m}{ }^{\text {OPHS }}$ of AtTS1 $\left((2.4 \pm 0.30) \times 10^{4} \mathrm{M}^{-1} \mathrm{~s}^{-1}\right)$, C. arietinum $\left((1.5 \pm 0.3) \times 10^{4} \mathrm{M}^{-1} \mathrm{~s}^{-1}\right)$ and L. culinaris $\left((1.4 \pm 0.2) \times 10^{4} \mathrm{M}^{-1} \mathrm{~s}^{-1}\right)$ are consistent with the reported value for AtTS1. Despite the consistency in the kinetic parameters of pulse and $A$. thaliana TS, the kinetic model of the $A$. thaliana OPHS branch-point may not be an appropriate model of flux in other species due to the difference in the proportion of flux control of AtTS1 (80\%) and the estimated values of CaTS (91\%) and LcTS (94\%). 


\subsection{Introduction}

In plants, the L-homocysteine precursor of the essential amino acid Lmethionine (L-Met) is derived from the carbon backbone of L-aspartate (L-Asp), via O-phospho-L-homoserine (OPHS), and the sulfur moiety of L-cysteine (L-Cys). The first committed step of L-Met biosynthesis is the cystathionine $\gamma$-synthase (CGS)catalyzed condensation of OPHS and L-Cys to form L-cystathionine (Kreft et al. 1994). This reaction competes with $\beta, \gamma$-rearrangement of OPHS, to produce threonine (L-Thr), catalyzed by threonine synthase (TS) (Laber et al. 1994a). The competition between TS and CGS for OPHS is unique to plants as L-Met is derived from $O$-succinyl-L-homoserine in bacteria. The partitioning of OPHS is regulated by the L-Met-metabolite, $S$-adenosyl-L-methionine (SAM), which post-transcriptionally modulates the stability of the $C G S$ mRNA transcript, and allosterically activates the TS enzyme (Curien et al. 1996; Chiba et al. 1999). The catalytic efficiency of the predominant $A$. thaliana TS isoform (AtTS1) is increased 87-fold in the presence of $100 \mu \mathrm{M}$ SAM (Laber et al. 1999).

L-Met is an essential amino acid used in the synthesis of proteins and for the biosynthesis of L-Cys in animals. Important crop plants such as legumes are deficient in the sulfur-containing amino acids, from the perspective of human nutritional requirement (Tabe and Higgins, 1998). Increasing the production of L-Met, to improve nutritional quality, requires a detailed understanding of the flux between the competing pathways at the OPHS branch-point. Kinetic models reconstruct a metabolic pathway or branch-point based on network, kinetic, and regulatory information (Schallau and Junker, 2010). Therefore, determination of the kinetic 
parameters of the relevant enzyme(s), CGS and TS in the case of L-Met, is required to model the effect of genetic engineering on metabolic flux through the competing pathways. This is exemplified by the kinetic model of the L-Asp metabolic pathway from A. thaliana created by Curien and coworkers (Curien et al. 2009). This model was employed to simulate the effects of increasing SAM concentration from 2-30 $\mu \mathrm{M}$ on the flux of OPHS, as a representation of a similar increase in L-Met levels (Curien et al. 2009). The result was a 10 -fold reduction in L-Met synthesis, and an approximately $50 \%$ reduction in the activity of L-Asp kinase (AK), which is feedback inhibited by SAM, leading to an overall reduction in L-Asp-derived amino acids (Curien et al. 2009). A model of this kind can thus be used to predict how other alterations, such as a 3-fold increase in L-Met flux would affect the overall L-Asp metabolic pathway in vivo. The $A$. thaliana model took into consideration different homologues for several enzymes, including L-Asp kinase (AK), dihydrodipicolinate synthase (DHDPS), and homoserine dehydrogenase (HSDH) (Curien et al. 2009). The authors recognized that these homologues have distinct effects on metabolic flux due to their different kinetic parameters, and so each homologue must be represented in the model. However, the second homologue of A. thaliana TS, AtTS2, was not included in the model because its measured $k_{\text {cat }}$ is 120 -fold lower than that of AtTS1 at physiological SAM concentrations $(20 \mu \mathrm{M})$, and it was assumed not to be colocated in the chloroplast with AtTS1 and CGS (Curien et al. 1996; Curien et al. 2009). We have subsequently shown that AtTS2 possesses a functional plastid targeting sequence, suggesting that it should be further characterized and considered in a model of OPHS partitioning in A. thaliana (Chapter 3). 
The biochemical characterization of TS from a variety of plant species, including A. thaliana, Lemna paucicostata, Pisum sativum, and Beta vulgaris, has been reported and inter-species variation is apparent (Madison and Thompson, 1976; Giovanelli et al. 1984; Thoen et al. 1978; Curien et al. 1998; Laber et al. 1999). For example, $K_{m}{ }^{\text {OPHS }}$ values of $2.2 \mathrm{mM}$ and $0.67 \mathrm{mM}$ have been reported for $P$. sativum TS in the absence and presence, respectively, of $400 \mu \mathrm{M}$ SAM, while the corresponding $K_{m}{ }^{\text {OPHS }}$ values of AtTS1, of A. thaliana, are $120 \mu \mathrm{M}$ and $30 \mu \mathrm{M}$ (Thoen et al. 1978; Laber et al. 1999). In contrast, the $K_{m}{ }^{\text {OPHS }}$ of CGS from $A$. thaliana and Spinacia oleraceae is reported at $2.5 \mathrm{mM}$ and $1.4 \mathrm{mM}$, respectively, more than one order of magnitude higher than the intraplastidial OPHS concentration of 50-100 $\mu \mathrm{M}$ (Ravanel et al. 1995; Ravanel et al. 1998b). This indicates the importance of TS in OPHS distribution, and for studies attempting to increase the free L-Met pool in vivo, as it accounts for 70-80\% of the flux of OPHS under physiological conditions (Curien et al. 2003). The inter-species variation in the kinetic parameters of TS and CGS also illustrates the need to develop kinetic models of the OPHS branch point in the species of interest prior to engaging in genetic engineering studies. The creation of a kinetic model of the OPHS branch-point for both C. arietinum and L. culinaris will enable prediction of effect of interventions on the partitioning of OPHS, and focus in vivo studies on those changes less likely to result in a deleterious phenotype. 


\subsection{Methods}

\subsubsection{Materials}

Pyruvate kinase (PK), L-homoserine (L-HSer), phospho(enol) pyruvate (PEP), adenosine-5'-triphosphate (ATP), ammonium sulfate, $\beta$-nicotinamide adenine dinucleotide (NADH), calf intestinal alkaline phosphatase (CIAP), ninhydrin, ammonium molybdate, and Triton X-100 were obtained from Sigma-Aldrich. 4-(2Hydroxyethyl)-1-piperazineethanesulfonic acid (Hepes), dithiothreitol (DTT), ethylenediaminetetraacetic acid (EDTA), and isopropyl- $\beta$-D-thiogalactopyranoside (IPTG) were Fisher Scientific products. Nickel-nitrilotriacetic acid (Ni-NTA) resin was purchased from Qiagen. Toyopearl butyl-650M resin was from TosoHaas. Malachite green and diethylaminoethyl (DEAE)-Sepharose resin were from BDH and GE Healthcare, respectively. The $\Delta t h r C 724($ del)::kan E. coli strain JW0003-2 was obtained from The Escherichia coli Genetic Stock Center. Synthesis of OPHS and expression and purification of 6-Histidine (6-His) tagged $\mathrm{eTD}_{\mathrm{L} 447 \mathrm{~F}}$ and $\mathrm{HO}-\mathrm{HxoDH}$ were completed as described in Chapter 3 (Morneau et al. 2012).

\subsubsection{Purification of wild-type plant TS}

Cells of E. coli strain JW0003-2 thrC724(del)::kan; ( $\Delta t h r C$; Baba et al. 2006), expressing wild-type TS from A. thaliana (AtTS1 and AtTS2), C. arietinum (CaTS), and L. culinaris (LcTS), under the trc promoter of the pTrc-99a2 expression vector were grown in $4 \mathrm{~L}$ Luria-Burtani (LB) broth at $37^{\circ} \mathrm{C}$ and $200 \mathrm{rpm}$ to mid-log phase $\left(\mathrm{OD}_{600}=0.5\right)($ Farsi et al. 2009). The cultures were induced with $150 \mu \mathrm{M}$ IPTG and incubated for a further $14 \mathrm{~h}$ prior to harvesting, via centrifugation at $5000 \mathrm{rpm}$ and 
$4^{\circ} \mathrm{C}$. Harvested cells were washed with $0.85 \% \mathrm{NaCl}$ and resuspended in $35 \mathrm{~mL}$ buffer A (50 mM Hepes, $\mathrm{pH} 7.5,20 \mu \mathrm{M}$ PLP). The cells were lysed by incubation with $1 \mathrm{mg} / \mathrm{mL}$ lysozyme on ice for $20 \mathrm{~min}$ followed by repeated $(8 \times 30 \mathrm{~s})$ cycles of sonication (Vibra Cell sonicator, Sonic and Material, Inc.).

The lysates were centrifuged at $15000 \mathrm{rpm}$ for $60 \mathrm{~min}$ at $4^{\circ} \mathrm{C}$ (Sorvall $\mathrm{RC} 6+$ centrifuge, Thermo Scientific). Ammonium sulfate was added to the supernatant to $30 \%$ saturation $(164 \mathrm{~g} / \mathrm{L})$ and centrifuged at $17500 \mathrm{rpm}$ for $75 \mathrm{~min}$. The resulting supernatant was applied to a $2.5 \times 10 \mathrm{~cm}$ column of Toyopearl butyl-650M resin equilibrated with buffer A containing 30\% ammonium sulfate. The column was washed with $250 \mathrm{~mL}$ of the same buffer, and the enzyme was eluted with a $500 \mathrm{~mL}$ linear gradient of $30 \%$ to $0 \%$ ammonium sulfate in buffer A. Fractions were tested for TS activity, using the continuous assay described in Chapter 3 (Morneau et al. 2012), and for purity, via sodium dodecyl sulfate-polyacrylamide gel electrophoresis (SDS-PAGE). The fractions containing TS activity and minimal contaminating proteins were pooled, concentrated, dialyzed against $3 \mathrm{~L}$ of buffer A for $16 \mathrm{~h}$, and loaded onto a $2.5 \times 10 \mathrm{~cm}$ column of DEAE-Sepharose resin. The column was washed with $250 \mathrm{~mL}$ buffer $\mathrm{A}$, and the enzyme was eluted with a $500 \mathrm{~mL}$ linear gradient of 0 to $500 \mathrm{mM} \mathrm{NaCl}$ in buffer A. Fractions were analyzed for activity and purity as described above, and those containing $>90 \%$ pure TS protein, as assessed by SDS-PAGE, were concentrated and dialyzed against buffer A containing $1 \mathrm{mM}$ EDTA for $16 \mathrm{~h}$ prior to the addition of $20 \%$ glycerol $(\mathrm{v} / \mathrm{v})$ and storage at $-80^{\circ} \mathrm{C}$. 


\subsubsection{Construction of expression construct and purification of affinity tagged CaTS}

The coding sequence of TS from C. arietinum (CaTS) was amplified with CaTS-specific primers to introduce a C-terminal, hexahistidine (6-His) affinity tag: 5' GC CAT ATG GCG GTG TCT TCT CTG TT and 5' GCT CTA GAC TAG TGG TGG TGG TGG TGG TGC TTT GGG GTC TTA CTC AAC (restriction sites are underlined, and the ATG start codon is in italics). The 6-His tagged CaTS (CaTS-His) was introduced between the NdeI and XbaI site of the pTrc99a2 expression vector (Farsi et al. 2009) and transformed into E. coli strain JW0003-2 thrC724(del)::kan ( $\Delta$ thrC; Baba et al. 2006).

Cells expressing CaTS-His were grown and harvested as described above. Harvested cells were washed with $0.85 \% \mathrm{NaCl}$ and resuspended in $35 \mathrm{~mL}$ buffer $\mathrm{B}$ (50 mM potassium phosphate, $\mathrm{pH} 7.5,20 \mu \mathrm{M}$ PLP). The cells were disrupted by incubation with $1 \mathrm{mg} / \mathrm{mL}$ lysozyme on ice for $20 \mathrm{~min}$, followed by sonication ( 8 cycles, $30 \mathrm{~s}$ each). The lysate was loaded onto a 1 x $5 \mathrm{~cm}$ column of Ni-NTA resin equilibrated with buffer B. The column was washed in $100 \mathrm{~mL}$ buffer $\mathrm{B}$, and the enzyme was eluted with a $200 \mathrm{~mL}$ gradient of $0-200 \mathrm{mM}$ imidazole. Fractions containing CaTS-His were analyzed as described above. Fractions were pooled, concentrated, and dialyzed overnight in buffer B containing $1 \mathrm{mM}$ EDTA prior to the addition of $20 \%$ glycerol $(\mathrm{v} / \mathrm{v})$ and storage at $-80^{\circ} \mathrm{C}$.

\subsubsection{Enzyme Assays}

All enzyme assays were performed in a total volume of $200 \mu \mathrm{L}$ at $25^{\circ} \mathrm{C}$ and monitored at $340 \mathrm{~nm}$ using an Agilent $8453 \mathrm{UV}$-visible spectrophotometer. The 
assay solution was composed of $50 \mathrm{mM}$ Hepes ( $\mathrm{pH} 7.5)$ containing $20 \mu \mathrm{M}$ PLP, $0.02-$ $5 \mathrm{mM}$ OPHS, $1.5 \mathrm{mM}$ NADH, eTD $\mathrm{L}_{447 \mathrm{~F}}(2.5 \mu \mathrm{M})$, HO-HxoDH $(5.4 \mu \mathrm{M})$. The requisite concentrations of the coupling enzymes $\mathrm{HO}-\mathrm{HxoDH}$ and $\mathrm{eTD}_{\mathrm{L} 447 \mathrm{~F}}$ at $\mathrm{pH} 7.5$ were calculated using equations (2.6) and (2.7), respectively, and were determined to be $13.3 \mu \mathrm{M}$ and $12.9 \mu \mathrm{M}$, respectively. The calculated concentrations were optimized experimentally to $5.4 \mu \mathrm{M}$ for $\mathrm{Ho}-\mathrm{HxoDH}$ and $2.5 \mu \mathrm{M}$ for eTD $\mathrm{T}_{\mathrm{L} 447 \mathrm{~F}}$ by independently varying the concentration of each enzyme. The reaction was demonstrated to be linear at TS concentrations ranging from $0.25-2 \mu \mathrm{M}$.

A background rate was recorded, and reactions were initiated with the addition of AtTS1 $(0.25-0.5 \mu \mathrm{M})$, AtTS2 $(1 \mu \mathrm{M})$, CaTS $(0.5 \mu \mathrm{M})$, CaTS-His $(0.25$ $0.5 \mu \mathrm{M})$, or LcTS $(0.25-0.5 \mu \mathrm{M})$. For assays containing SAM, the TS enzyme was incubated with $100 \mu \mathrm{M}$ SAM on ice for 5 min prior to initiation of the reaction. The $k_{c a t}$ and $K_{m}{ }^{\text {OPHS }}$ of AtTS1, AtTS2, CaTS, CaTS-His, and LcTS in the presence and absence of SAM were determined by fitting the data to the Michaelis-Menten equation. The $k_{c a} / K_{m}{ }^{\text {OPHS }}$ values were obtained independently using equation (2.1).

\subsection{Results}

Wild-type TS from A. thaliana (AtTS1 and AtTS2), C. arietinum (CaTS), L. culinaris (LcTS), and CaTS-His were recombinantly expressed in E. coli. The wildtype enzymes were purified via hydrophobic interaction and anion-exchange chromatography and the 6-His tagged CaTS protein was purified by Ni-NTA affinity chromatography. Their purity was assessed to be $>90 \%$ by SDS-PAGE (Figure 4.1 ). The yields of recombinant AtTS1, AtTS2, CaTS, CaTS-His, and LcTS were 39.9, 2.6, $6.4,8.5$, and $6.3 \mathrm{mg}$ per liter of $E$. coli culture, respectively. 
Figure 4.1. SDS polyacrylamide gel showing purified recombinant plant TS enzymes. Lanes: 1, protein molecular weight ladder (Benchmark, Invitrogen); 2, AtTS1; 3, AtTS2; 4, CaTS; 5, CaTS-His; 6, LcTS. The 10\% polyacrylamide gel was loaded with $2 \mu \mathrm{g}$ protein per lane and stained with Coomassie brilliant blue. 


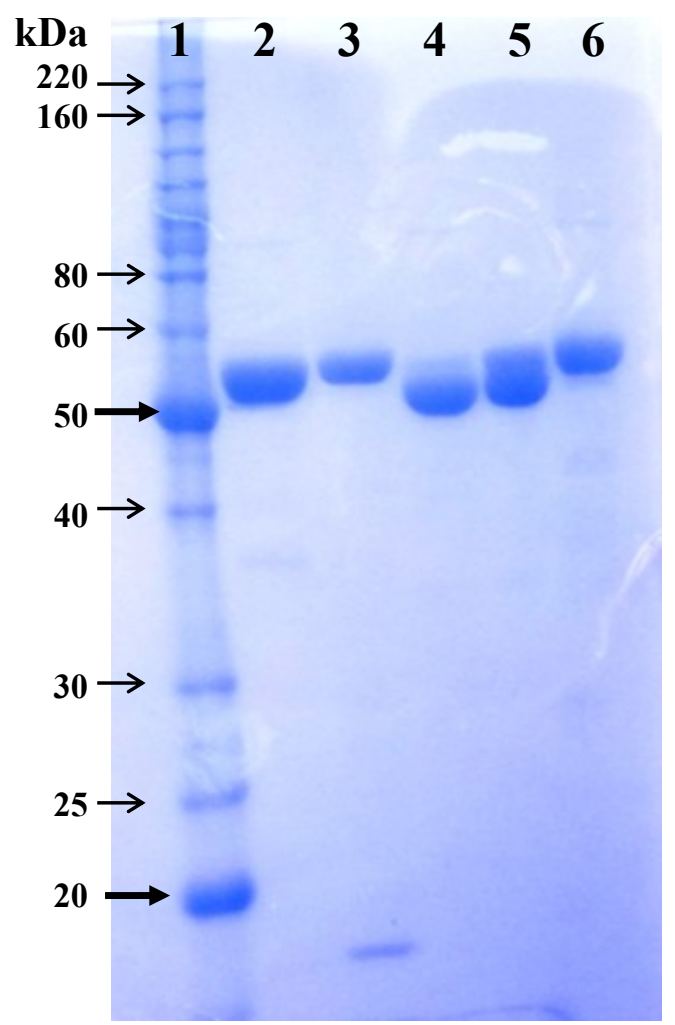




\subsubsection{Kinetic Parameters}

The kinetic parameters of AtTS1 were measured in the presence and absence of $100 \mu \mathrm{M}$ SAM (Figure 4.2; Table 4.1). The presence of $100 \mu \mathrm{M}$ SAM in the reaction results in an 8.5-fold increase in the $k_{c a t}$ of AtTS1, from $0.20 \pm 0.04 \mathrm{~s}^{-1}$ to 1.7 $\pm 0.1 \mathrm{~s}^{-1}$. The measured $k_{\text {cat }} / K_{m}{ }^{\text {OPHS }}$ of AtTS1 increases 80 -fold in the presence of SAM, from $(3 \pm 1) \times 10^{2} \mathrm{M}^{-1} \mathrm{~s}^{-1}$ to $(2.4 \pm 0.3) \times 10^{4} \mathrm{M}^{-1} \mathrm{~s}^{-1}$ (Table 4.1). For CaTS and LcTS, the presence of $100 \mu \mathrm{M}$ SAM results in a 2.5 -fold and 4-fold increase in $k_{c a t}$, respectively, and a 11 -fold and 5 -fold decrease in $K_{m}{ }^{\mathrm{OPHS}}$, respectively (Table 4.1; Figure $4.3 \mathrm{~A}$ and B). The $k_{c a t} / K_{m}$ OPHS of CaTS increases 25-fold in the presence of SAM, from $(6 \pm 1) \times 10^{2} \mathrm{M}^{-1} \mathrm{~s}^{-1}$ to $(1.5 \pm 0.3) \times 10^{4} \mathrm{M}^{-1} \mathrm{~s}^{-1}$ (Table 4.1). Similarly, the $k_{\text {cat }} / K_{m}{ }^{\text {OPHS }}$ of LcTS increases 20 -fold, from $(7 \pm 3) \times 10^{2} \mathrm{M}^{-1} \mathrm{~s}^{-1}$ to $(1.4 \pm 0.2) \mathrm{x}$ $10^{4} \mathrm{M}^{-1} \mathrm{~s}^{-1}$ in the presence of SAM (Table 4.1). The addition of the 6-His tag on the C-terminus of CaTS results in 5-fold and 3-fold increases in $K_{m}{ }^{\text {OPHS }}$ and $k_{\text {cat }}$, respectively, thereby lowering $k_{c a t} / K_{m}{ }^{\text {OPHS }} 1.4$-fold in the presence of $100 \mu \mathrm{M}$ SAM, compared to wild-type CaTS (Figure 4.4).

The $k_{c a t}$ of AtTS2 increases 7 -fold with a 1.5 -fold decrease in $K_{m}{ }^{\text {OPHS }}$ in the presence of $100 \mu \mathrm{M}$ SAM (Table 4.1; Figure 4.3C). These changes in kinetic parameters lead to an 8.5 -fold increase in the $k_{\text {cat }} / K_{m}{ }^{\text {OPHS }}$ value of AtTS2 when 100 $\mu \mathrm{M}$ SAM is added to the reaction (Table 4.1). 
Figure 4.2. The dependence of AtTS1 activity on OPHS concentration in the presence $(\bullet)$ and absence $(\circ)$ of $100 \mu \mathrm{M}$ SAM. The kinetic parameters are given in Table 4.1. Reaction conditions: 50 mM Hepes (pH 7.5), $1.5 \mathrm{mM}$ NADH, $20 \mu \mathrm{M}$ PLP, $2.5 \mu \mathrm{M}_{\text {eTD }}$ L447F,, $4 \mu \mathrm{M}$ HO-HxoDH, 0.25-0.5 $\mu \mathrm{M}$ AtTS1, and 0.02-5 mM OPHS. 


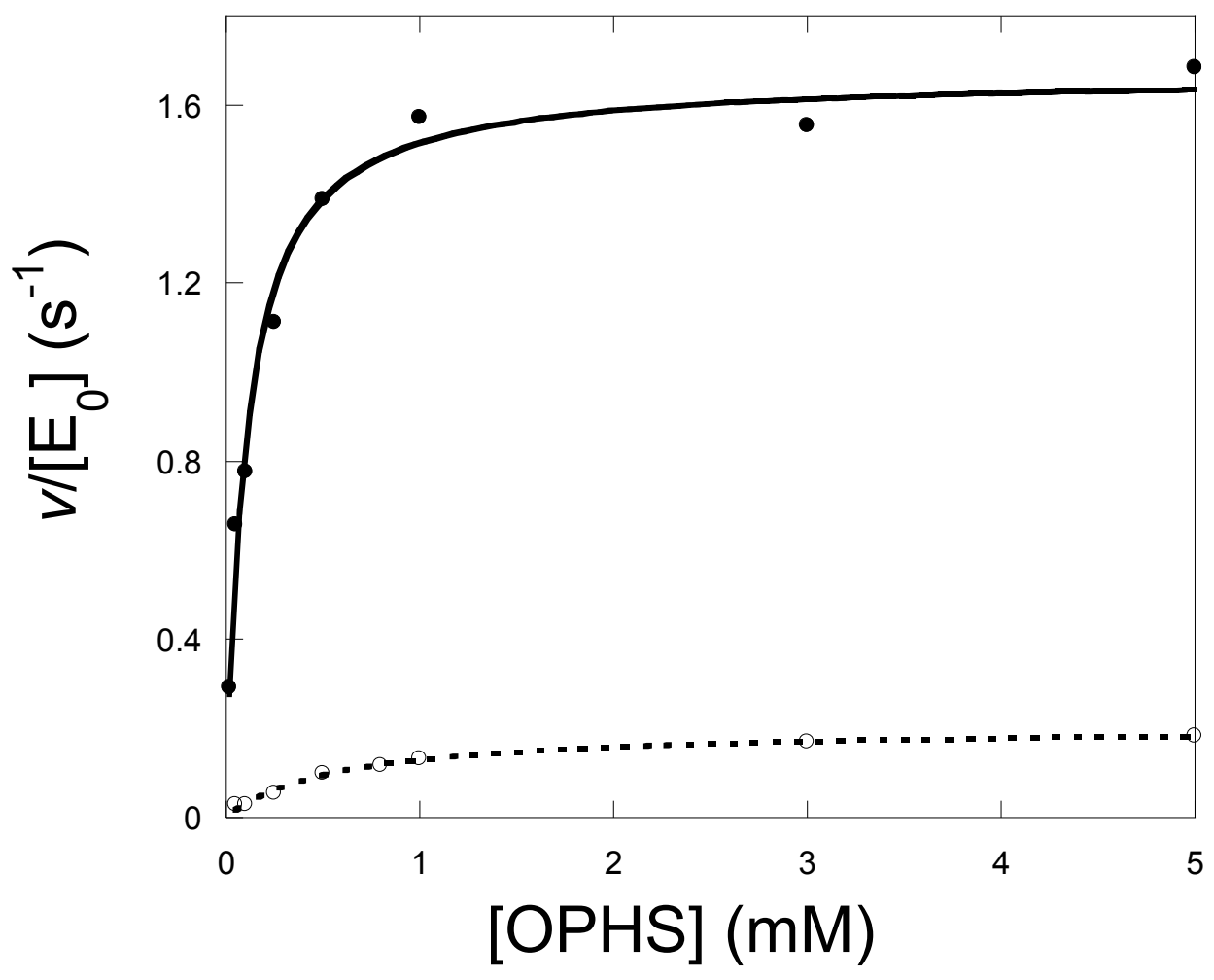


Table 4.1. Kinetic parameters of wild-type TS from A. thaliana, C. arietinum and L. culinaris and C-terminally 6-His tagged TS from $C$. arietinum (CaTS-His), in the presence and absence of $100 \mu \mathrm{M}$ SAM.

\begin{tabular}{ccccccc}
\hline TS Construct & $\begin{array}{c}K_{m}{ }^{\text {OPHS }}(\mu \mathrm{M}) \\
(100 \mu \mathrm{M} \mathrm{SAM})\end{array}$ & $\begin{array}{c}K_{m}{ }^{\mathrm{OPHS}} \\
(\mu \mathrm{M}) \\
(\text { no SAM })\end{array}$ & $\begin{array}{c}k_{\text {cat }}\left(\mathrm{s}^{-1}\right) \\
(100 \mu \mathrm{M} \\
\mathrm{SAM})\end{array}$ & $\begin{array}{c}k_{\text {cat }}\left(\mathrm{s}^{-1}\right) \\
(\text { no SAM })\end{array}$ & $\begin{array}{c}k_{\text {cat }} / K_{m}{ }^{\text {OPHS }}\left(\mathrm{M}^{-1} \mathrm{~s}^{-1}\right) \\
(100 \mu \mathrm{M} \mathrm{SAM})\end{array}$ & $\begin{array}{c}k_{\text {cat }} / K_{m}{ }^{\text {OPHS }}\left(\mathrm{M}^{-1} \mathrm{~s}^{-1}\right) \\
(\text { no SAM })\end{array}$ \\
\hline CaTS (WT) & $70 \pm 20$ & $800 \pm 200$ & $1.00 \pm 0.04$ & $0.40 \pm 0.03$ & $(1.5 \pm 0.3) \times 10^{4}$ & $(6 \pm 1) \times 10^{2}$ \\
CaTS-His & $300 \pm 30$ & $500 \pm 200$ & $2.9 \pm 0.1$ & $1.5 \pm 0.2$ & $(1.1 \pm 0.1) \times 10^{4}$ & $(3 \pm 1) \times 10^{3}$ \\
LcTS (WT) & $100 \pm 15$ & $500 \pm 250$ & $1.50 \pm 0.04$ & $0.35 \pm 0.05$ & $(1.4 \pm 0.2) \times 10^{4}$ & $(7 \pm 3) \times 10^{2}$ \\
AtTS2 (WT) & $400 \pm 30$ & $600 \pm 300$ & $0.70 \pm 0.01$ & $0.10 \pm 0.02$ & $(1.7 \pm 0.1) \times 10^{3}$ & $(2.0 \pm 0.1) \times 10^{2}$ \\
AtTS1 (WT) & $70 \pm 10$ & $700 \pm 500$ & $1.7 \pm 0.1$ & $0.20 \pm 0.04$ & $(2.4 \pm 0.3) \times 10^{4}$ & $(3 \pm 1) \times 10^{2}$ \\
Reported & 30 & 120 & 0.86 & 0.04 & $2.9 \times 10^{4}$ & $3.3 \times 10^{2}$ \\
AtTS1 & & & & & & \\
\hline
\end{tabular}

${ }^{a}$ Laber et al. 1999 
Figure 4.3. The dependence of the activity of CaTS (A), LcTS (B), and AtTS2 (C) on OPHS in the presence $(\bullet)$ and absence $(\circ)$ of $100 \mu \mathrm{M}$ SAM. Reaction conditions: 50 mM Hepes (pH 7.5), $1.5 \mathrm{mM}$ NADH, $20 \mu \mathrm{M}$ PLP, $2.5 \mu \mathrm{M}$ eTD L447F, $5.4 \mu \mathrm{M}$ HO$\mathrm{HxoDH}$, and 0.02-5 mM OPHS. Reactions were initiated with the addition of $0.5 \mu \mathrm{M}$ CaTS, 0.25-0.5 $\mu \mathrm{M}$ LcTS, or $1 \mu \mathrm{M}$ AtTS2. 

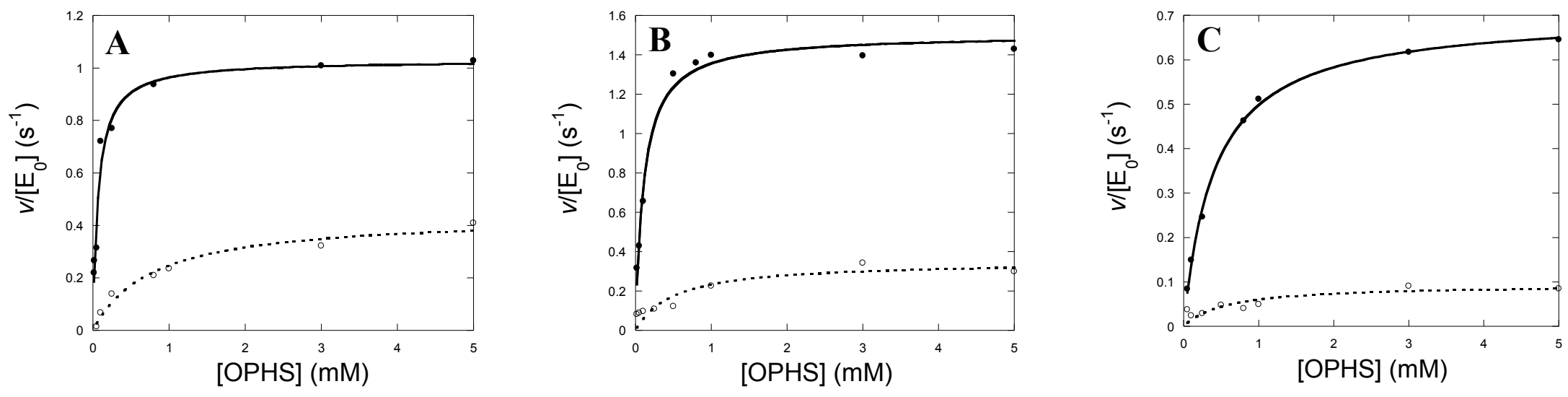
Figure 4.4. The dependence of the activity of CaTS (•) and CaTS-His (०) on OPHS concentration in the presence (A) or absence (B) of $100 \mu \mathrm{M}$ SAM. Reaction conditions were $50 \mathrm{mM}$ Hepes $(\mathrm{pH}$ 7.5), $1.5 \mathrm{mM}$ NADH, $20 \mu \mathrm{M}$ PLP, $2.5 \mu \mathrm{M}$ $\mathrm{eTD}_{\mathrm{L} 447 \mathrm{~F}}, 5.4 \mu \mathrm{M}$ HO-HxoDH, 0.02-5 mM OPHS, and 0.5-1 $\mu \mathrm{M}$ CaTS or 0.25-0.5 $\mu \mathrm{M}$ CaTS-His. 

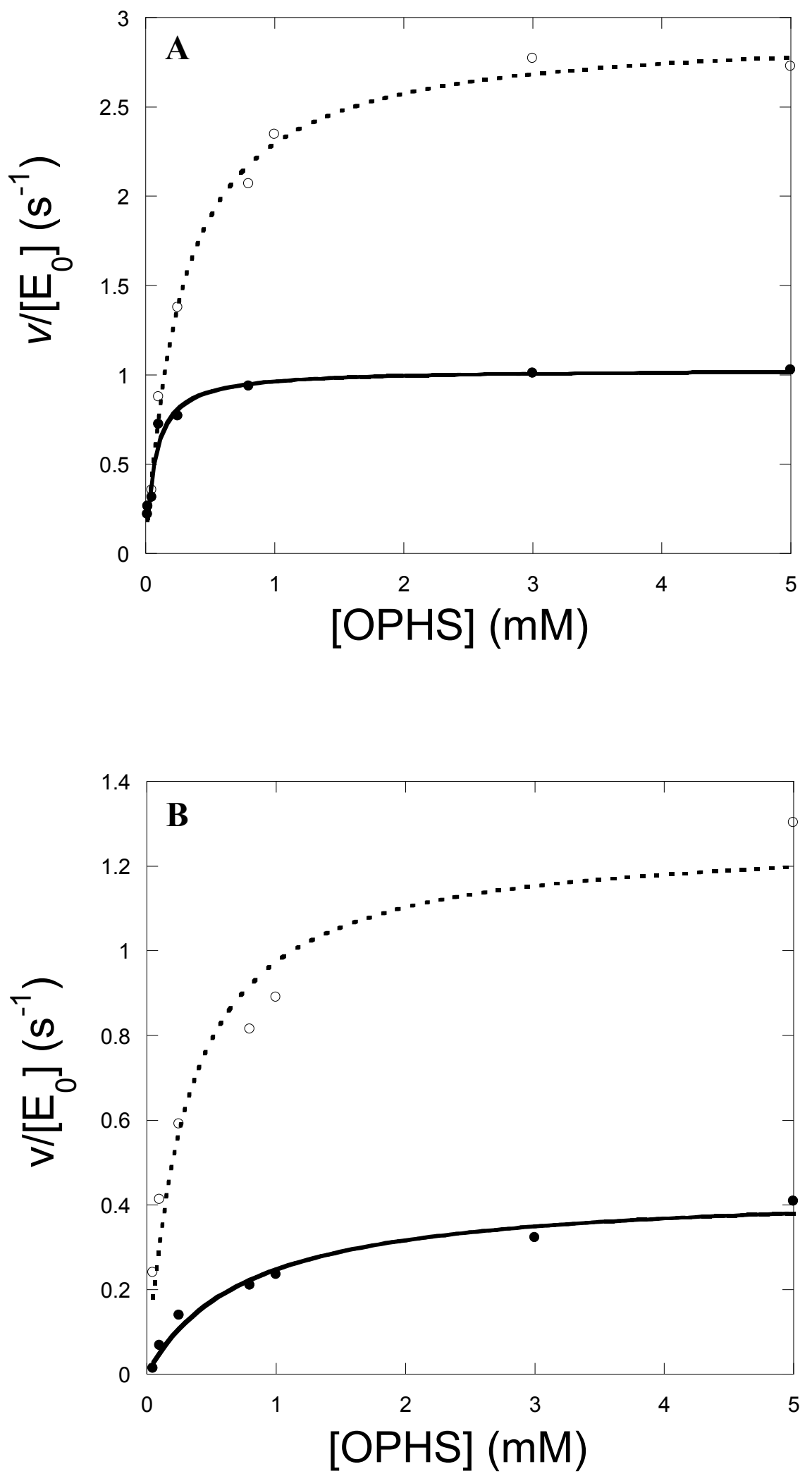


\subsection{Discussion}

Increasing L-Met in staple crops such as $C$. arietinum and L. culinaris is of particular interest in the field of plant biotechnology, given their nutritional deficiency in this essential amino acid. In plants, OPHS occupies the branch-point between L-Met and L-Thr biosynthesis, and the metabolic flux between these two pathways is regulated by the L-Met-metabolite SAM. The complexity of the regulation of OPHS partitioning has confounded metabolic engineering endeavours, as exemplified in the systemic metabolic disruptions observed in previous attempts (Zeh et al. 2001; Gakiere et al. 2002; Avraham and Amir, 2005; Kusano et al.2010). The creation of a kinetic model of the OPHS branch-point in the target species will facilitate the pursuit of increased L-Met biosynthesis by providing a tool for predicting the effect of genetic engineering studies focusing on CGS and/or TS (Curien et al. 2009; Rohwer, 2012). This type of model first requires the kinetic parameters of the component enzymes under conditions of minimum and maximum activity (Rohwer, 2012).

The presence of $100 \mu \mathrm{M}$ SAM results in an 8.5-fold increase in the $k_{\text {cat }}$ of AtTS1 (from $0.20 \pm 0.04 \mathrm{~s}^{-1}$ to $1.7 \pm 0.1 \mathrm{~s}^{-1}$ ) and a 10 -fold decrease in $K_{m}{ }^{\text {OPHS }}$ (from $700 \pm 500 \mu \mathrm{M}$ to $70 \pm 10 \mu \mathrm{M})$. The resulting $k_{c a t} / K_{m}{ }^{\text {OPHS }}$ value of $(2.4 \pm 0.3) \times 10^{4} \mathrm{M}^{-}$ ${ }^{1} \mathrm{~s}^{-1}$, in the presence of SAM, is consistent with the previously reported value of $2.9 \mathrm{x}$ $10^{4} \mathrm{M}^{-1} \mathrm{~s}^{-1}$ at $100 \mu \mathrm{M}$ SAM (Laber et al. 1999). The catalytic efficiency of AtTS 1 in the absence of SAM $\left(k_{c a t} / K_{m}{ }^{\text {OPHS }}=(3 \pm 1) \times 10^{2} \mathrm{M}^{-1} \mathrm{~s}^{-1}\right)$ is also consistent with the previously reported value of $3.3 \times 10^{2} \mathrm{M}^{-1} \mathrm{~s}^{-1}$ (Laber et al. 1999). The minor, 2-fold 
differences in the $k_{\text {cat }}$ and $K_{m}{ }^{\text {OPHS }}$ values of AtTS1, compared to those reported by Laber and colleagues $\left(k_{c a t}=0.86 \mathrm{~s}^{-1}, K_{m}{ }^{\text {OPHS }}=30 \mu \mathrm{M}\right)$, may be due to differences in assay conditions, as Laber et al used the end-point malachite green assay while we employed the recently developed continuous assay, described in Chapter 3 (Laber et al. 1999; Morneau et al. 2012). The use of a continuous assay ensures that kinetic parameters are measured under steady-state conditions (Shepherd and Dailey, 2005). The assumption of linearity over the course of the assay period and the potential of product, which builds up in an end point assay, to compete with substrate for binding to the active site can lead to underestimation of $k_{c a t}$ when employing an end-point assay. The discrepancies in the observed kinetic parameters of AtTS1 may also be the result of variation in the estimation of OPHS or protein concentrations, which would affect $K_{m}{ }^{\mathrm{OPHS}}$ and $k_{\text {cat }}$, respectively.

The $k_{c a t}$ and $K_{m}{ }^{\text {OPHS }}$ values of CaTS $\left(1.00 \pm 0.04 \mathrm{~s}^{-1}\right.$ and $\left.70 \pm 20 \mu \mathrm{M}\right)$ and LcTS $\left(1.50 \pm 0.04 \mathrm{~s}^{-1}\right.$ and $\left.100 \pm 15 \mu \mathrm{M}\right)$ are similar to the measured parameters for AtTS1 $\left(1.7 \pm 0.1 \mathrm{~s}^{-1}\right.$ and $\left.70 \pm 10 \mu \mathrm{M}\right)$, suggesting the L-Asp metabolic model could be used to inform the rational metabolic engineering of the pulse species (Curien et al. 2009). However, the effect of SAM on the $k_{\text {cat }}$ of AtTS1 (8.5-fold increase), CaTS (2.5-fold increase) and LcTS (4-fold increase) is distinct. The $k_{c a t}$ and $K_{m}$ values of both enzymes in the presence and absence of SAM were analyzed using the equations 4.1 and 4.2, respectively (Curien et al. 2003), in order to determine the apparent kinetic parameters as a function of SAM concentration to measure the flux of OPHS at the branch-point. 


$$
\begin{aligned}
k_{c a t}^{a p p} & =\frac{k_{c a t}^{n o S A M}+k_{c a t}^{S A M} x \frac{[S A M]^{2}}{K_{1} K_{2}}}{\frac{\left(1+[S A M]^{2}\right)}{K_{1} K_{2}}} \\
K_{m}^{a p p} & =\left(\frac{K_{m}^{n o S A M} x \frac{1+\frac{[S A M]}{0.5}}{1+\frac{[S A M]}{1.1}}}{1+\frac{[S A M]^{2}}{K_{m}^{S A M}}}\right)
\end{aligned}
$$

With $K_{l} K_{2}$ representing the binding constants for the association of SAM $\left(73 \mu \mathrm{M}^{2}\right)$ with AtTS1 (Curien et al. 2003). These equations take into account SAM concentration as a factor in the $k_{\text {cat }}$ and $K_{m}$ value of plant TS, allowing for the calculation of the parameters at varying SAM concentrations. Setting the SAM concentration to physiological levels $(20 \mu \mathrm{M})$, the $k_{c a t}^{a p p}$ and $K_{m}^{a p p}$ of AtTS1 were calculated as $1.5 \mathrm{~s}^{-1}$ and $230 \mu \mathrm{M}$, respectively. The $k_{c a t}^{a p p}$ and $K_{m}^{a p p}$ of AtTS2, CaTS, and LcTS were calculated as $0.6 \mathrm{~s}^{-1}$ and $650 \mu \mathrm{M}, 0.9 \mathrm{~s}^{-1}$ and $260 \mu \mathrm{M}$, and $1.3 \mathrm{~s}^{-1}$ and $220 \mu \mathrm{M}$, respectively. The flux of OPHS ( $\left.J_{\mathrm{OPHS}}\right)$ is equal to the sum of the flux of $\mathrm{L}-$ cystathionine $\left(J_{\text {Cyst }}\right)$ and the flux of L-Thr $\left(J_{\text {Thr }}\right)$, which are defined as the MichaelisMenten equation using $k_{c a t}^{a p p}$ and $K_{m}^{a p p}$ of TS and CGS. The calculation of $J_{\text {Thr }}$ was completed using equation 4.3.

$$
J_{T h r}=\frac{k_{c a t}^{a p p}[T S][O P H S]}{K_{m}^{a p p}+[O P H S]}
$$

With [OPHS] and [TS] set to the physiological concentration estimates used in the construction of the $A$. thaliana OPHS branch-point ( $80 \mu \mathrm{M}$ and $5 \mu \mathrm{M}$, respectively) (Curien et al. 2003), the $J_{\mathrm{Thr}}$ of CaTS and LcTS was calculated as $1.1 \mu \mathrm{M} \mathrm{s}^{-1}$ and 1.7 
$\mu \mathrm{M} \mathrm{s}^{-1}$, respectively, compared to the $J_{\mathrm{Thr}}$ of $1.9 \mu \mathrm{M} \mathrm{s}^{-1}$ of AtTS1 and $0.3 \mu \mathrm{M} \mathrm{s}^{-1}$ of AtTS2. In comparison, $J_{\text {Cyst }}$ in $A$. thaliana was calculated as $0.1 \mu \mathrm{M} \mathrm{s}^{-1}$ based on $k_{\text {cat }}$ and $K_{m}{ }^{\text {OPHS }}$ and $K_{m}{ }^{\text {Cys }}$ values measured previously (Ravanel et al. 1998a; Curien et al. 2003). These values indicate that in A. thaliana, under physiological conditions and including the two forms of TS, $J_{\mathrm{OPHS}}=2.4 \mu \mathrm{M} \mathrm{s}^{-1}$. AtTS1 was calculated to account for $80 \%$ of OPHS flux, however, the addition of AtTS2, which was calculated to be responsible for $14 \%$ of OPHS flux, decreases $J_{\text {Cyst }}$ to approximately $6 \%$ of the flux of OPHS, compared to the $20-30 \%$ it was previously attributed (Curien et al. 2003). Since the kinetic parameters of CGS from the pulse species are lacking, an estimation of $J_{\mathrm{OPHS}}$ can be made using $J_{\mathrm{Cyst}}$ from $A$. thaliana, where $J_{\mathrm{OPHS}}$ in C. arietinum and $L$. culinaris are equal to $1.2 \mu \mathrm{M} \mathrm{s}^{-1}$ and $1.8 \mu \mathrm{M} \mathrm{s}^{-1}$, respectively. With this assumption, CaTS and LcTS account for $91 \%$ and $94 \%$ of OPHS flux, respectively. The role of CaTS and LcTS in OPHS flux partitioning is subject to change with the determination of the kinetic parameters of pulse CGS. According to these calculations, the branchpoint model from $A$. thaliana cannot be used to study OPHS flux in the pulse species because the magnitude of flux partitioning of AtTS1 differs from that of CaTS and LcTS.

The $k_{\text {cat }} / K_{m}{ }^{\text {OPHS }}$ of AtTS2 is 14 -fold lower than that of AtTS1 in the presence of $100 \mu \mathrm{M}$ SAM. The presence of SAM has negligible effect on the $K_{m}{ }^{\text {OPHS }}$ of AtTS2 $(600 \pm 300 \mu \mathrm{M}$ in the presence of $100 \mu \mathrm{M}$ SAM versus $400 \pm 30 \mu \mathrm{M}$ in the absence of SAM). In contrast, the allosteric effector resulted in similar increases of 8.5-fold and 7-fold in the $k_{\text {cat }}$ of AtTS1 and AtTS2, respectively. These results demonstrate that while AtTS2 is allosterically activated by SAM, the mechanism is likely different 
from that of AtTS1 (Table 4.1). A. thaliana gene expression array tools revealed ubiquitous mRNA expression of AtTS1 and AtTS2 in A. thaliana, with similar expression levels between the two homologues, although the expression of AtTS1 is approximately 30-fold higher in select tissues than that of AtTS2 (Figure 4.5). Peak expression of AtTS1 is observed in the late-stage development of seeds, and peak AtTS2 transcript expression is found in the apical meristem, floral organs, and the hypocotyl of $A$. thaliana (Figure 4.5) (Schmid et al. 2005; Winter et al. 2007). The systemic expression of both forms of AtTS indicates that the biosynthesis of L-Thr occurs in all plant tissues; however, the concentration of both AtTS1 and AtTS2 in rapidly developing tissues such as seeds, flowers, and meristemic tissue, suggests high levels of amino acid biosynthesis are required for developing tissues. This is similar to the transcript expression patterns of $A$. thaliana aspartate kinase (AK), which has distinct peak transcript expression in rapidly developing tissues for its various homologues, such as the rosette $(A K 1)$, first node ( $A K 2$ and $A K 3)$, and shoot apex (bifunctional $A K-H S D H$ ) (Winter et al. 2007). The expression pattern of AtTS2 suggests that the second form of TS in A. thaliana may have evolved to support amino acid biosynthesis in developing tissues in order to meet the amino acid requirements for development.

When creating a kinetic model of a metabolic pathway, all active forms of the enzyme(s) in the pathway must be included in order to develop an accurate model, since the different homologues of each enzyme in the pathway may contribute uniquely to the flux of metabolites. The use of an incomplete kinetic model in metabolic engineering design may lead to ineffective alterations to flux due to the 
Figure 4.5. Expression patterns of AtTS1 (A) and AtTS2 (B) in various tissues of $A$. thaliana. The fold-change $(\mathrm{C})$ of the expression of AtTS1 relative to AtTS2 is also shown. Data obtained from the Arabidopsis electron fluorescent pictograph (eFP) browser provided by the Bio-Analytic Resource (BAR) at the University of Toronto (Winter et al. 2007). 
A

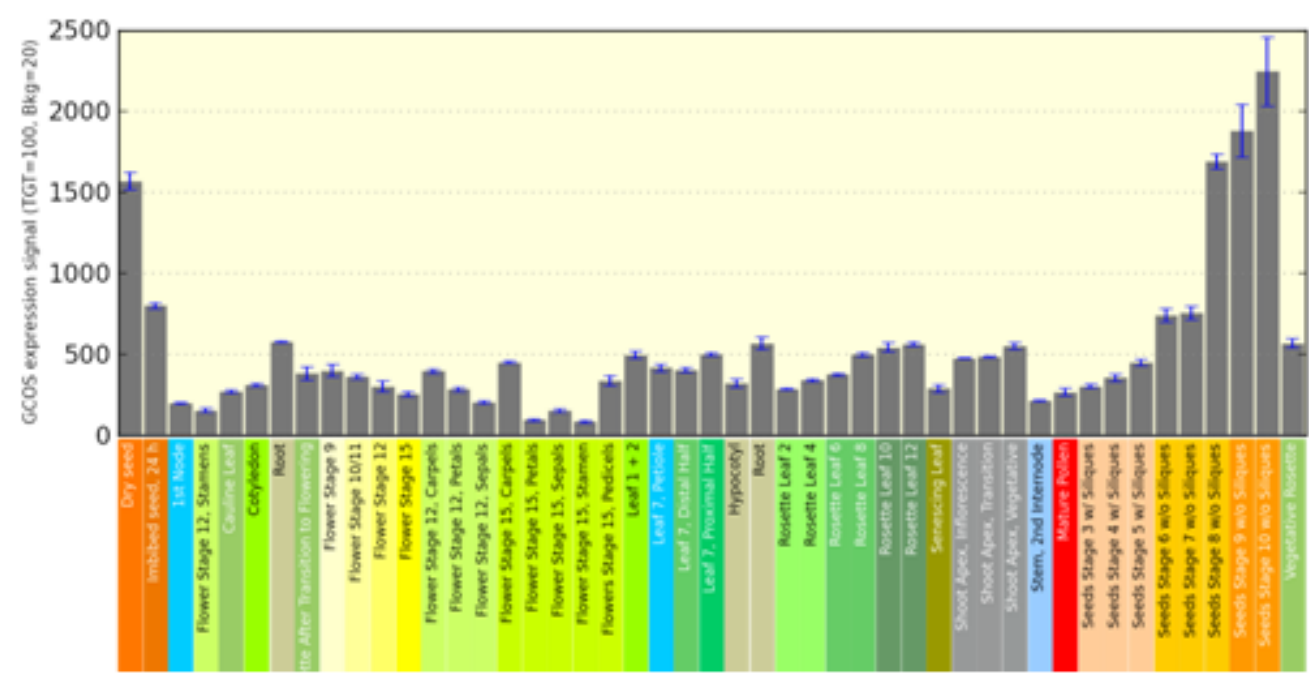

B

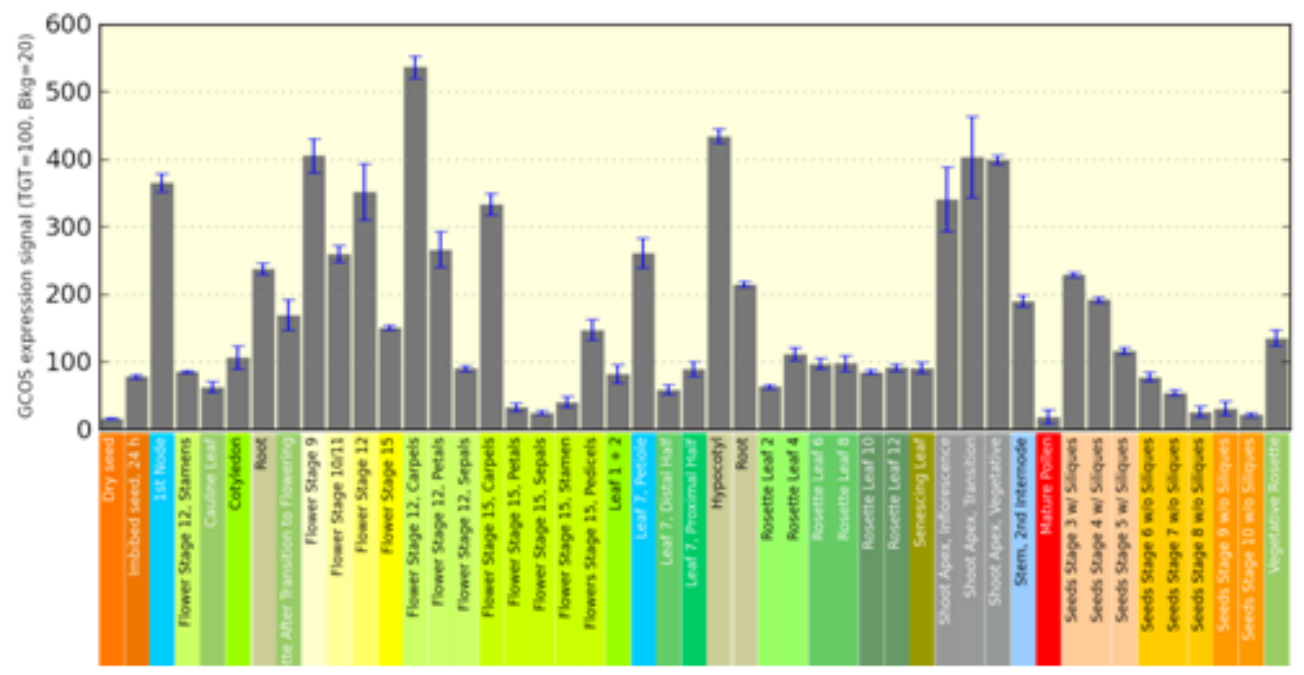

C

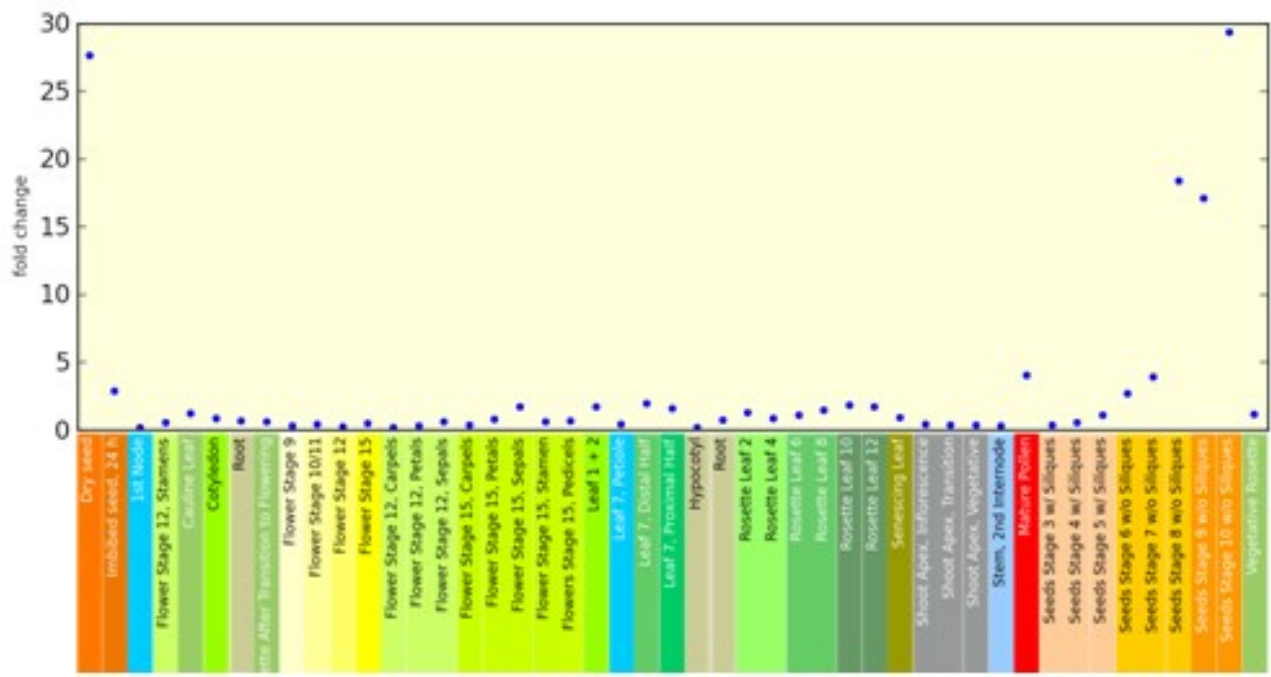


unforeseen contribution of the omitted isoforms of the enzyme. For example, a kinetic model of the L-Asp metabolic pathway that were to use only one homologue of AK to represent the flux of L-Asp, rather than the four forms of AK found in $A$. thaliana, would result in that particular homologue being attributed $100 \%$ of the control over metabolic flux, leading to an overestimation of its influence (Curien et al. 2007). In the case of AtTS1, the calculations of $J_{\text {Thr }}$ indicate that while AtTS1 may account for $80 \%$ of the flux, only approximately $6 \%$ of the remaining flux of OPHS goes to L-Met synthesis. Any attempts at altering the regulation or expression of AtTS1 in order to reduce the flux would not have accounted for the $14 \%$ of OPHS flux diverted to AtTS2, thus leading to the potential overestimation of the effect of metabolic engineering strategies.

A C-terminal 6-His tag was added to CaTS to enable affinity chromatography in an attempt to expedite purification and increase enzyme purity. The addition of the affinity tag to CaTS results in a 3-fold increase in $k_{\text {cat }}$ and a 4-fold increase in $K_{m}{ }^{\text {OPHS }}$, compared to wild-type CaTS, in the presence and absence of $100 \mu \mathrm{M}$ SAM. The shift in the kinetic parameters indicates that the addition of a C-terminal affinity tag should not be employed for plant TS. The C-terminus of the protein is situated in proximity to the SAM-binding domain at the dimer interface, such that the 6-His tag may influence communication between the 2 sites, thereby shifting the kinetic parameters compared to the wild-type version of the enzyme (Mas-Droux et al. 2006). In $A$. thaliana, the two solvent-exposed SAM molecules (SAM2 and SAM4) form stacking interactions between their adenosine rings and W101 (W139 in CaTS) of each monomer, triggering a $150^{\circ}$ rotation of the PLP molecule (Mas-Droux et al. 2006). 
This shift results in the catalytically competent form of the active site and facilitates the binding of substrate (Mas-Droux et al. 2006). In the absence of SAM, the imidazole rings of the 6-His tag may interact with these tryptophan residues in a similar manner, causing a partial shift in the PLP co-factor, accounting for the 4-fold

increase in $k_{\text {cat }}$, and the subsequent 5 -fold increase in $k_{c a t} / K_{m}{ }^{\text {OPHS }}$ when compared to CaTS in the absence of SAM.

\subsection{Conclusion}

In plants, the concentration of many amino acids may be altered by perturbations in the metabolic flux of neighboring pathways, as many amino acid biosynthetic pathways, like those derived from L-Asp, rely on common metabolite pools. Previous attempts to increase L-Met biosynthesis, that modified the regulation or expression of TS or CGS, resulted in unintended changes in the partitioning of metabolites in the L-Asp pathway, often associated with undesirable phenotypic effects (Inaba et al. 1994; Bartlem et al. 2000; Zeh et al. 2001; Gakiere et al. 2002; Avraham and Amir, 2005). A kinetic model recreating the OPHS branch-point in the target species will be useful in informing metabolic engineering by providing a tool to predict potential alterations to the flux of adjoining pathways (Rohwer, 2012). Since the flux of OPHS depends exclusively on TS and CGS activity, branch-point kinetics can be modelled with the rate equations of both enzymes and the physiological concentrations of OPHS, L-Cys, and SAM (Curien et al. 2003). The kinetic parameters of TS from C. arietinum and L. culinaris are now known, and can be combined with those of CGS from the pulse species, when they become available, to 
create the branch-point model. Following the mathematical reconstruction of the OPHS branch-point, the model must be validated by reconstitution in vitro, using enzymes and metabolites at physiological concentrations, and making any necessary adjustments to variables of the model based on experimental data (Curien et al. 2003; Curien et al. 2009). The data presented in this chapter can be used to inform future metabolic engineering projects in pulse species to successfully increase L-Met production to levels that meet human daily intake requirements. 


\section{GENERAL CONCLUSION}

Legumes such as $C$. arietinum and $L$. culinaris are rich in carbohydrates, proteins, fiber, and minerals, and so are considered to be among the most nutritional sources of plant protein (Singh, 1985; Dixon and Hosking, 1992). However, they are not balanced sources of amino acids, as they are deficient in the essential amino acid methionine (L-Met) from the perspective of human dietary requirements. Supplementing a legume-rich diet with a balanced intake of cereals and animal sources can provide adequate amounts of essential amino acids. However, up to $90 \%$ of the consumption of legumes occurs in developing countries where vegetarianism is predominant and particularly in rural areas where poverty prevents access to a varied diet (Muntz et al. 1998; Agriculture and Agri-Food Canada, 2011). A sub-optimal intake of essential amino acids can lead to protein energy malnutrition (PEM), which manifests itself in lowered disease resistance, decreased blood proteins, as well as mental and physical developmental retardation in children (Hoorweg and Stanfield, 1976). It is estimated that one third of the children in developing countries suffer from PEM (de Onis, 1993; World Health Organization, 2006). The demand to improve the nutritional quality of staple crops such as C. arietinum and L. culinaris has grown in recent years (Acharjee and Sarmah, 2013). Enhancement of the nutritional quality of grain legumes has been attempted through seed-specific expression of L-Met-rich seed storage proteins, or the expression of SAM-insensitive AtCGS under seed-specific promoters (Chiaiese et al. 2004; Hanafy et al. 2013; Song et al. 2013). These projects had limited success in increasing protein-bound L-Met to levels that meet human dietary requirements, either due to the concurrent decrease in 
endogenous sulfur-rich seed proteins (Chiaiese et al. 2004), or the limited incorporation of the accumulated L-Met into seed storage proteins and its subsequent degradation (Hanafy et al. 2013; Song et al. 2013).

L-Met belongs to the L-Asp family of amino acids, along with L-Thr, L-Lys, and L-Ile (Jander and Joshi, 2010). In plants, the enzymes CGS and TS, involved in L-Met and L-Thr biosynthesis, respectively, compete for the OPHS substrate. The flux of OPHS between these two pathways is regulated by the L-Met-derivative SAM, through the allosteric activation of TS and the post-transcriptional modulation of $C G S$ transcript stability (Curien et al. 1998; Chiba et al. 2003). Given the competition for a common substrate by CGS and TS, manipulations of the OPHS branch-point for the purpose of increasing L-Met biosynthesis must consider the effects on both metabolic pathways. A kinetic model of the OPHS branch-point in the target species can be used to inform the in vivo engineering of the branch-point by predicting the effects of alterations on flux distribution in both L-Met and L-Thr metabolism (Rohwer, 2012). The work presented in this thesis provides an important step in building a kinetic model of the OPHS branch-point in C. arietinum and L. culinaris.

The characterization of plant TS for informing future genetic engineering projects requires a suitable kinetic assay and a reliable method for synthesizing the OPHS substrate. In Chapter 2, I described the development of these procedures. Unlike many previous OPHS synthetic protocols, I opted for the use of purified homoserine kinase (HSK) over crude protein extracts and the addition of limited amounts of ATP and recycling of the ADP by-product using phospho(enol) pyruvate (PEP) and pyruvate kinase (PK) (Laber et al. 1994a; Laber et al. 1994b). Newly 
formed OPHS must be separated from residual ADP for accurate quantification using the phosphate-detecting malachite green assay, yet the separation process is difficult, thus potentially confounding the results of kinetic assays. I modified the synthetic method described by Laber and colleagues, by further reducing the concentration of ATP from $5 \mathrm{mM}$ to $1 \mathrm{mM}$ to limit residual phosphates in the reaction mixture, thereby avoiding the mis-estimation of OPHS concentration (Laber et al.1994a; Laber et al. 1994b). However, the use of PEP introduced the potential for an increased background rate of the reaction caused by residual pyruvate. Separation of OPHS from pyruvate was completed via anion exchange chromatography, and any contaminating pyruvate was measured using $\mathrm{HO}-\mathrm{HxoDH}$, so as to detect OPHS fractions containing sufficient pyruvate levels to affect the background rate. The measurement of TS kinetic parameters was completed using a range of OPHS up to enzyme saturation $(0.2-5 \mathrm{mM})$. Typically, kinetic assays use substrate concentrations at $10 \mathrm{x} K_{m}$ in order to simulate saturation conditions. In the case of TS, $1.2 \mathrm{mM}$ OPHS was identified as the requisite maximum OPHS concentration in the assay (Laber et al. 1999). Ultimately, the maximum concentration required for plant TS was experimentally determined to be $3-5 \mathrm{mM}$ (Chapter 4). Recovered OPHS was concentrated to $15-30 \mathrm{mM}$.

The development of a continuous, coupled-coupled assay used to study the activity of plant TS was necessary for accurately measuring the steady-state kinetic parameters reported in this thesis. Previous studies have employed discontinuous assays quantifying the L-Thr or phosphate products of TS via HPLC or reaction with malachite green, respectively (Laber et al. 1994a; Curien et al. 1998). A continuous 
method, coupling the reaction of AtTS1 with threonine deaminase (TD) and lactate dehydrogenase (LDH) was reported for the in vitro measurement of flux at the OPHS branch-point, but had not been optimized for determination of the steady-state parameters of TS (Curien et al. 2003). The A. thaliana OPHS branch-point model was constructed with kinetic parameters determined using an end-point assay, and so the model may have utilized non-steady state kinetic parameters in its construction, potentially leading to the miscalculation of flux distribution (Curien et al. 2003). The TD/LDH system was not used for the subsequent measurement of the kinetic parameters of TS from other species (Lee et al. 2005; Covarrubias et al. 2008; Murakawa et al. 2011). LDH and TD are not optimal coupling enzymes for measuring TS activity, due to the preference of the former for pyruvate rather than the $\alpha$-ketobutyrate product of $\mathrm{TD}$, and the dependence of the latter on allosteric activation by L-valine (Eisenstein, 1991; Aitken et al. 2003). In contrast, the use of hydroxyisocaproate dehydrogenase $(\mathrm{HO}-\mathrm{HxoDH})$ and the non-allosteric variant of TD from E. coli $\left(\mathrm{eTD}_{\mathrm{L} 447 \mathrm{~F}}\right)$ as coupling enzymes provides optimal conditions for the measurement of the activity of TS from both plants and microorganisms by relieving the L-valine requirement of TD, and due to the higher catalytic efficiency for pyruvate of HO-HxoDH compared to LDH (Chapter 2). This assay is suitable for the construction of future kinetic models of both the OPHS branch-point, and the L-Asp metabolic pathway.

The construction of a kinetic model requires a detailed understanding of the regulation, compartmentalization, and activity of the component enzymes, such as the information described in this thesis for TS from C. arietinum (CaTS) and L. culinaris 
(LcTS). CaTS and LcTS share 77-82\% identity with TS from G. max, with the residues key to cofactor and SAM-binding being conserved (Chapter 3). TS function in vivo was verified through the complementation of a L-Thr-auxotrophic E. coli strain, lacking the coding sequence for TS, with the full-length and mature (lacking the transit peptide) constructs of CaTS, LcTS, and AtTS2 (Baba et al. 2006). Fusing of the N-terminal region of the CaTS and LcTS coding sequences in frame with GFP, and subsequent transformation into A. tumefaciens and transient expression in $N$. tabacum leaves, showed that these regions encode a functional chloroplast transit peptide (Chapter 3). This indicates that L-Thr biosynthesis occurs in the chloroplast in these two pulse species, as was expected from the localization of the pathway in $A$. thaliana and S. tuberosum (Curien et al. 1996; Casazza et al. 2000). The kinetic parameters of CaTS $\left(k_{c a t}=1.00 \pm 0.04 \mathrm{~s}^{-1}, K_{m}{ }^{\mathrm{OPHS}}=70 \pm 20 \mu \mathrm{M}\right)$ and $\operatorname{LcTS}\left(k_{\text {cat }}=\right.$ $\left.1.50 \pm 0.04 \mathrm{~s}^{-1}, K_{m}{ }^{\text {OPHS }}=100 \pm 15 \mu \mathrm{M}\right)$ in the presence of $100 \mu \mathrm{M}$ SAM are consistent with those of AtTS1 $\left(k_{\text {cat }}=1.7 \pm 0.1 \mathrm{~s}^{-1}, K_{m}{ }^{\text {OPHS }}=70 \pm 10 \mu \mathrm{M}\right)$ (Chapter 4). However, the recently constructed mathematical model of the A. thaliana L-Asp metabolic pathway (Curien et al. 2009) may not be suitable to describe the flux distribution in the pulse species due to the disparate number of TS homologues between A. thaliana, C. arietinum, and G. max (Arabidopsis Genome Initiative, 2000; Schmutz et al. 2010; Jain et al. 2013). Furthermore, the degree of OPHS flux control of AtTS1 (80\%) differs from that of CaTS (estimated at 91\%) and LcTS (estimated at 94\%). Successfully increasing L-Met production in the C. arietinum and L. culinaris will require the creation of a species-specific kinetic model of the OPHS metabolic branch-point. The information presented in this thesis provides a starting point for 
the development of the mathematical model of OPHS flux toward L-Thr synthesis. When combined with similar data from CGS, this model will be a powerful tool for informing future metabolic engineering of pulse species. One such kinetic model, which recreated the pathway of sucrose metabolism, has been used to inform strategies for the improvement of sucrose accumulation by predicting the effects of altered expression of one of the enzymes involved in futile sucrose cycling (Rossouw et al. 2007; Rohwer, 2012). Similar predictions of flux in relation to increased or decreased expression and regulation of CGS and TS in the pulse species will facilitate the identification of metabolic engineering strategies with high chances of success prior to integrating these strategies in vivo.

AtTS2 was studied in this work in an attempt to elucidate its role in OPHS flux partitioning. Prior to the discovery of AtTS2, it was believed that AtTS1 was unique in A. thaliana chloroplasts (Curien et al. 1996). The construction of the L-Asp pathway model omitted AtTS2, since it was found to have 120-fold lower activity than AtTS1 at physiological SAM concentrations (Curien et al. 2009). In this thesis, I reported the finding that the coding sequence of AtTS2 encodes a functional protein, able to complement L-Thr auxotrophy (Chapter 3). The coding sequence of AtTS2 also contains a functional chloroplast transit peptide, indicating that the enzyme is likely found in the plastid, along with the other L-Asp metabolic enzymes (Chapter 3). In Chapter 4, I reported that AtTS2 is allosterically regulated, displaying an 8.5-fold higher $k_{\text {cat }} / K_{m}{ }^{\text {OPHS }}$ in the presence of $100 \mu \mathrm{M}$ SAM. The $k_{\text {cat }} / K_{m}{ }^{\text {OPHS }}$ of AtTS2 is one order of magnitude lower than that of AtTS1 in the presence of SAM, confirming the reported lower activity of the enzyme (Curien et al. 2009). The distinct kinetic 
parameters of AtTS2, the finding that this enzyme may account for $28 \%$ of OPHS flux partitioning, along with the similar transcript expression levels of both forms of TS in most $A$. thaliana tissues, indicate that this enzyme is likely involved in the partitioning of OPHS flux, and that it should be considered in future branch-point modelling in A. thaliana.

\subsection{Future Directions}

The creation of a kinetic model of the OPHS branch-point will facilitate future attempts to increase the synthesis of L-Met in the pulse species. TS is a promising target for metabolic engineering, since it accounts for approximately $70 \%$ of OPHS flux (Curien et al. 2003; Chapter 4). To date, no evidence exists of the OPHS branchpoint model or the L-Asp metabolic model having informed subsequent metabolic engineering projects. I propose first that the kinetic parameters of the $m t o 2$ variant of AtTS1, with an Arg substitution at Leu204, should be measured and integrated into the branch-point model to examine the effect of impaired AtTS1 activity on metabolic flux, as a baseline for determining levels of TS activity that would be useful in increasing flux toward L-Met synthesis (Bartlem et al. 2000; Curien et al. 2003). Since no kinetic studies were done on this TS variant, there is a lack of understanding about the mechanism for impaired TS activity, whether it is $K_{m}{ }^{\text {OPHS }}, k_{c a t}$, or both values that are primarily affected by the substitution of the large, basic, polar amino acid, adjacent to the active site lysine (Bartlem et al. 2000). In these plants, L-Thr concentration is decreased to $6 \%$ of wild-type levels, however it is not clear if this is due to a low level of activity of AtTS1, or if it is a result of a basal level of AtTS2 
activity (Bartlem et al. 2000). Understanding the mechanism of impaired TS activity in the mto 2 line, as well as the ability of AtTS2 to compensate for impaired AtTS1 activity, may provide a starting point for future alterations to the TS active site to manipulate activity and increase L-Met synthesis.

Given the large changes in $k_{c a t} / K_{m}$ OPHS of plant TS in the presence of SAM, ranging from 20-fold in LcTS to 80-fold in AtTS1, the residues involved in SAMbinding have the potential to be manipulated, thus resulting in alterations of the allosteric activation of the enzyme. Probing the allosteric site of AtTS1 has the potential to identify key residues that can be mutated to alter SAM binding and modify the activation of AtTS1, thus lessening its effect on OPHS flux distribution between L-Met and L-Thr biosynthesis (Mas-Droux et al. 2006). However, to date, no such studies have been reported. The topography of the AtTS1 SAM-binding sites, as well as the orientation of the bound SAM molecules, is different from those observed in other SAM-binding proteins, including methyltransferases and SAM-radical dependent enzymes such as biotin synthase, representing a plant-specific SAMbinding mechanism (Martin and McMillian, 2002; Berkovitch et al. 2004; Mas-Droux et al. 2006). As such, mutagenesis studies in other SAM-binding enzymes will not be useful in informing the selection of target residues for altering the allosteric activation of plant TS. Nevertheless, several residues conserved only in plant TS that play key roles in SAM-binding are potential targets for the exploration of the allosteric site, such as P102, Y103, and G104, residues that form polar interactions with the adenosyl group of SAM, and W101 which forms a stacking interaction with the adenine ring (Figure 1.4) (Mas-Droux et al. 2006). After identification of these 
residues and kinetic characterization of TS mutant proteins, the effect of these mutants on the OPHS branch-point can be measured in silico through the kinetic model and in vitro using the continuous, coupled-coupled assay, prior to engaging in in vivo genetic modifications.

TS is an attractive target for the metabolic engineering of important crop plants aimed at increasing L-Met levels, due to its key role in the partitioning of OPHS flux. Altering the effect of TS on flux distribution would permit the increased biosynthesis of L-Met by lessening the competition between TS and CGS, resulting in an increase in free L-Met. Historically, the use of constitutive or seed-specific promoters to increase the expression of SAM-insensitive CGS in plants has improved the pool of free L-Met, with little or no effect on the levels of protein-bound L-Met, thus failing to meet the human daily L-Met requirements (Gakiere et al. 2002; Hanafy et al. 2013; Song et al. 2013). For example, the expression of the mtol variant of AtCGS in the seeds of G. $\max$ was met with a 9-fold increase in total seed L-Met levels, with no increase in protein-bound L-Met, and excess L-Met likely being degraded or converted into SAM, rather than being integrated into seed proteins (Hanafy et al. 2013). This indicates that increasing the pool of free L-Met alone through manipulations in OPHS flux is not a suitable strategy for increasing the nutritional significance of important crop species (Hesse et al. 2004). The expression of L-Met-rich proteins in legume seeds, in combination with alterations in OPHS flux to meet the increased demand for L-Met, is more likely to be successful in the creation of pulse species that meet the amino acid requirements for adequate human nutrition. Through the use of a kinetic model of the OPHS branch-point, informed by the results 
described in this thesis, future metabolic engineering endeavours in the important pulse species $C$. arietinum and $L$. culinaris have a greater chance of successfully enhancing L-Met production to meet global nutritional needs. 


\section{REFERENCES}

Acharjee, S., and Sarmah, B.K. 2013. Biotechnologically generating "super chickpea" for food and nutritional security. Plant Science 207: 108-116.

Agriculture and Agri-Food Canada. 2011. Canadian Pulse Industry: Situation and Outlook. Market Outlook Report 3(2). Accessed online at http://www5.agr.gc.ca/resources/prod/doc/misb/mag-gam $/$ morrmar/pdf/rmar_03_02_2011-06-08_eng.pdf (accessed on January 9, 2014).

Aitken, S.M., Kim, D.H., and Kirsch, J.F. 2003. Escherichia coli cystathionine synthase does not obey ping-pong kinetics: novel continuous assays for the elimination and substitution reactions. Biochemistry 42: 11297-11306.

Alliance grain traders. 2011. History of pulse [online]. Available from http://www.alliancegrain.com/about-pulses/history-of-pulse.htm (accessed on October 7, 2012)

Amir, R., Han, T., and Ma, F. 2012. Bioengineering approaches to improve the nutritional values of seeds by increasing their methionine content. Molecular Breeding 29: 915-924.

Arabidopsis Genome Initiative. 2000. Analysis of the genome sequence of the flowering plant Arabidopsis thaliana. Nature 408: 796-815.

Avraham, T., and Amir, R. 2005. The expression level of threonine synthase and cystathionine -synthase is influenced by the level of both threonine and methionine in Arabidopsis plants. Transgenic Research 14: 299-311.

Azavedo, RA., Arruda, P., Turner, W., and Lea, P. 1997. The biosynthesis and metabolism of the aspartate derived amino acids in higher plants. Phytochemistry 46: $395-419$.

Azavedo, RA., Lancien, M., Lea, PJ. 2006. The aspartic acid metabolic pathway, and exciting and essential pathway in plants. Amino Acids 30: 143-162.

Baba, T., Ara, T., Hasegawa, M., Takai, Y., Okumura, Y., Baba, M., Datsenko, K.A., Tomita, M., Wanner, B.L., Mori, H. 2006. Construction of Escherichia coli K-12 inframe, single-gene knockout mutants: the Keio collection. Mol Syst Biol 2:1-11.

Bartlem, D., Lambein, I., Okamoto, T., Itaya, A., Uda, Y., Kijima, F., Tamaki, Y., Nambara, E., and Naito, S. 2000. Mutation in the threonine synthase gene results in overaccumulation of soluble methionine in Arabidopsis. Plant Physiology 123: 101110. 
Berkovitch, F., Nicolet, Y., Wan, J.T., Jarrett, J.T., and Drennan, C.L. 2004. Crystal structure of biotin synthase, an $S$-adenosylmethionine-dependent radical enzyme.

Science: 303(5654): 76-79.

Bernard, N., Johnsen, K., Ferain, T., Garmyn, D., Hols, P., Holbrook, J.J., and Delcour, J. 1994. NAD ${ }^{+}$-dependent D-2-hydroxyisocaproate dehydrogenase of Lactobacillus delbrueckii subsp. Bulgaricus - gene cloning and enzyme characterization, Eur. J. Biochem. 224: 439-446.

Bockelmann, W., Beuck, H.P., Lick, S., and Heller, K. 1995. Purification and characterization of a new tripeptidase from Lactobacillus delbrueckii ssp Bulgaricus B14, Int. Dairy J. 5: 493-502.

Bourniquel, A.A., and Mollet, B. 2002. Purification and characterization of the 3phosphoglycerate kinase from the thermophile Lactobacillus delbrueckii subsp lactis, Int. Dairy J. 12: 723-728.

Bradford, M.M. 1976. A rapid and sensitive method for the quantification of microgram quantities of protein utilizing the principle of protein-dye binding. Anal. Biochem. 72: 248-254.

Burr, B., Walker, J., Truffa-Bachi, P., and Cohen, G.N. 1976. Homoserine kinase from Escherichia coli K12. European Journal or Biochemistry 62: 519-526.

Casazza, AP., Basner, A., Hofgen, R., and Hesse, H. 2000. Expression of a threonine synthase from Solanum tuberosum L. is not metabolically regulated by photosynthesis related signals or by nitrogenous compounds. Plant Science 157: 4350 .

Chassagnole, C., Rais, B., Quentin, E., Fell, D.A., and Mazat, J-P. 2001. An integrated study of threonine-pathway enzyme kinetics in Escherichia coli, Biochem. J. 356: 415-423.

Chiaiese, P., Ohkama-Ohtsu, N., Molvig, L., Godfree, R., Dove, H., Hocart, C., Fujiwara, T., Higgins, T.J.V., and Tabe, L.M. 2004. Sulphur and nitrogen nutrition influence the response of chickpea seeds to an added, transgenic sink for organic sulphur. Journal of Experimental Botany 55(404): 1889-1901.

Chiba, Y., Ishikawa, M., Kijima, F., Tyson, RH., Kim, J., Yamamoto, A., Nambara, E., Leustek, T., Wallsgrove, R., and Naito, S. 1999. Evidence for autoregulation of cystathionine -synthase mRNA stability in Arabidopsis. Science 286: 1371-1374.

Chiba, Y., Sakurai, R., Yoshino, M., Ominato, K., Ishikawa, M., Onouchi, H., and Naito, S. 2003. $S$-adenosyl-L-methionine is an effector in the posttranscriptional autoregulation of the cystathionine -synthase gene in Arabidopsis. Proceedings of the National Academy of Sciences 100: 10225-10230. 
Clausen, T., Huber, R., Prade, L., Wahl, M.C., and Messerschmidt. 1998. Crystal structure of Escherichia coli cystathionine $\gamma$-synthase at $1.5 \AA$ resolution. The EMBO Journal 17(23): 6827-6838.

Covarrubias, A.S., Hogbom, M., Bergfors, T., Carroll, P., Mannerstedt, K., Oscarson, S., Parish, T., Jones, T.A., and Mowbray, S.L. 2008. Structural, biochemical, and in vivo investigations of the threonine synthase from Mycobacterium tuberculosis, J. Mol. Biol. 381: 622-633.

Curien, G., Dumas, R., Ravanel, S., Douce, R. 1996. Characterization of an Arabidopsis thaliana cDNA encoding an $S$-adenosylmethionine-sensitive threonine synthase. Federation of European Biochemical Societies 390: 85-90.

Curien, G., Job, D., Douce, R., and Dumas, R. 1998. Allosteric activation of Arabidopsis thaliana threonine synthase by $S$-adenosylmethionine, Biochemistry 37 : 13212-13221.

Curien, G., Ravanel, S., Dumas, R. 2003. A kinetic model of the branchpoint between the methionine and threonine biosynthetic pathways in Arabidopsis thaliana.

European Journal of Biochemistry 270: 4615-4627.

Curien, G., Laurencin, M., Robert-Genthon, M., and Dumas, R. 2007. Allosteric monofunctional aspartate kinases from Arabidopsis. FEBS Journal 274(1): 164-176.

Curien, G., Bastien, O., Robert-Genthon, M., Cornish-Bowden, A., Cardenas, M.L., and Dumas, R. 2009. Understanding the regulation of aspartate metabolism using a model based on measured kinetic parameters. Molecular Systems Biology 5: 1-14.

Datko, A.H., Giovanelli, J., and Mudd S.H. 1974. Homocysteine biosynthesis in green plants, J. Biol. Chem. 249: 1139-1155.

Dixon, R.M., and Hosking, B.J. 1992. Nutritional value of grain legumes for ruminants. Nutritional Research Reviews 5: 19-43.

Dizigan, M.A., Kelly, R.A., Voyles, D.A., Leuthy, M.H., Malvar, T.M., and Malloy, K.P. 2007. High lysine maize compositions and event LY038 maize plants. United States Patent No, 7157281.

Eichel, J., González, J.C., Hotze, M., Matthews, R.G. and Schröder, J. 1995. Vitamin B12-independent methionine synthase from a higher plant (Catharanthus roseus). European Journal of Biochemistry 230: 1053-1058.

Eisenstein, E. 1991. Cloning, expression, purification, and characterization of biosynthetic threonine deaminase from Escherichia coli, J. Biol. Chem. 266: 58015807. 
Eisenstein, E., Yu, H.D., Fisher, K.E., Iacuzio, D.A., Ducote, K.R., and Schwarz, F.P. 1995. An expanded two-state model accounts for homotropic cooperativity in biosynthetic threonine deaminase from Escherichia coli, Biochem. 34: 9403-9412.

Eliot, A.C., and Kirsch, J.F. 2004. Pyridoxal phosphate enzymes: mechanistic, structural, and evolutionary considerations. Annual Review of Biochemistry 73: 383415.

Farrington, G.K., Kumar, A., Shames, S.L., Ewaskiewicz, J.I., Ash, D.E., and Wedler F.C. 1993. Threonine synthase of Escherichia coli: inhibition by classical and slowbinding analogues of homoserine phosphate, Arch. Biochem. Biophys. 307: 165-174.

Farsi, A., Lodha, P., Skanes, J.E., Los, H., Kalidindi, N., and Aitken, S.M. 2009. Interconversion of a pair of active-site residues in Escherichia coli cystathionine $\gamma$ synthase, E. coli cystathionine $\beta$-lyase, and Saccharomyces cerevisiae cystathionine $\gamma$-lyase and development of tools for the investigation of their mechanisms and reaction specificity. Biochemistry and Cell Biology 87: 445-457.

Flavin, M., and Slaughter, C. 1960. Threonine synthetase mechanism: studies using isotopic hydrogen, J. Biol. Chem. 235: 1112-1118.

Gakiere, B., Denis, L., Droux, M., and Job, D. 2002. Over-expression of cystathionine $\gamma$-synthase in Arabidopsis thaliana leads to increased levels of methionine and Smethylmethionine. Plant Physiology and Biochemistry 40: 119-126.

Galili, G., and Amir, R. 2012. Fortifying plants with the essential amino acids lysine and methionine to improve nutritional quality. Plant Biotechnology Journal 11:211222.

Galili, G., and Hofgen, R. 2002. Metabolic engineering of amino acids and storage proteins in plants. Metabolic Engineering 4: 3-11.

Garrido-Franco, M., Ehlert, S., Messerschmidt, A., Marinkovic, S., Huber, R., Laber, B., Bourenkov, GP., and Clausen, T. 2002. Structure and function of threonine synthase from yeast. The Journal of Biological Chemistry 277: 12396-12405.

Giovanelli, J., Veluthambi, K., Thompson, G., Mudd, SH., and Datko, A. 1984. Threonine synthase of Lemna paucicostata. Plant Physiology 76: 285-292.

Hacham, Y., Avraham, T., and Amir, R. 2002. The N-terminal region of Arabidopsis cystathionine -synthase plays in important regulatory role in methionine metabolism. Plant Physiology 128: 454-462.

Hanafy, M.S., Rahman, S.M., Nakamoto, Y., Fujiwara, T., Naito, S., Wakasa, K., and Ishimoto, M. 2013. Differential response of methionine metabolism in two grain 
legumes, soybean and azuki bean, expressing a mutated form of Arabidopsis cystathionine $\gamma$-synthase. Journal of Plant Physiology 170: 338-345.

Hesse H., Kreft, O., Maimann, S., Zeh, M., Willmitzer, L., and Hofgen, R. 2001. Approaches toward understanding methionine biosynthesis in higher plants. Amino Acids 20: 281-289.

Hesse, H., Kreft, O., Maimann, S., Zeh, M., and Hoefgen, R. 2004. Current understanding of the regulation of methionine biosynthesis in plants. Journal of Experimental Botany 55: 1799-1808.

Hoffman, LM., Donaldson, DD., and Heman, EM. 1988. A modified storage protein is synthesized, processed, and degraded in the seeds of transgenic plants. Plant Molecular Biology 11: 717-729

Hoorweg, J., and Stanfield, J.P. 1976. The effects of protein energy malnutrition in early childhood on intellectual and motor abilities in later childhood and adolescence. Developmental Medicine \& Child Neurology 18: 330-350.

Hughes, C., Gebhardt, J., Reuss, A., and Matthews, B. 1999. Identification and expression of a cDNA encoding cystathionine -synthase in soybean. Plant Science 146: 69-79.

Inaba, K., Fujiwara, T., Hayashi, H., Chino, M., Komeda, Y., and Naito, S. 1994. Isolation of an Arabidopsis thaliana mutant, $\mathrm{mtol}$, that overaccumulates soluble methionine. Plant Physiology 104: 881-887.

Jain, M., Misra, G., Patel, R.K., Priya, P., Jhanwar, S., Khan, A.W., Shah, N., Singh, V.K., Garg, R., Jeena, G., Yadav, M., Kant, C., Sharma, P., Yadav, G., Bhatia, S., Tyagi, A.K., and Chattopadhyay, D. 2013. A draft genome sequence of the pulse crop chickpea (Cicer arietinum L.). The Plant Journal 74: 715-729.

Jander G., and Joshi, V. 2010. Recent progress in deciphering the biosynthesis of aspartate-derived amino acids in plants. Molecular Plant 3(1): 54-65.

Jaworski, A. F., Lodha, P. H., Manders, A. L., and Aitken, S. M. Exploration of the Active Site of Escherichia coli Cystathionine $\gamma$-Synthase. Protein Science 21(11): 1662-1671.

Kim, J., Lee, M., Chalam, R., Martin, M.N., Leustek, T., and Boerjan, W. 2002. Constitutive overexpression of cystathionine $\gamma$-synthase in Arabidopsis leads to accumulation of soluble methionine and $S$-methylmethionine. Plant Physiology 128: 95-107.

Kingsbury, J.M., and McCusker, J.H. 2008. Threonine biosynthetic genes are essential in Cryptococcus neoformans, Microbiology 154: 2767-2775. 
Knoke, B., Textor, S., Gershenzon, J., and Schuster, S. 2009. Mathematical modelling of aliphatic glucosinolate chain length distribution in Arabidopsis thaliana leaves. Phytochemistry Reviews 8: 39-51.

Kusano, M., Fukushima, A., Redestig, H., Kobayashi, M., Otsuki, H., Onouchi, H., Naito, S., Hirai, M.Y., Saito, K. 2010. Comparative metabolomics charts the impact of genotype-dependent methionine accumulation in Arabidopsis thaliana. Amino Acids 39: 1013-1021.

Kreft, B., Townsend, A., Pohlenz, HD., Laber, B. 1994. Purification and properties of cystathoinine -synthase from wheat (Triticum aestivum L.). Plant Physiology 104: 1215-1220.

Kreft, O., Hoefgen, R., and Hesse, H. 2003. Functional analysis of cystathionine $\gamma-$ synthase in genetically engineered potato plants. Plant Physiology 131: 1843-1854.

Laber, B., Gerbling, K-P., Harde, C., Neff, K-H., Nordhoff, E., and Pohlenz, H-D. 1994a. Mechanisms of interaction of Escherichia coli threonine synthase with substrates and inhibitors, Biochem. 33: 3413-3423.

Laber, B., Lindell, S.D., and Pohlenz, H-D. 1994b. Inactivation of Escherichia coli threonine synthase by DL-Z-2-amino-5-phosphono-3-pentoic acid, Arch. Microbiol. $161: 400-403$.

Laber, B., Maurer, W., Hanke, C., Grafe, S., Ehlert, S., Messerschmidt, A., and Clausen, T. 1999. Characterization of recombinant Arabidopsis thaliana threonine synthase. European Journal of Biochemistry 263: 212-221.

Laloi, P., Atlan, D., Blanc, B., Gilbert, C., and Portalier, R. 1991. Cell-wallassociated proteinase of Lactobacillus delbrueckii subsp blugaricus CNRZ 397 Differential extraction, purification and properties of the enzyme, Appl. Microbiol. Biot. 36: 196-204.

Lanzetta, P.A., Alvarez, L.J., Reinach, P.S., and Candia, O.A. 1979. An improved assay for nanomole amounts of inorganic phosphate, Anal. Biochem. 100: 95-97.

Lee, S.I., Kim, H.U., Lee, Y.-H., Suh, S.-C., Lim, Y.P., Lee, H.-Y., and Kim, H.-I. 2001. Constitutive and seed-specific expression of a maize lysine-feedbackinsensitive dihydrodipicolinate synthase gene leads to increased free lysine levels in rice seeds. Molecular Breeding 8: 75-84.

Lee, M., Martin, M.N., Hudson, A.O., Lee, J., Muhitch, M.J., and Leustek, T. 2005. Methionine and threonine synthesis are limited by homoserine kinase availability and not the activity of homoserine kinase in Arabidopsis thaliana. Plant J. 41: 685-696. 
Madison, JT., and Thompson, JF. 1976. Threonine synthetase from higher plants: stimulation by $S$-adenosylmethionine and inhibition by cysteine. Biochemical and Biophysical Research Communications 71: 684-691.

Maimann, S., Wagner, C., Kreft, O., Zeh, M., Willmitzer, L., Hofgen, R., Hesse, H. 2000. Transgenic potato plants reveal the indispensable role of cystathionine B-lyase in plant growth and development. The Plant Journal 23: 747-758.

Maimann, S., Hoefgen, R., Hesse, H. 2001. Enhanced cystathionine $\beta$-lyase activity in transgenic potato does not force metabolite flow towards methionine. Planta 214: $163-170$.

Mandal S., and Mandal R.K. 2000. Seed storage proteins and approaches for improvement of their nutritional quality by genetic engineering. Current Science 79(5): 576-589.

Martin, J.L., and McMillan, F.M. 2002. SAM (dependent) I am: the $S$ adenosylmethionine-dependent methyltransferase fold. Current Opinion in Structural Biology 12(6): 783-793.

Mas-Droux, C., Biou, V., and Dumas, R. 2006. Allosteric threonine synthase: reorganization of the pyridoxal phosphate site upon asymmetric activation through $S$ adenosylmethionine binding to a novel site. The Journal of Biological Chemistry 281: 5188-5196.

Mato, JM., Martinez-Chantar, ML., and Lu, SC. 2008. Methionine metabolism and liver disease. Annual Review of Nutrition 28: 273-293.

Morneau, D.J.K., Abouassaf, E., Skanes, J.E., and Aitken, S.M. 2012. Development of a continuous assay and steady-state characterization of Escherichia coli threonine synthase. Analytical Biochemistry 423: 78-85.

Morneau, D.J.K., Jaworski, A.F., and Aitken, S.M. 2013. Identification of cystathionine $\gamma$-synthase and threonine synthase from Cicer arietinum and Lens culinaris. Biochemistry and Cell Biology 95: 95-101.

Muntz, K., Christov, V., Saalbach, G., Saalbach, I., Waddell, D., Pickardt, T., Schieder, O., and Wustenhagen, T. 1998. Genetic engineering for high methionine grain legumes. Nahrung 42: S125-S127.

Murakawa, T., Machida, Y., and Hayashi, H. 2011. Product-assisted catalysis as the basis of the reaction specificity of threonine synthase, J. Biol. Chem. 286: 2774-2784. Cohen, G.N., and Hirsch, M.-L. 1954. Threonine synthase, a system for synthesizing L-threonine from L-homoserine, J. Bacteriol. 67: 182-190. 
Nikiforova, V., Kempa, S., Zeh, M., Maimann, S., Kreft, O., Casazza, AP., Riedel, K., Tauberger, E., Hofgen, R., and Hesse, H. 2002. Engineering of cysteine and methionine biosynthesis in potato. Amino Acids 22: 259-278.

Nordlee, J.A., Taylor, S.L., Townsend, J.A., Thomas, L.A., and Bush, R.K. 1996. Identification of Brazil-nut allergen in transgenic soybeans. New England Journal of Medicine 334(11): 688-692.

Ominato, K., Akita, H., Suzuki, A., Kijima, F., Yoshino, T., Yoshino, M., Chiba, Y., Onuchi, H., and Naito, S. 2002. Identification of a short highly conserved amino acid sequence as the functional region required for posttranscriptional autoregulation of the cystathionine $\gamma$-synthase gene in Arabidopsis. The Journal of Biological Chemistry 277(39): 36380-36386.

de Onis, M., Monteiro, C., Akré, J., Clugston, G. 1993. The worldwide magnitude of protein-energy malnutrition: an overview from the WHO Global Database on Child Growth. Bulletin of the World Health Organization 71: 703-712.

Parsot, C., Cossart, P., Saint-Girons, I., and Cohen, G.N. 1983. Nucleotide sequence of thrC and of the transcription termination region of the threonine operon in Escherichia coli K12. Nucleic Acids Research 11: 7331-7345.

Perrachi, A., Bettati, S., Mozzarelli, A., Rossi, G.L., Miles, E.W., and Dunn, M.F. 1996. Allosteric regulation of tryptophan synthase: effects of $\mathrm{pH}$, temperature, and $\alpha$ subunit ligands on the equilibrium distribution of pyridoxal 5'-phosphate-Lhomoserine intermediates. Biochemistry 35: 1872-1880.

Rais, B., Chassagnole, C., Letellier, T., Fell, D.A., and Mazat, J-P. 2001. Threonine synthesis from aspartate in Escherichia coli cell-free extracts: pathway dynamics, Biochem. J. 356: 425-432.

Ramos, C., and Calderon, I.L. 1994. Biochemical evidence that the Saccharomyces cerevisiae THR4 gene encodes threonine synthetase, FEBS Lett. 351: 357-359.

Ravanel, S., Droux, M., and Douce, R. 1995. Methionine biosynthesis in higher plants. I. Purication and characterization of cystathionine $\gamma$-synthase from spinach chloroplasts. Archives of Biochemistry and Biophysics 316: 572-584.

Ravanel, S. 1997. Methionine biosynthesis in higher plants: biochemical and molecular characterization of the transsulfuration pathway enzymes. Comptes Rendus de l'Academie des Sciences Series III: Sciences de la vie 320: 497-504.

Ravanel, S., Gakiere, B., Job, D., and Douce, R. 1998a. Cystathionine -synthase from Arabidopsis thaliana: purification and biochemical characterization of the recombinant enzyme over-expressed in Escherichia coli. Biochemical Journal 331: 639-648. 
Ravanel, S., Gakiere, B., Job, D., Douce, R. 1998b. The specific features of methionine biosynthesis and metabolism in plants. Proceedings of the National Academy of Sciences 95: 7805-7812.

Rohwer, J.M. 2012. Kinetic modelling of plant metabolic pathways. Journal of Experimental Botany 63(6): 2275-2292.

Roje, S. 2006. S-adenosyl-L-methionine: beyond the universal methyl group donor. Phytochemistry 67: 1686-1698.

Rossouw, D., Bosch, S., Kossmann, J., Botha, F.C., and Groenewald, J.H. 2007. Downregulation of neutral invertase activity in sugarcane cell suspension cultures leads to a reduction in respiration and growth and an increase in sucrose accumulation. Functional Plant Biology 34(6): 490-498.

Schallau, K., and Junker, B.H. 2010. Simulating plant metabolic pathways with enzyme-kinetic models. Plant Physiology 152: 1763-1771.

Schildkraut I., and Greer, S.B. 1973. Threonine synthetase-catalyzed conversion of phosphohomoserine to $\alpha$-ketobutyrate in Bacillus subtilis, J. Bacteriol 115: 777-785

Schmid, M., Davison, T.S., Henz, S.R., Pape, U.J., Demar, M., Vingron, M., Scholkopf, B., Weigel, D., and Lohmann, J.U. 2005. A gene expression map of Arabidopsis thaliana development. Nature Genetics 37: 501-506.

Schmutz, J., Cannon, S.B., Schlueter, J., Ma, J., Mitros, T., Neslson, W., Hyten, D.L., Song, Q., Thelen, J.J., Cheng, J., Xu, D., Hellsten, U., May, G.D., Yu, Y., Sakurai, T., Umezawa, T., Bhattacharyya, M.K., Sandhu, D., Valliyodan, B., Lindquist, E., Peto, M., Grant, D., Shu, S., Goodstein, D., Barry, K., Futrell-Griggs, M., Abernathy, B., Du, J., Tian, Z., Zhu, L., Gill, N., Joshi, T., Libault, M., Sethuraman, A., Zhang, X.C., Shinozaki, K., Nguyen, H.T., Wing, R.A., Cregan, P., Specht, J., Grimwood, J., Rokhsar, D., Stacey, G., Shoemaker, R.C., and Jackson, S.A. 2010. Genome sequence of the palaeopolyploid soybean. Nature 463: 178-183.

Schnyder, J., and Rottenberg, M. 1975. Improved synthesis of $O$-phosphohomoserine, Helv. Chim. Acta 58: 518-521.

Shames, S.L., and Wedler, F.C. 1984. Homoserine kinase of Escherichia coli: kinetic mechanism and inhibition by L-aspartate semialdehyde, Arch. Biochem. Biophys. 235: $359-370$.

Shaver, J.M., Bittel, D.C., Sellner, J.M., Frisch, D.A., Somers, D.A., and Gengenbach, B.G. 1996. Single-amino acid substitutions eliminate lysine inhibition of maize dihydrodipicolinate synthase. Proceedings of the National Academy of Sciences 93(5): 1962-1966. 
Shen, B., Li, C., Tarczynski, M. 2002. High free-methionine and decreased lignin content result from a mutation in the Arabidopsis $S$-adenosyl-L-methionine synthetase 3 gene. The Plant Journal 29: 371-380.

Shepherd, M., and Dailey, H.A. 2005. A continuous fluorimetric assay for protoporphyrinogen oxidase by monitoring porphyrin accumulation. Analytical Biochemistry 344(1): 115-121.

Singh, U. 1985. Nutritional quality of chickpea (Cicer arietinum L.): current status and future research needs. Plant Foods for Human Nutrition 35: 339-351.

Skarstedt, M.T., and Greer, S.B. 1973. Threonine synthetase of Bacillus subtilis, J. Biol. Chem. 248: 1032-1044.

Song, S., Hou, W., Godo, I., Wu, C., Yu, Y., Matityahu, I., Hacham, Y., Sun, S., Han, T., and Amir, R. 2013. Soybean seeds expressing feedback-insensitive cystathionine $\gamma$-synthase exhibit a higher content of methionine. Journal of Experimental Botany 64(7): 1917-1926.

Sparkes, I.A., Runions, J., Kearns, A., and Hawes, C. 2006. Rapid, transient expression of fluorescent fusion proteins in tobacco plants and generation of stably transformed plants. Nature Protocols 1(4): 2019-2025.

Steegborn, C., Messerschmidt, A., Laber, B., Streber, W., Huber, R., and Clausen, T. 1999. The crystal structure of cystathionine $\gamma$-synthase from Nicotiana tabacum reveals its stubstrate and reaction specificity. Journal of Molecular Biology 290: 983996.

Stitt, M., Sulpice, R., and Keurentjes, J. 2010. Metabolic networks: how to indentify key components in the regulation of metabolism and growth. Plant Physiology 152: 428-444.

Sun, S., and Liu, Q. 2004. Transgenic approaches to improve the nutritional quality of plant proteins. In Vitro Cellular Developmental Biology 40: 155-162.

Szczesiul, M., and Wampler, DE. 1976. Regulation of a metabolic system in vitro: synthesis of threonine from aspartic acid. Biochemistry 15: 2236-2244.

Tabe, L., and Higgins, TJV. 1998. Engineering plant protein composition for improved nutrition. Trends in Plant Science 3(7): 282-286.

Theze, J., Kleidman, L., and Saint Girons, I. 1974. Homoserine kinase from Escherichia coli K-12: properties, inhibition by L-threonine, and regulation of biosynthesis, J. Bacteriol. 118: 577-581. 
Thoen, A., Rognes, S., Aarnes, H. 1978. Biosynthesis of threonine from homoserine in pea seedlings: 2. Threonine synthase. Plant Physiology and Biochemistry 13: 113119.

Thomazeau, K., Curien, G., Dumas, R., and Biou, V. 2001. Crystal structure of threonine synthase from Arabidopsis thaliana. Protein Science 10: 638-648.

Uys, L., Botha, F.C., Hofmeyr J.-H.S., and Rohwer, J.M. 2007. Kinetic model of sucrose accumulation in maturing sugarcane culm tissue. Phytochemistry 68: 23752392.

Van Veldhoven, P.P., and Mannaerts, G.P. 1987. Inorganic and organic phosphate measurements in the nanomolar range, Anal. Biochem. 161: 45-48.

Watanabe, Y., and Shimura, K. 1955. Biosynthesis of threonine from homoserine, J. Biochem. 42: 181-192.

Winter, D., Vinegar, B., Nahal, H., Ammar, R., Wilson G.V., and Provart, N.J. 2007. An "electronic fluorescence pictograph" browser for exploring and analyzing largescale biological data sets. PLoS One 8: e718.

World Health Organization (WHO). 2006. Global burden of protein-energy malnutrition in the year 2000. Global Burden of Disease 2000. Accessed online at http://www.who.int/healthinfo/statistics/bod_malnutrition.pdf (January 16, 2014).

Wormser, E., and Pardee, A. 1958. Regulation of threonine biosythesis in Escherichia coli. Archives of Biochemistry and Biophysics 78: 416-432.

Zeh, M., Casazza, AP., Kreft, O., Roessner, U., Bieberich, K., Willmitzer, L., Hoefgen, R., and Hesse, H. 2001. Antisense inhibition of threonine synthase leads to high methionine content in transgenic potato plants. Plant Physiology 127: 792-802. 